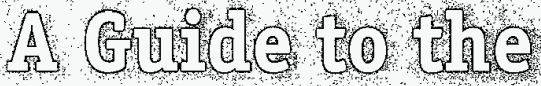

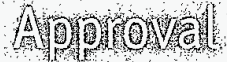

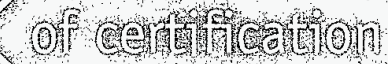

1)

gos

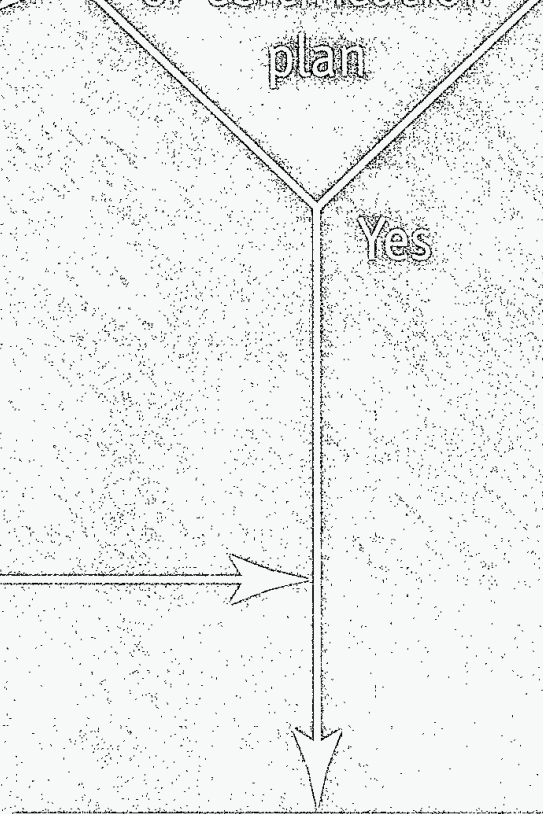

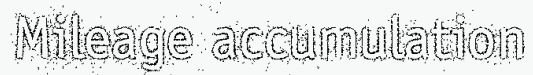

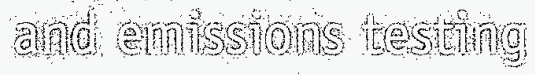

NO

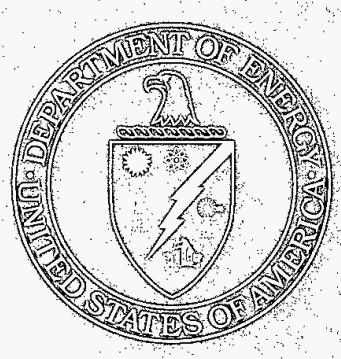

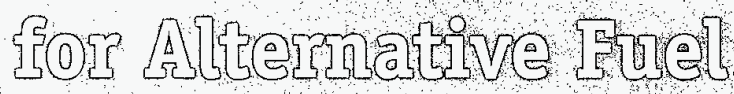
A 


\section{A Guide to the \\ Emissions Certification Procedures for Alternative Fuel Aftermarket Conversions}

January 1998

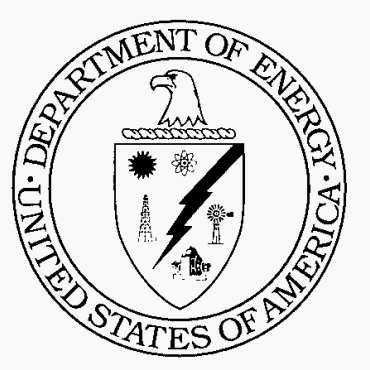

U.S. Department of Energy (DOE)

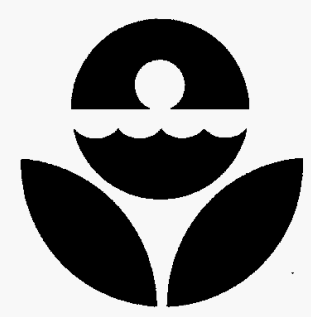

U.S. Environmental Protection Agency (EPA) 


\section{Preface}

In February 1997, the U.S. Environmental Protection Agency (EPA) hosted a public meeting in Washington, DC, to discuss its concerns about the ability of aftermarket vehicle conversions to satisfy federal emissions standards. Those concerns had been heightened by the recent publication of data indicating that vehicles may exhibit increases in one or more regulated pollutants after their fuel systems are converted from a conventional fuel to an alternative fuel.

As a direct result of the meeting, the U.S. Department of Energy (DOE) offered to fund the development of a simple and straightforward reference guide designed to explain the processes of emissions certification for aftermarket conversions. DOE's offer was extended to satisfy stakeholders' requests for more succinct explanations of the certification requirements of various regulatory agencies. DOE's National Renewable Energy Laboratory (NREL) was assigned the task of collecting the information and publishing the guide.

Since the meeting in February, the EPA has made two important announcements that relate to the certification of aftermarket vehicle conversions. The first occurred on September 4, 1997, when the EPA issued an addendum to Mobile Source Enforcement Memorandum 1A. This document provides clarifications and revisions of the agency's tampering enforcement policy for alternative fuel aftermarket conversions. The second came on October 31, 1997 (just before this guide was published) in which EPA proposed changes to the certification procedures designed to ease the burden of certification for vehicle manufacturers who qualify for the Clean-Fuel Vehicle Program. Details from both announcements are covered in this guide.

The guide contains extensive information provided by the EPA, the California Air Resources Board (CARB), and the Colorado Department of Public Health and Environment, as well as numerous fleet managers, cooperative industry organizations, and equipment manufacturers, installers, and distributors. NREL and DOE gratefully acknowledge the contributions of each project participant. 


\section{Table of Contents}

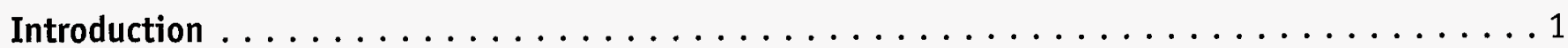

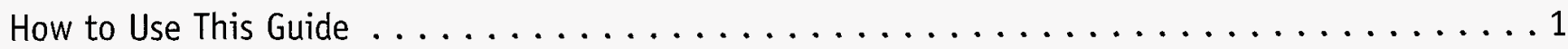

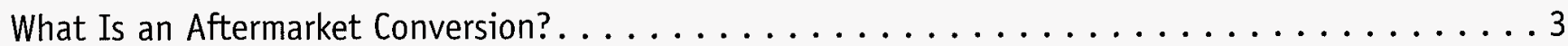

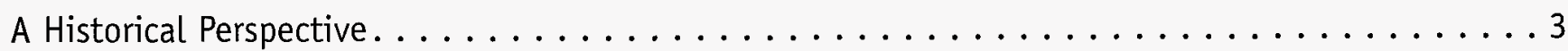

Authority for Emissions Certification $\ldots \ldots \ldots \ldots \ldots \ldots \ldots \ldots \ldots \ldots \ldots \ldots \ldots \ldots \ldots \ldots \ldots \ldots$

Certification by the U.S. Environmental Protection Agency. . . . . . . . . . . . . . 5

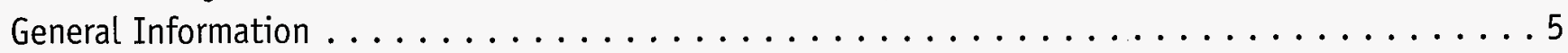

Regulations ................................ 5

Memorandum $1 \mathrm{~A}$ and Addendum to Memorandum $1 \mathrm{~A} \ldots \ldots \ldots \ldots \ldots \ldots$

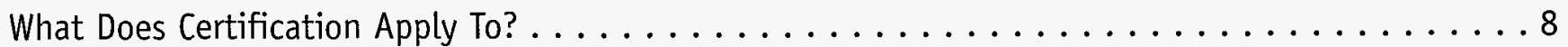

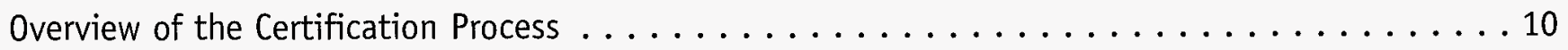

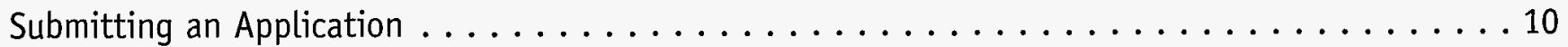

EPA Review and Issuance of a Certificate of Conformity . . . . . . . . . . . . . . . . . 12

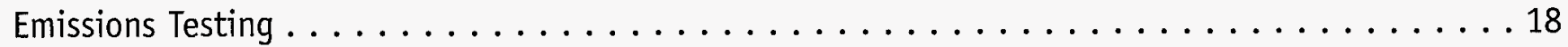

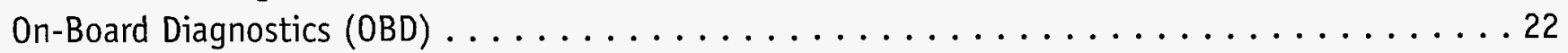

Labels, Decals, and Maintenance Schedule . . . . . . . . . . . . . . . . . . . 23

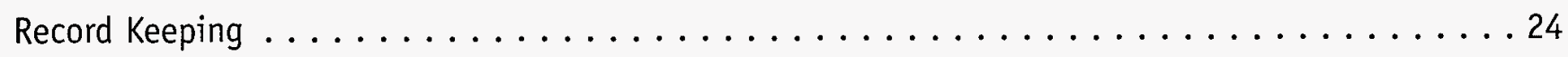

Warranty . . . . . . . . . . . . . . . . . . . . . . . . . . . . 24

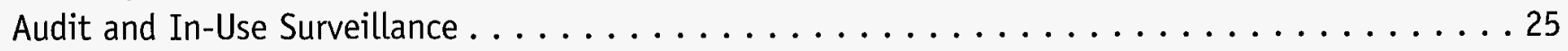

Responsibilities of Distributors and Installers . . . . . . . . . . . . . . . . . . 25

Clean-Fuel Vehicles and Mobile Emissions Reduction Credits. . . . . . . . . . . . . . . 26

Certification by the California Air Resources Board . . . . . . . . . . . . . . . . . . 27

General Information . . . . . . . . . . . . . . . . . . . . . . . . . . . . . . . . . . . . . . . . . . . . . . .

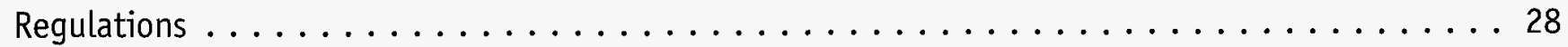

What Does Certification Apply To? . . . . . . . . . . . . . . . . . . . . . . 28

Introduction to the Certification Process . . . . . . . . . . . . . . . . . . . . . . . . . . 29

Certification Plan, Application, and Fees . . . . . . . . . . . . . . . . . . . . . 29

Emissions Standards . . . . . . . . . . . . . . . . . . . . . . . . 29

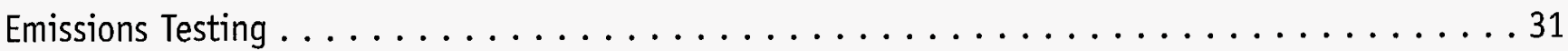

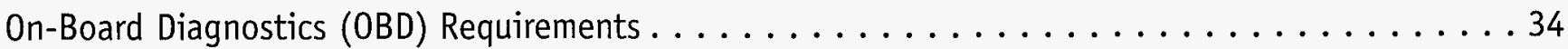

General Emissions Warranty Coverage . . . . . . . . . . . . . . . . . . . . . . . 34

Owner's Manual, Maintenance Schedule, and Vehicle Labels . . . . . . . . . . . . . . . . . 34

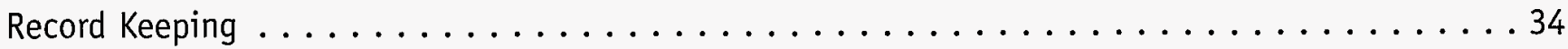

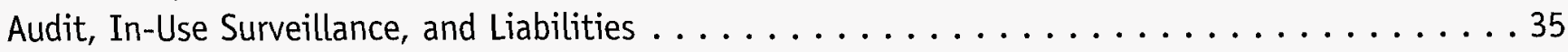

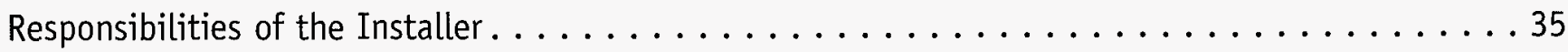

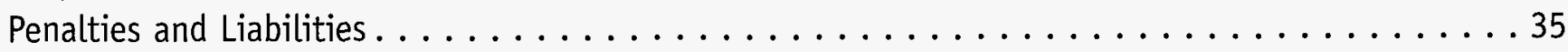

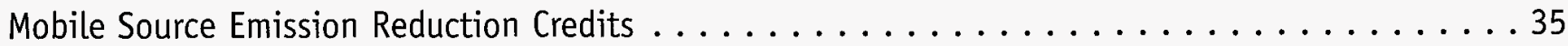

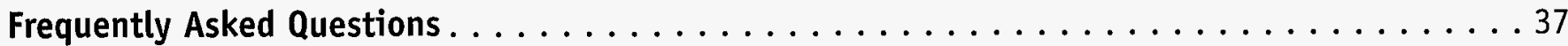


Appendices . . . . . . . . . . . . . . . . . . . . . . . . . 41

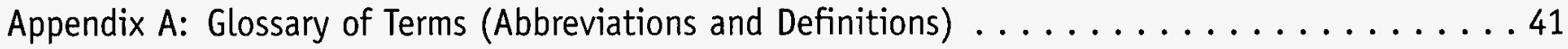

Appendix B: Schematics of Commercial Aftermarket Conversion Systems . . . . . . . . . 46

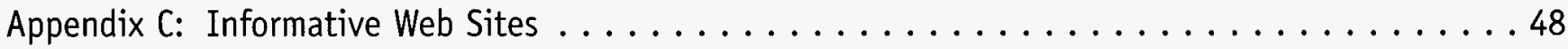

Appendix D: Emissions Standards. . . . . . . . . . . . . . . . . . . 49

Appendix E: Fuel Specifications for Emissions Certification Purposes. . . . . . . . . . . . . . 53

Appendix F: California Certification Process for Aftermarket Conversions-

Use of Gasoline Deterioration Factors . . . . . . . . . . . . . . 54

Appendix G: California Certification Process for Aftermarket Conversions-

Using Carry-Over and Carry-Across of Deterioration Factors. . . . . . . . . . . 55

Appendix H: California Certification Process for Light- and Medium-Duty Aftermarket Conversions-

Using Derived Deterioration Factors . . . . . . . . . . . . . . . 56

Appendix I: California Certification Process for Heavy-Duty Aftermarket Conversions-

Using Derived Deterioration Factors . . . . . . . . . . . . . . . 57

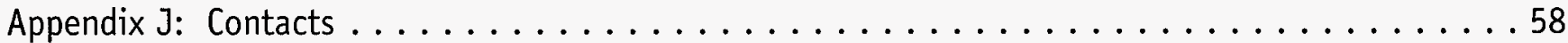

Appendix K: Important Documents. . . . . . . . . . . . . . . . . . . 59 


\section{Some Words about Terminology}

Appendix $A$ is an extensive glossary of terms. However, a few terms require early clarification.

1. Aftermarket conversion-a vehicle or engine originally designed and certified to operate on gasoline or diesel that has been modified to run on an alternative fuel. Retrofit kit or system, aftermarket conversion, and conversion all have the same meaning, but for the sake of consistency, we use "aftermarket conversion" throughout this guide.

2. Dual-fuel-we use the term "dual-fuel" to refer to vehicles or engines that have two separate fuel systems and are designed to run on either an alternative fuel or conventional gasoline, but using only one fuel at a time. This is consistent with the usage of the term in EPA and California regulations.

3. Manufacturer - in the context of this guide, "manufacturer" refers to any company that produces, assembles, or packages aftermarket vehicle conversion kits.

4. Emissions standards, procedures, and regulations-the regulations governing aftermarket conversions also include references to emissions standards and acceptable testing and implementation procedures. Procedures are the methods that a manufacturer uses to test vehicles, systems, or components. A standard is a regulated emissions level. Examples of emissions standards are tier 1, transitional low-emission vehicle (TLEV), and low-emission vehicle (LEV). The sidebar on page 17 provides more information about these standards.

5. Vehicle and engine-We use the terms "vehicle" and "engine" frequently in the guide. In some parts of the certification process, different regulations or procedures apply depending on whether you are certifying a vehicle or an engine. In others, the regulations and procedures are identical for engines and vehicles. When there are no differences, we use the term "vehicle" frequently in this guide to imply all vehicles and engines. This helps to avoid repeating "vehicle and/or engine" throughout. Unless otherwise specified, the term "engine" is used to refer to heavy-duty engines. Other specific terms used in the guide and the regulations include light-duty vehicle, light-duty truck, medium-duty vehicle, and heavy-duty vehicle. These terms are defined in the glossary.
Because EPA and California certification processes differ, we have devoted a separate section of the guide to each. In each section, we have attempted to lead you through all the major steps in the emissions certification process.

First, we provide contact information for each agency. Then, we present an overview of the governing regulations, with specific references to the necessary documentation. We explain the certification process (with a flow chart for visual reference), provide examples, and define important terms. Emissions standards and test procedures are outlined and accompanied by references to the appropriate sections of the regulations. Finally, we describe other responsibilities and requirements (such as information labels, warranty requirements, and record keeping) needed to obtain an emissions certification.

The two sections in the back of the guide provide answers to "Frequently Asked Questions" and detailed reference material in the form of appendices. The appendices include a glossary of terms, sample schematic diagrams, informative World Wide Web sites, emissions standards, fuel specifications, additional flow charts, and an index of related documents.

The guide is not meant to replace the use of EPA and California regulations; it is designed to give an overview and to serve as a reference. The official regulations are the cornerstone for emissions certification-they explain the detailed test procedures and the emissions standards. Any discrepancy between this guide and the regulations is unintentional. Because both EPA and California regulations are constantly being updated, consult with the EPA and the California Air Resources Board (CARB) to ensure that you have current information. If you're interested in certifying vehicles, always refer to the actual regulations governing the vehicles or engines you wish to convert. 


\section{What Is an Aftermarket Conversion?}

An aftermarket conversion is a vehicle that was originally designed, produced, and certified by an original equipment manufacturer (OEM) to operate on a particular fuel and has been altered to allow it to operate on a different fuel. Typically, an aftermarket conversion involves modifying a gasoline- or diesel-fueled vehicle to run on CNG or LPG. After conversion, the vehicle may be "dedicated" to an alternative fuel, meaning that it can operate solely on the new fuel, or it can be "dual-fuel," meaning that it can run either on the conventional fuel or the alternative fuel, but not on both simultaneously. In the context of this guide, dual-fuel vehicles produced under the qualified vehicle modifier programs of various OEMs are not considered to be aftermarket conversions.

Aftermarket conversion of vehicles involves removing, altering, or replacing various fuel system components. The conversion equipment is frequently called a "conversion kit." Many companies produce conversion kits, and each kit has its own unique characteristics. Schematics of two such kits, which are commercially available today, are contained in Appendix B.

\section{A Historical Perspective}

Emissions control regulations date back to the early and mid-1960s. California required its first emissions control systems on 1966 vehicles. In 1967, CARB was established to ensure the protection of air quality, including motor vehicle emissions.

In 1970, the federal Clean Air Act (CAA) was adopted and the EPA was created. The CAA gave the EPA broad responsibilities for regulating motor vehicle pollution. Emissions standards for crankcase, exhaust, and evaporative emissions from light-duty vehicles, as well as standards for exhaust emissions from heavy-duty gasoline- and diesel-fueled engines, became effective during that same year.

In 1974, the EPA issued an important policy statement known as Memorandum 1A ("Interim Tampering Enforcement Policy," see page 7), which outlined steps that aftermarket conversion companies could take to ensure that installing their kits and equipment did not violate the CAA's anti-tampering provisions. One such method was to obtain a representation from a state environmental control agency that the converted vehicle's emissions performance had not been compromised. For instance, through its Regulation No. 14 ("The Control of Emissions from Alternative Fueled Motor Vehicles"), the Colorado Department of Health and Environment provided a process for obtaining a "Letter of Certification" for vehicles converted in Colorado.

California has had the longest-running certification program for aftermarket conversions, establishing its first regulations in 1975. Since then, California has updated its certification procedures for aftermarket conversions a number of times.

In 1994, the EPA established the first national emissions standards and regulations for vehicles and engines powered by CNG and LPG (see 59 Federal Register [FR] 48472). These standards and regulations apply to aftermarket conversions and vehicles produced by OEMs. The certification process outlined in the EPA's rule-making was optional prior to the 1997 vehicle model year, but it is required for 1997 and successive model years. Prior to 1994, no federal emissions standards or test procedures existed for CNG and LPG vehicles.

On September 4, 1997, the EPA revised and updated the tampering enforcement policy with an addendum to Mobile Source Enforcement Memorandum 1A ("Tampering Enforcement Policy for Alternative Fuel Aftermarket Conversions"). As outlined in the addendum, the EPA no longer accepts Colorado 
Regulation No. 14 or the California certification procedure for 1993 and earlier model year vehicles as an adequate demonstration that a vehicle or engine modified with an aftermarket conversion system complies with the applicable emission standards for its useful life. The addendum outlines three alternatives for providing a reasonable basis that an aftermarket conversion does not adversely affect emissions performance. The EPA section of this guide presents additional information on the addendum.

\section{Authority for Emissions Certification}

Section 209 of the CAA provides that "no state or political subdivision thereof shall adopt or attempt to enforce any standard relating to the control of emissions from new motor vehicles or new motor vehicle engines subject to this part." However, this requirement is waived for states that adopted emissions control standards prior to March 30, 1966. Based on this waiver, the state of California may adopt and enforce its own emissions standards.
In all cases, manufacturers of new motor vehicles and engines must receive certification from the EPA before the vehicles can be introduced into commerce. For California-only vehicles, the manufacturer first obtains certification from CARB, then submits this to the EPA for certification. The EPA will then issue a California-only certificate. For all other new vehicles, manufacturers must first obtain a certificate from the EPA. This also applies to aftermarket conversions, except for vehicles converted according to the steps outlined in the addendum to Mobile Source Enforcement Memorandum 1A.

Currently, manufacturers may obtain emissions certification for aftermarket conversions from the EPA and the state of California. For more information on this subject, see the sections of this guide on EPA and California certification, along with the section entitled Frequently Asked Questions. 

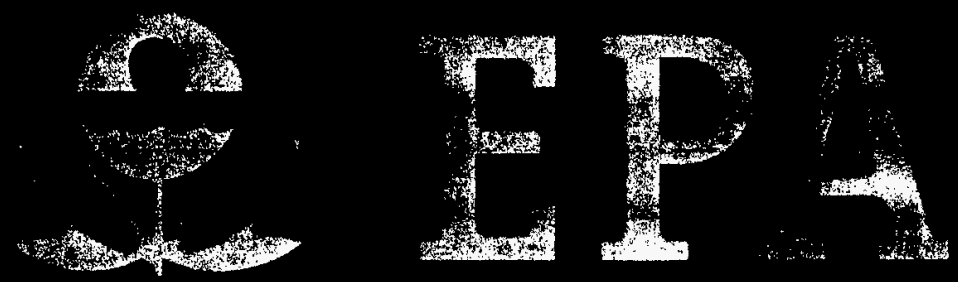

\section{Certification by the U.S. Environmental Protection Agency}

\section{General Information}

The EPA is responsible for federal emissions certification of motor vehicles and motor vehicle engines in the United States. As we noted in the introduction, California may also grant emissions certification to vehicles and engines for use in California.

\section{Regulations}

The U.S. regulations regarding air quality are contained within Title 40 ("Protection of Environment") of the Code of Federal Regulations (CFR). Title 40 comprises 18 volumes, and each volume is separated into parts for ease of reference. Title 40 is updated each July with any new regulations enacted during the previous 12 months, including changes and additions as recorded in the Federal Register (FR).

The regulations governing emissions certification and test procedures are contained within Part 86 ("Control of Air Pollution from New and In-Use Motor Vehicles and New and In-Use Motor Vehicle Engines: Certification and Test Procedures"), and the final rules for Part 86 as listed in the FR. This material applies to OEM vehicles, to OEM heavy-duty engines, and to aftermarket conversions.

\section{Who to Contact}

\section{EPA Light-Duty Vehicles and Trucks}

Environmental Protection Agency

Office of Mobile Sources

Vehicle Programs and Compliance Division

Vehicle Programs Group

2565 Plymouth Road

Ann Arbor, MI 48105

EPA Alternative Fuels Hotline

Telephone: (734) 668-4312

Fax:

(734) $741-7869$

${ }^{\star \star}$ New Hotline numbers as of May 1998

Telephone: (734) 214-4312

Fax:

(734) $214-4869$
EPA Heavy-Duty Engines

Environmental Protection Agency

Office of Mobile Sources

Engine Compliance Programs Group

Mailing Address:

401 M St. S.W. (6403J)

Washington, DC 20460

Visiting Location and Courier Shipments:

501 3rd St. N.W.

Washington, DC 20001

Telephone: (202) 564-9261

Fax:

(202) $565-2057$

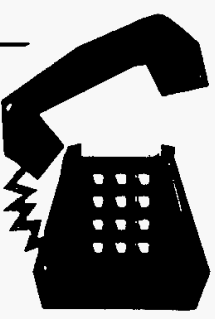


Table 1

The Parts of Title $\mathbf{4 0}$ of the Code of Federal Regulations (CFR) That Affect Certification of Aftermarket Conversions

\begin{tabular}{|l|l|}
\hline Part & Name \\
\hline 85 & Control of Air Pollution from Motor Vehicles and Motor Vehicle Engines \\
\hline 86 & $\begin{array}{l}\text { Control of Air Pollution from New and In-Use Motor Vehicles and } \\
\text { New and In-Use Motor Vehicle Engines: Certification and Test Procedures }\end{array}$ \\
\hline 88 & Clean-Fuel Vehicles \\
\hline 600 & Fuel Economy of Motor Vehicles \\
\hline
\end{tabular}

The FR is an important reference source. It is the official publication for Notices, Rules, and Proposed Rules from federal agencies and organizations. As part of the regulation and rule-making process, the FR contains a preamble for the regulations. This preamble provides manufacturers with information that addresses many frequently asked questions about the regulations.

Table 1 lists the other parts of Title 40 that are key to the certification process. For example, Part 85 (or 40 CFR Part 85 , as it is more technically known) contains the provisions under which parties are exempt from the tampering prohibition contained in Section 203 of the CAA (see the sidebar on page 7). Also, Part 88 contains the regulations that govern the Clean-Fuel Vehicle (CFV) and the CleanFuel Fleet (CFF) Program requirements.

Because the EPA updates its requirements from time to time, information presented here about the location of certain rules and regulations is also subject to change. To obtain the most up-to-date information, check with the EPA.

On October 31, 1997, just before this guide was printed, the EPA issued a draft of a number of proposed changes to 40 CFR Part 86 . The changes ease the burden of certification for manufacturers of CFVs.
The title of the proposed rule is Expanded Engine Family Definition, Fee Exemption, and Revised Definition for Dedicated Fuel System for Vehicles and Engines Meeting Low-Emission Vehicle (LEV), Inherently Low-Emission Vehicle (ILEV), Ultra-Low Emission Vehicle, or Zero Emission Vehicle Exhaust Emission Standards. It is available from the EPA Office of Mobile Sources Clean Fuel Fleets World Wide Web site, listed in Appendix C.

In this document, the EPA has proposed revisions to the definition of dedicated fuel systems, adopted provisions to allow manufacturers of CFVs to group certain engine families into engine family classes, and provided for an exemption from certification fees for vehicles meeting CFV emissions standards. The revised definition of a dedicated vehicle includes vehicles capable of operating on a second (conventional) fuel for a maximum of one hour in any three-hour period, or with a total conventional fuel capacity that allows for an operational range of 50 miles. The proposed rule allows engine families to be grouped under engine family classes as defined in the document. The proposed fee ex-emption would be available for vehicles that certify to the EPA's LEV, ultra low-emission vehicle (ULEV), inherently low-emission vehicle (ILEV), or zero-emission vehicle (ZEV) emissions standards. 


\section{Memorandum 1A and Addendum to Memorandum 1A}

As noted in the introduction, in 1974 the EPA clarified the tampering prohibition contained in Section 203 of the CAA. Memorandum 1A, or Memo 1A as it is commonly known, states, in part, that using an aftermarket part, alteration, or add-on part will not constitute tampering if the manufacturer has a reasonable basis to believe that such alterations will not adversely affect emissions performance. Through Memo 1A, the EPA outlined steps for aftermarket conversion companies to follow to arrive at this reasonable basis. The two main methods were: (1) perform emissions testing after installation, following all federal procedures to ensure that emissions were within the standards for the model year in question over the useful life of the vehicle; or (2) have a federal, state, or local environmental control agency accept that the converted vehicle's emissions performance has not been compromised. This latter provision was limited to the geographic area over which the state or local government had jurisdiction.

In an important update on September 4, 1997, the EPA released an addendum to Memo 1A, which clarifies the tampering enforcement policy and revises the terms for establishing the reasonable basis. The revised policy states "EPA will no longer accept a representation based on the pre-1994 California Procedures for alternative fuel conversion systems or on the procedures under Colorado Regulation No. 14." Three options are listed for establishing a reasonable basis:

1) A federal Certificate of Conformity under 40 CFR Part 86 or 40 CFR Part 88

2) A retrofit system certification (Executive Order) from CARB under the "California Certification and Installation Procedures for Alternative Fuel Retrofit Systems for Motor Vehicles Certified for 1994 and Subsequent

\section{Anti-Tampering Provision of the Clean Air Act (Section 203 (a) (3))}

"The following acts and the causing thereof are prohibited...

(3) for any person to remove or render inoperative any device or element of design installed on or in a motor vehicle or motor vehicle engine in compliance with regulations under this title prior to its sale and delivery to the ultimate purchaser, or for any person knowingly to remove or render inoperative any such device or element of design after such sale and delivery to the ultimate purchaser."

Model Years and for All Model Year Motor Vehicle Retrofit Systems Certified for Emission Reduction Credit" for a conversion system installed and tested under the above procedures on a vehicle or engine from a 50 -state engine family for use nationwide, or for a conversion system installed and tested under the above procedures on a vehicle or engine from a California engine family for use in California only

3) Until December 31, 1998, the use of an alternative fuel conversion system designed, tested, and installed on a single engine family, or multiple engine families (providing certain conditions are met) if testing is complete by March 31, 1998.

The addendum details the conditions required by Option 3 . In general terms, Option 3 allows, for a limited time, manufacturers to establish a reasonable basis by performing specific emissions testing and demonstrating that the test vehicle or engine conforms with emissions standards after conversion.

Copies of the EPA policy are available from the EPA's Mobile Source Enforcement Branch at 202-564-2255 or on the EPA Office of Mobile Sources Web site. Refer to Appendix C (Informative Web Sites) and Appendix J (Contacts) in this guide for addresses. 


\section{An Example of Determining the Duration of a Certificate of Conformity}

In the following example, the term "model year" refers to the model year of the certified aftermarket conversion, not the vehicle's original model year. EPA Certificates of Conformity are good for one model year, which must always include January 1 of the calendar year for which it is designated and may not include January 1 of any other calendar year. The maximum duration of a model year is one calendar year plus 364 days. The certificate has an effective date on which conversions may begin, and they must stop no later than December 31 of the model year. If your company were issued a 1998 model year certificate with an effective date of September 26, 1997, you could start conversions on the effective date and convert vehicles through to December 31 , 1998.

To take advantage of the maximum period for converting vehicles, your company would try to have the certificate issued with an effective date of January 2 of the year prior to the model year. For example, a 1998 model year certificate could be issued with an effective date of January 2, 1997, so that conversions could be done from January 2, 1997 through to December 31 of 1998 (one calendar year plus 364 days).

\section{What Does Certification Apply To?}

The EPA certification procedures give manufacturers a method to follow for certifying light-duty vehicles and trucks, as well as heavy-duty engines, to operate on CNG or LPG, either in dedicated or dualfuel modes. Manufacturers that successfully complete the process receive a "Certificate of Conformity" from the EPA. With this certificate, manufacturers may convert the engine family or vehicle referenced in the certificate. Further, they become exempt from the tampering provisions under the CAA for the duration specified, as long as the vehicles are converted in the exact manner in which they were certified.

Each Certificate of Conformity applies to a specific engine family (see sidebar on page 9). The manufacturer or installer may only convert vehicles in the engine family named on the certificate. The certificate is valid for a single model year, and it lists the period during which vehicles from the specified engine family may be converted. The sidebar on this page contains an example of how these dates are established and applied.

There are three basic federal emissions certifications: (1) the so-called "49-state" certification, under which vehicles can be certified for operations in all states except California; (2) "50-state" certification, under which vehicles can be certified for operations throughout the country (vehicles issued a " 50 -state" certification and scheduled to be operated in California must also be certified by CARB); and (3) "California-only" certification, under which vehicles can be certified for operation in California only. California-only vehicles must first go through the CARB certification. This provision applies to OEM vehicles and to aftermarket conversions. 


\section{Engine Family Names Explained}

For the purposes of emissions certification, and for ease in identification, the EPA classifies vehicles and engines with a standardized 12-character code known as an engine family name. Engines are grouped into families based on criteria provided in 40 CFR Part 86 (see 86.096-24), and the EPA's Advisory Circular No. 20-B, dated June 27, 1974 ("Determination of Engine Families and Classification of Emission Control Systems"). Changes in the format are scheduled to take effect for the 1998 model year. Although briefly outlined below, more information on the changes is available on the EPA's Office of Mobile Sources' World Wide Web site (see Appendix C, Informative Web Sites, for EPA Standardized Engine and Evaporative Family Names).

\section{7 and Earlier Model Years}

The engine family name contains a wealth of information about a given vehicle or engine, including:

- The vehicle or engine model year

- Manufacturer

- Engine displacement

- Vehicle or engine class (for example, light-duty vehicle or heavy-duty engine)

- Fuel system (such as valves per cylinder, carburetor, or fuel injection)

- Combustion cycle (such as Otto or diesel) and fuel

- Applicable emissions standards

- Exhaust gas aftertreatment device (for example, a catalyst or a particulate trap)

- Whether on-board diagnostics (OBD) regulations apply.

VFM4.628GKEK is an example of a 1997 engine family code for a 1997 (V); Ford Motor Company (FM); 4.6 liter engine (4.6); in a light light-duty truck with a loaded vehicle weight between 3,751 and 5,750 pounds (2); equipped with electronic multi-point fuel injection and two valves per cylinder (8). It is an Otto-Cycle piston gasoline engine $(G)$; certified to tier 1 emissions standards $(K)$; with a three-way catalyst (E); and complies with federal OBD or California OBD II requirements (K).

\section{Beginning with the 1998 Model Year ...}

The engine family name format has changed, although it still contains 12 characters. The first character is the model year, the second through fourth are the code for the manufacturer, the fifth is the family type (for example, light-duty vehicle, light-duty truck, heavy-duty engine), the sixth through ninth are displacement in liters, and the tenth through twelfth are reserved for the manufacturer's own use. WG9XT05.46BF is an example of a 1998 engine family code - the W signifies 1998 model year; the G9X signifies GFI Control Systems, Inc.; the T signifies light-duty truck family; the 05.4 signifies 5.4 liters; and the $6 \mathrm{BF}$ is a code defined by the manufacturer. Much of the information contained in the 1997 and earlier engine family names for light-duty vehicles and trucks is now included in the vehicle emission configuration bar code label (or format), which is part of the emissions control information label. 


\section{Small Volume Manufacturer Status and Its Benefits}

A small volume manufacturer is defined as a company that will sell or convert fewer than 10,000 vehicles or engines during the model year in question. The company must apply to the EPA for this status. If the company qualifies under the specific terms that the EPA outlines, options for developing DFs may prove beneficial (see the discussion beginning on page 20 for more information about DFs).

A small volume manufacturer may qualify for a partial waiver of the certification fees, and may also qualify for a delay in the initial years of the phase-in schedules for certain emissions regulations. Refer to 40 CFR Part 86.085-1(e) for the criteria used to qualify companies as small volume manufacturers and to 40 CFR Part 86.098-14 for the 1998 model year certification procedures applicable to small volume manufacturers.

\section{Overview of the Certification Process}

Figure 1 illustrates the steps necessary for obtaining EPA certification. The process outlined here applies to small volume manufacturers of aftermarket conversions (the sidebar on this page explains small volume manufacturer status). The process includes applying to EPA for small volume manufacturer status, paying fees, conducting durability and emissions testing, comparing the test results with applicable emissions standards, applying for certification, and obtaining the Certificate of Conformity.

The EPA furnishes an information package to companies interested in certification using the small volume manufacturer rules. The information package contains reference materials about the certification process, the criteria companies must use to qualify as small volume manufacturers, instructions on applying for small volume manufacturer status, and other details such as the application fees.

After receiving the EPA information package, each company must decide whether it is interested, and determine whether it qualifies for small volume manufacturer status. If the answer to both questions is "yes," the next step is to send a written request for the status to the EPA. The written request must include responses to the list of questions contained in the information package. If the request is granted, the EPA will issue a manufacturer's identification code. Next, the company must submit the application fees (see the section on page 13 entitled "Fces," along with Table 2 on page 12).

The company must then determine the process it wants to use to establish deterioration factors (DFs). DFs are used to predict the increase in vehicle emissions associated with increased mileage accumulation (see the example contained in the discussion and sidebar on page 20).

After establishing the process for determining DFs, emissions testing can begin (see 40 CFR Part 86.094-14(c)). For lightduty vehicles and trucks, the EPA may decide to undertake additional testing of its own to verify emissions results. The manufacturer may be required to provide a prepared vehicle to the EPA for this testing. More information about emissions testing is provided in the section of this guide beginning on page 18 . Once all the test results are gathered, the company submits an application for certification to the EPA for its review.

\section{Submitting an Application}

Submitting an application is really the final step in the process of obtaining emissions certification of a vehicle from the EPA. The application represents the culmination of considerable information gathering, and formally presents that information in such a way as to facilitate the EPA's review and acceptance. To shorten the review process and to guarantee the speediest response time, the EPA suggests submitting the application in the format outlined in its information package. Following the EPA's directions and providing the exact information requested will result in the quickest turnaround. 


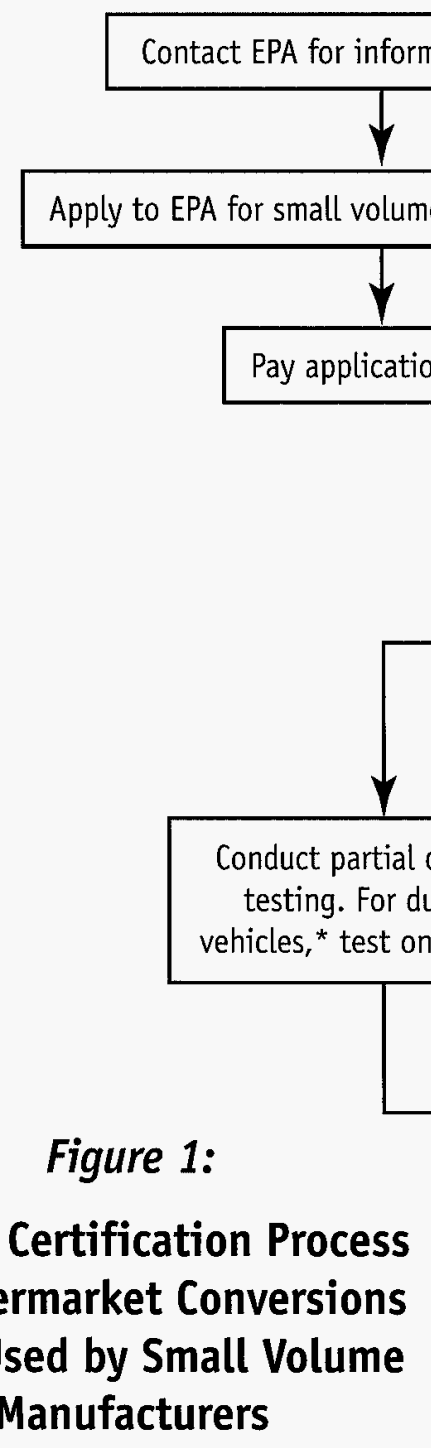

Federal Certification Process for Aftermarket Conversions to Be Used by Small Volume Manufacturers

$\bigodot_{\text {Action }}^{\text {Manufacturer }}$

EPA

Action

\section{Abbreviations}

DF - Deterioration Factor

EPA - Environmental Protection Agency

EO - Executive Order from CARB

* In this figure, the term "vehicle" collectively refers to light-duty vehicles and trucks, and heavy-duty engines
Is this a

California-only engine
Determine DF

process

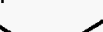

Conduct full durability testing. For dual-fuel vehicles, ${ }^{*}$ test on both fuels

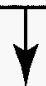

Select and test emission data vehicle. * For dual-fuel vehicles, test on both fuels. Apply DFs

Use EPA-assigned or manufacturer-established DFs 
Table 2

\section{EPA Certification Fees}

\begin{tabular}{|l|c|c|}
\hline Vehicle or Engine Type & Certification Type & Fee Per Certification \\
\hline \multirow{2}{*}{$\begin{array}{l}\text { Light-Duty Vehicle } \\
\text { or Truck }\end{array}$} & Federal & $\$ 23,731$ \\
\cline { 2 - 3 } $\begin{array}{l}\text { Heavy-Duty Vehicle } \\
\text { or Engine }\end{array}$ & California Only & $\$ 9,127$ \\
\cline { 2 - 3 } & Federal & $\$ 12,584$ \\
\hline
\end{tabular}

For light-duty vehicles and trucks, the information that must be submitted with the application package includes:

- Pertinent company information, along with the name of the contact person

- A brief description of the vehicles to be certified, including:

- Engine family name and vehicle models

- List of parts to be added, removed, and modified

- Conversion equipment description

- Engine details

- Emissions control system details

- Engine calibration information

- Durability information

- All emissions test results, and information about the facility that performed the tests

- Emissions standards with which the vehicle complies

- Appropriate signatures ensuring that the regulations have been met

- Examples of the emissions control labels, as well as examples of the ILEV decals if the certification is to meet ILEV standards (see the discussion on page 23 of this guide)

- Maintenance instructions

- Emissions warranty statements (see the discussion on page 24 of this guide)

- Statement of compliance.
To certify vehicles to the CFF Program (see 40 CFR Part 88), the application must also include the name of the installer(s) who will complete the conversions if the installer(s) is different from the holder of the certificate.

The application for heavy-duty engines is similar, but is currently under review as a result of an effort to reduce the level of reporting. Contact the EPA Office of Mobile Sources, Engine Compliance Programs, listed in Appendix J, and ask for the U.S. EPA Large Engine and Evaporative Certification Guidance document.

\section{EPA Review and Issuance of a Certificate of Conformity}

Upon receiving an application, the EPA begins its review process. If the review is positive, a Certificate of Conformity is issued. If all the required information is submitted with the application, the turnaround time for issuing the certificate is relatively short. However, for a light-duty vehicle or truck, the EPA may request a test vehicle for verification purposes. If the EPA does not request one, the turnaround time is approximately one month. If the EPA does request an emissions test vehicle, and it is made available to the EPA as soon as it is requested, the turnaround time will be approximately two additional weeks from the time the test vehicle arrives at the EPA test facility. This vehicle must already be prepped and have the required minimum mileage (minimum of 2,000 miles) on the alternative fuel system and on the stabilized emissions control system. 
Table 3

Index to Locating Emissions Standards in Title 40, Part 86 of the Code of Federal Regulations (CFR)

\begin{tabular}{|l|c|c|c|c|c|c|c|c|c|}
\hline & $\begin{array}{c}1991 \\
\text { \& Later }\end{array}$ & $\begin{array}{c}1993 \\
\text { \& Later }\end{array}$ & $\begin{array}{c}1994 \\
\text { \& Later }\end{array}$ & $\begin{array}{c}1996 \\
\text { \& Later }\end{array}$ & $\begin{array}{c}1997 \\
\text { \& Later }\end{array}$ & $\begin{array}{c}1998 \\
\text { \& Later }\end{array}$ & $\begin{array}{c}1999 \\
\text { \& Later }\end{array}$ & $\begin{array}{c}2001 \\
\text { \& Later }\end{array}$ & $\begin{array}{c}2004 \\
\text { \& Later }\end{array}$ \\
\hline $\begin{array}{l}\text { Light-Duty } \\
\text { Vehicle }\end{array}$ & $86.090-8$ & $86.090-8$ & $86.094-8$ & $86.096-8$ & $86.096-8$ & $86.098-8$ & $86.099-8$ & $86.099-8$ & $86.099-8$ \\
\hline $\begin{array}{l}\text { Light-Duty } \\
\text { Truck }\end{array}$ & $86.091-9$ & $86.091-9$ & $86.094-9$ & $86.096-9$ & $86.097-9$ & $86.097-9$ & $86.099-9$ & $86.001-9$ & $86.004-9$ \\
\hline $\begin{array}{l}\text { Heavy-Duty } \\
\text { Otto-Cycle Engine }\end{array}$ & $86.091-10$ & $86.091-10$ & $86.091-10$ & $86.096-10$ & $86.096-10$ & $86.098-10$ & $86.099-10$ & $86.099-10$ & $86.099-10$ \\
\hline $\begin{array}{l}\text { Heavy-Duty } \\
\text { Diesel Engine }\end{array}$ & $86.091-11$ & $86.093-11$ & $86.094-11$ & $86.096-11$ & $86.096-11$ & $86.098-11$ & $86.099-11$ & $86.099-11$ & $86.099-11$ \\
\hline
\end{tabular}

Table 4

Index to Locating Clean-Fuel Vehicle Emissions Standards in Title 40, Part 88 of the Code of Federal Regulations (CFR)

\begin{tabular}{|c|c|c|c|}
\hline & $\begin{array}{c}1994 \text { \& Later } \\
\left(\text { LEV }^{\mathrm{a}}, \mathrm{ULEV}^{\mathrm{b}}\right. \\
\text { \& ILEVc) }\end{array}$ & $\begin{array}{l}1993 \text { \& Later } \\
\text { (ILEVc) }\end{array}$ & $\begin{array}{l}1998 \text { \& Later } \\
\text { (ILEV') }\end{array}$ \\
\hline Light-Duty Vehicle & $88.104-94$ & $88.311-93$ & $88.311-98$ \\
\hline Light-Duty Truck & $88.104-94$ & $88.311-93$ & $88.311-98$ \\
\hline Heavy-Duty Otto-Cycle Engine & $88.105-94$ & $88.311-93$ & $88.311-98$ \\
\hline Heavy-Duty Diesel Engine & $88.105-94$ & $88.311-93$ & $88.311-98$ \\
\hline
\end{tabular}

a Low-Emission Vehicle

${ }^{b}$ Ultra Low-Emission Vehicle

${ }^{c}$ Inherently Low-

Emission Vehicle

\section{Fees}

The EPA charges a fee for each engine family certification request; Table 2 contains examples of these fees.

Small volume manufacturers must either pay the predetermined fee or apply for a partial waiver. The waiver must be requested prior to payment of any fee because it provides only an alternative method of fee calculation. For aftermarket conversions, the alternative fee is based on $1 \%$ of the total value of all vehicles to be converted. This includes both the value of the vehicle and the value of the conversion kit. Vehicle value is determined using the National Automobile Dealer's Association (NADA) price guide or other evidence of the actual market value if the vehicle is not included in the NADA price guide. A request for the waiver should be submitted at the same time as the request for small volume manufacturer status.

Applications that do not result in a certification are eligible for a partial refund.

\section{Emissions Certification Standards}

Emissions standards are found in various sections of the CFR. Tables 3 and 4 summarize the locations by model year and vehicle or engine type. In addition, Appendix D summarizes the exhaust emissions standards.

Vehicles or engines that are converted to dual-fuel operation must be tested on and meet the emissions standards for both fuels. The standards are fuel-specific. Exhaust emissions standards for LPG 


\section{Example of Applying Standards and Test Procedures for CFV Dual-Fuel Aftermarket Conversions}

Suppose a manufacturer requests a 1998 model year certification for a light-duty truck that it has converted to a $\mathrm{CNG} /$ gasoline dual-fuel vehicle, and wishes to certify to the LEV standard. Before the conversion, the original model year of the truck was 1996, and it was originally certified on gasoline. To certify it as a dual-fuel vehicle for the 1998 model year, the manufacturer must perform emissions tests on CNG using the 1998 emissions test procedures for CNG, apply the DFs, and compare the results to the LEV certification standards.

In addition, the vehicle must be tested on gasoline after conversion using the 1996 test procedures, the 1996 gasoline standards and the CFV NMOG and formaldehyde standards for gasoline. Testing on gasoline must include all of the 1996 test procedures-cold temperature carbon monoxide $(\mathrm{CO})$, certification short test, evaporative, and spitback. Manufacturers do not need to comply with the new $O B D$ requirements if they can provide a written technical justification. $O B D$ requirements are explained on page 22 of this guide.

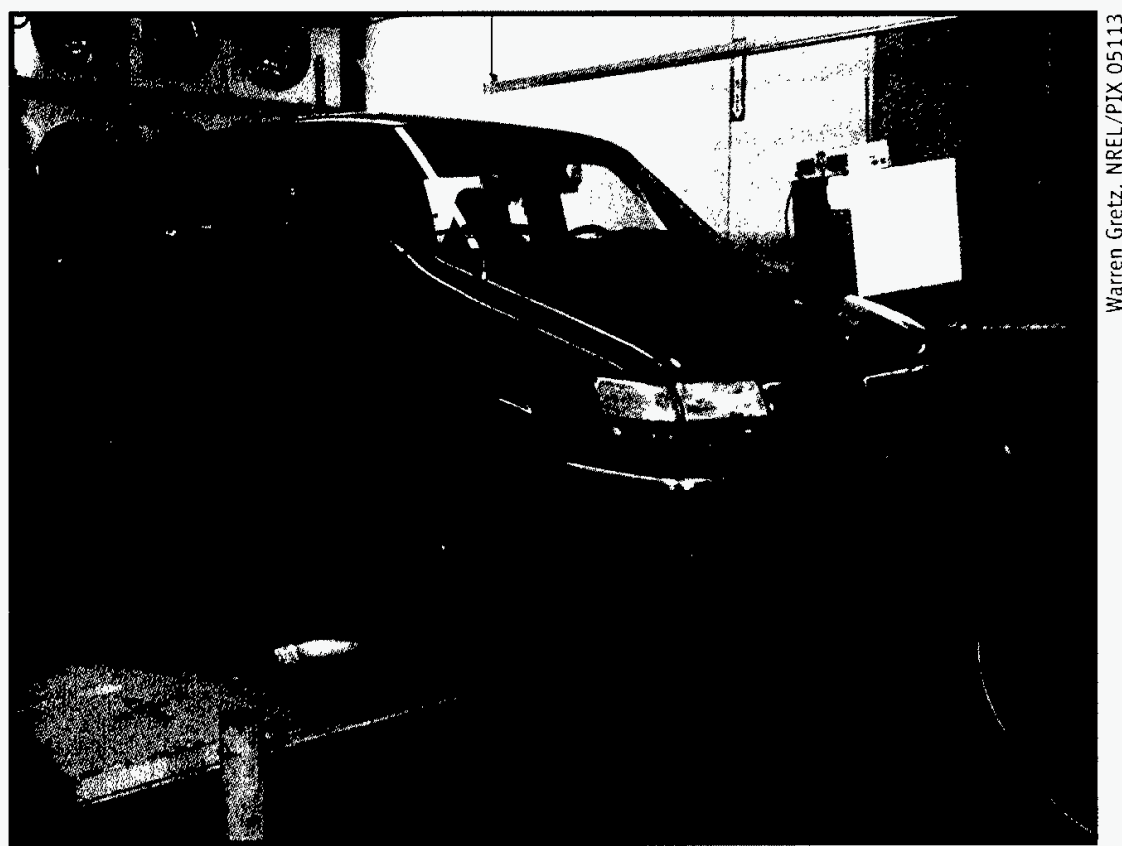

Emissions test on an aftermarket conversion being performed on the Colorado Department of Health and Environment's chassis dynamometer vehicles are identical to those for gasoline vehicles. The standards for CNG vehicles are also identical to the gasoline standards, except for hydrocarbons. The certification standards for hydrocarbon emissions from CNG vehicles are specified in terms of non-methane hydrocarbons instead of total hydrocarbons. CFV standards include a non-methane organic gas (NMOG) standard.

Manufacturers who are certifying a vehicle to tier 1 standards (see sidebar on page 17) must meet the tier 1 standards that were in place for the model year in which the vehicle was originally certified. This applies to dedicated and dual-fuel vehicles. Dual-fuel vehicles must be tested on and meet the applicable standards for both fuels. Manufacturers certifying to the CFV standards must meet the standard that applies to the alternative fuel for the model year for which certification is being requested. In other words, a 1996 model year vehicle converted and being certified to CFV standards in 1998 must meet the 1998 emissions standards. Dual-fuel vehicles being certified to meet CFV standards must also satisfy a NMOG and formaldehyde standard on the conventional fuel. They must also comply with the other conventional fuel standards that were in effect when the vehicle received its original certification. Dual-fuel vehicles cannot be certified to the ILEV standard. The sidebar on this page gives an example of applying emissions standards for CFVs.

EPA's emissions certification standards vary with vehicle type and weight. For example, there are specific standards for light-duty vehicles and trucks, which can weigh up to 8,500 pounds gross vehicle weight rating (GVWR). Such vehicles are tested using a chassis dynamometer following the applicable light-duty test 
Table 5

\section{Weight Groupings for Light-Duty Trucks}

\begin{tabular}{|l|c|c|c|}
\hline Vehicle Type & $\begin{array}{c}\text { Weight } \\
\text { Class }\end{array}$ & GVWR $^{\mathbf{a}}$ & LVW $^{\mathbf{b}}$ or ALVW \\
\hline Light Light-Duty Truck & 1 & $0-6,000 \mathrm{lb}$ & $0-3,750 \mathrm{lb} \mathrm{LVW}$ \\
\hline Light Light-Duty Truck & 2 & $0-6,000 \mathrm{lb}$ & $3,751-5,750 \mathrm{lb} \mathrm{LVW}$ \\
\hline Heavy Light-Duty Truck & 3 & $6,000-8,500 \mathrm{lb}$ & $3,751-5,750 \mathrm{lb}$ ALVW \\
\hline Heavy Light-Duty Truck & 4 & $6,000-8,500 \mathrm{lb}$ & Greater than $5,750 \mathrm{lb}$ ALVW \\
\hline
\end{tabular}

a Gross Vehicle Weight Rating

${ }^{b}$ Loaded Vehicle Weight

${ }^{c}$ Adjusted Loaded Vehicle Weight

\section{Table 6}

\begin{tabular}{|l|c|c|}
\hline \multicolumn{2}{|c|}{ Heavy-Duty Engine Classifications } & $\begin{array}{c}\text { Typical } \\
\text { Engine Type }\end{array}$ \\
\hline Light Heavy-Duty Engine & $8,501-19,499 \mathrm{lb}$ & 70 to 170 \\
\hline Medium Heavy-Duty Engine & $19,500 \mathrm{lb}-33,000 \mathrm{lb}$ & 170 to 250 \\
\hline Heavy Heavy-Duty Engine & $33,001 \mathrm{lb}$ and greater & Greater than 250 \\
\hline
\end{tabular}

${ }^{a}$ Gross Vehicle Weight Rating

procedures. For these tests, exhaust emissions are measured in grams per mile. Light-duty trucks are further divided into subgroups according to weight (see Table 5). The tier 0 emissions category has two subgroups, tier 1 has four, and CFV has five.

Vehicles that weigh more than 8,500 pounds GVWR are classified as heavyduty, and different test procedures and standards apply. Instead of testing the vehicle on a chassis dynamometer, the engine is tested separately using an engine dynamometer. Exhaust emissions are measured in grams per brake horsepower-hour. Refer to Table 6 for a description of the heavy-duty engine classifications. Vehicles that weigh between 8,501 and 10,000 pounds GVWR can either be tested on a chassis dynamometer as heavy light-duty trucks or their engines can be tested as heavy-duty engines (see 40 CFR Part 86.094-1(b)).

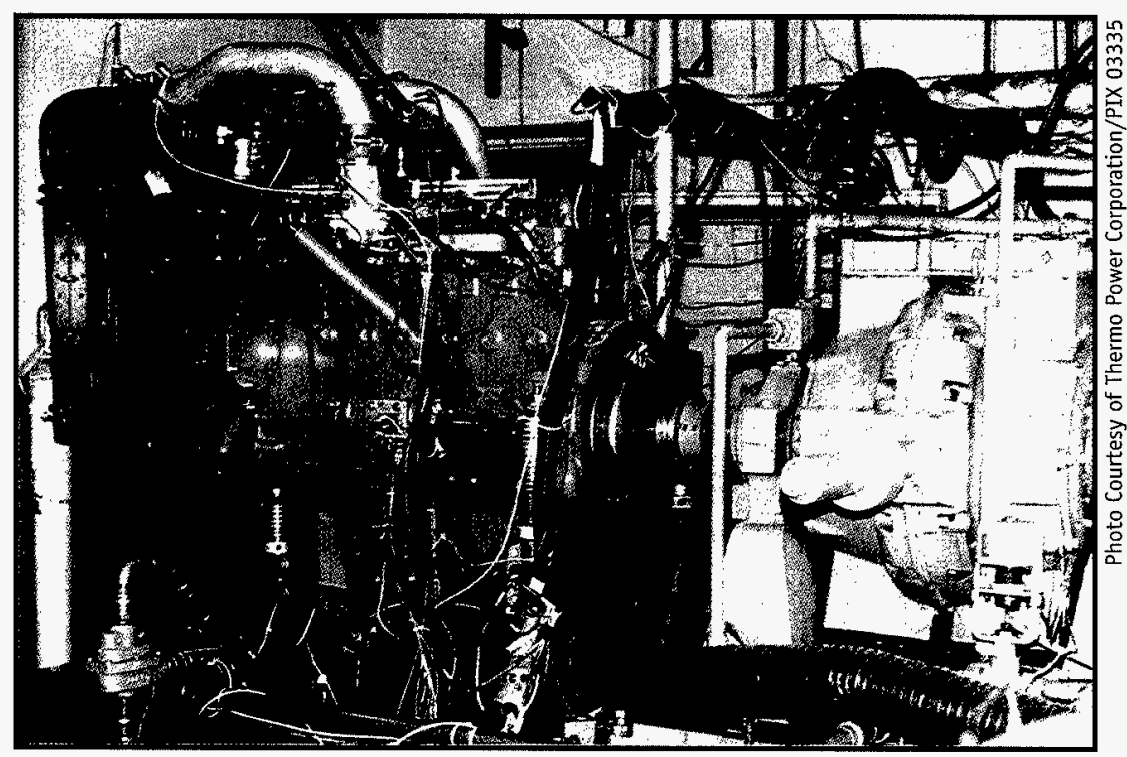

Navistar 466 diesel engine converted to natural gas, being tested on an engine dynamometer 


\section{Table 7}

\section{Time and Mileage Limitsa for Determining the Tier 1 Standards Applicable to Intermediate and} Full Useful Life Exhaust and Evaporative Emissions

\begin{tabular}{|l|c|c|c|}
\hline \multirow{2}{*}{ Vehicle/Engine Type } & \multicolumn{2}{|c|}{ Useful Life for Exhaust Emissions } & \multicolumn{1}{c|}{$\begin{array}{c}\text { Useful Life for } \\
\text { Evaporative Emissions }\end{array}$} \\
\cline { 2 - 4 } & Intermediate & \multicolumn{1}{c|}{ Full } & Full \\
\hline Light-Duty Vehicle & 5 years or 50,000 miles & 10 years or 100,000 miles & 10 years or 100,000 miles \\
\hline Light-Duty Truck 1 \& 2 & 5 years or 50,000 miles & 10 years or 100,000 miles & 10 years or 100,000 miles \\
\hline Light-Duty Truck 3 \& 4 & 5 years or 50,000 miles & 11 years or 120,000 miles & 11 years or 120,000 miles \\
\hline $\begin{array}{l}\text { Heavy-Duty } \\
\text { Otto-Cycle Engine }\end{array}$ & none & 8 years or 110,000 miles & 10 years or 110,000 miles \\
\hline $\begin{array}{l}\text { Light Heavy-Duty } \\
\text { Diesel Engine }\end{array}$ & none & 8 years or 110,000 miles & 8 years or $110,000 \mathrm{miles}$ \\
\hline $\begin{array}{l}\text { Medium Heavy-Duty } \\
\text { Diesel Engine }\end{array}$ & none & 8 years or 185,000 miles & 8 years or 185,000 miles \\
\hline $\begin{array}{l}\text { Heavy Heavy-Duty } \\
\text { Diesel Engine }\end{array}$ & none & 8 years or 290,000 miles & 8 years or 290,000 miles \\
\hline
\end{tabular}

"Time and mileage are expressed in years and miles, and are one or the other, whichever comes first
For light-duty vehicles and trucks, the EPA also assigns different emissions standards on the basis of years or miles in service. These are known as intermediate and full useful life standards (see "Terms" in Appendix A for a definition of useful life), and Table 7 specifies the time and mileage limits that apply. The standards for full useful life are less stringent than those for intermediate useful life to account for the wear and tear on components resulting from normal use. In other words, emissions performance is expected to deteriorate over time. Compliance with both the intermediate and full useful life standards is determined by applying the appropriate DFs to the emissions test results (more information about DFs is found on page 20 of this guide). Compliance with tier 0 emissions standards is required only at 50,000 miles. Emissions test results after factoring in the DFs are to be within the values set for each period.
The useful life period of a vehicle does not change as the result of conversion. For example, if a light light-duty truck has 10,000 miles on its odometer at the time of conversion, its full useful life will end once its odometer reaches 100,000 miles (not 110,000 miles).

In addition to testing for exhaust emissions, a number of other tests must also be performed as part of the EPA Federal Test Procedures (FTP) for emissions certification. These may include multi-day measurement of evaporative emissions and on-board vapor recovery, as well as the spitback, refueling, cold temperature $\mathrm{CO}$, idle, and certification short tests (see CFR 40 Part 86 for details). Results from each test must be compared to the corresponding certification standards.

Some of the EPA's regulations that govern emissions standards are being phased in over time, and others will not become effective for a number of years. As previously noted, small volume manufacturers are exempt from the initial years of the phase-in of the regulations. 


\section{Evolving Emissions Standards}

Emissions standards have been undergoing continuous change for a number of yearsa trend that is expected to continue. This trend is driven by the need for improvements in air quality, changes in vehicle emissions control technology and, of course, changes in the fuels themselves.

The EPA and CARB use various names and abbreviations to refer to the various emissions standards. The EPA currently uses tier 0, tier 1, TLEV, LEV, ILEV, ULEV, and ZEV. These standards are ranked from less stringent to more stringent (for example, tier 1 is a more stringent emissions standard than tier 0 , and ZEV is the most stringent). The term TLEV applies to California vehicles only. CARB does not have an ILEV standard, but it does have a super-ultra-low-emission vehicle (SULEV) standard for medium-duty vehicles. SULEV is even more stringent than the ULEV standard. Although the name of a standard may be used for many vehicle types, the actual value can be different for each vehicle type. For example, the federal tier 1 standards for light-duty vehicles are more stringent than the federal tier 1 standards for light-duty trucks 2. EPA and CARB emission standards may differ for the same vehicle type even though they may be described by the same name.

The EPA has implemented the LEV, ILEV, ULEV, and ZEV standards under the CFF Program to address air quality issues in cities that do not comply with federal air quality standards. Although vehicles that meet those standards can be used elsewhere, fleets within cities that do not meet the air standards are mandated to phase in purchases of new vehicles that comply with LEV and ULEV standards. Vehicle manufacturers certifying vehicles for sale in California are required to phase in sales of TLEV, LEV, ULEV, and ZEV vehicles.

Appendix A presents additional details on the names and abbreviations of various standards, and Appendix D summarizes each of the standards by vehicle type. 


\section{Figure 2:}

\section{FTP-75 Using the Urban Dynamometer Driving Schedule}

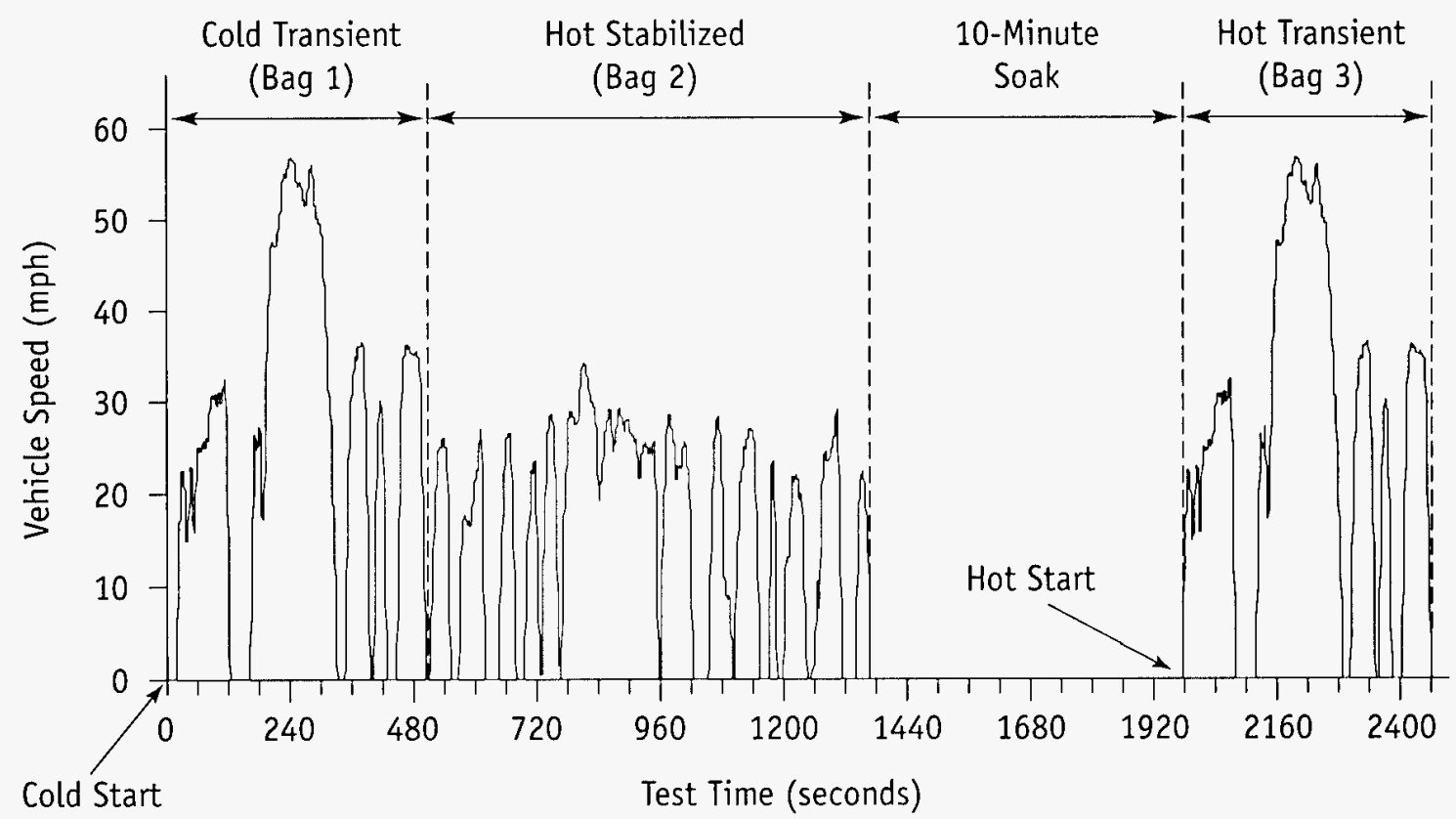

\section{Emissions Testing}

Emissions testing is perhaps the most time-consuming and costly part of the certification process, but it is also the most important. We encourage you to become as familiar with the details of emissions testing as possible.

\section{Exhaust and Evaporative Testing Procedures}

The procedures that the EPA specifies for emissions testing of light-duty vehicles and trucks are contained in 40 CFR Part 86, Subpart B. The exhaust emissions test procedures follow the EPA FTP 75, which uses the urban dynamometer driving schedule (Figure 2). New multi-day procedures for enhanced evaporative emissions testing are being phased in. Although small volume manufacturers are exempt from the initial years of this phase-in, they must comply with the $100 \%$ requirement for the model year listed in the regulations.
Both the exhaust and evaporative testing procedures must be conducted in a specific sequence and in temperaturecontrolled environments. Several steps in the evaporative testing procedures for gaseous fuels differ from those required for gasoline. For example, different fuel tank levels are involved, and the supplemental two-day diurnal test and the refueling spitback test are not required for CNG and LPG. If the vehicle is dual-fuel, it must be tested on both fuels, including all the test procedures normally required for gasoline systems.

The exhaust and evaporative emissions test procedures for heavy-duty engines are contained in a number of different subparts of 40 CFR Part 86 (see Table 8). Heavy-duty engines are tested on an engine dynamometer using the transient engine dynamometer test cycle (Figure 3 ). 


\section{Figure 3:}

\section{Transient Engine Dynamometer Test Cycle}

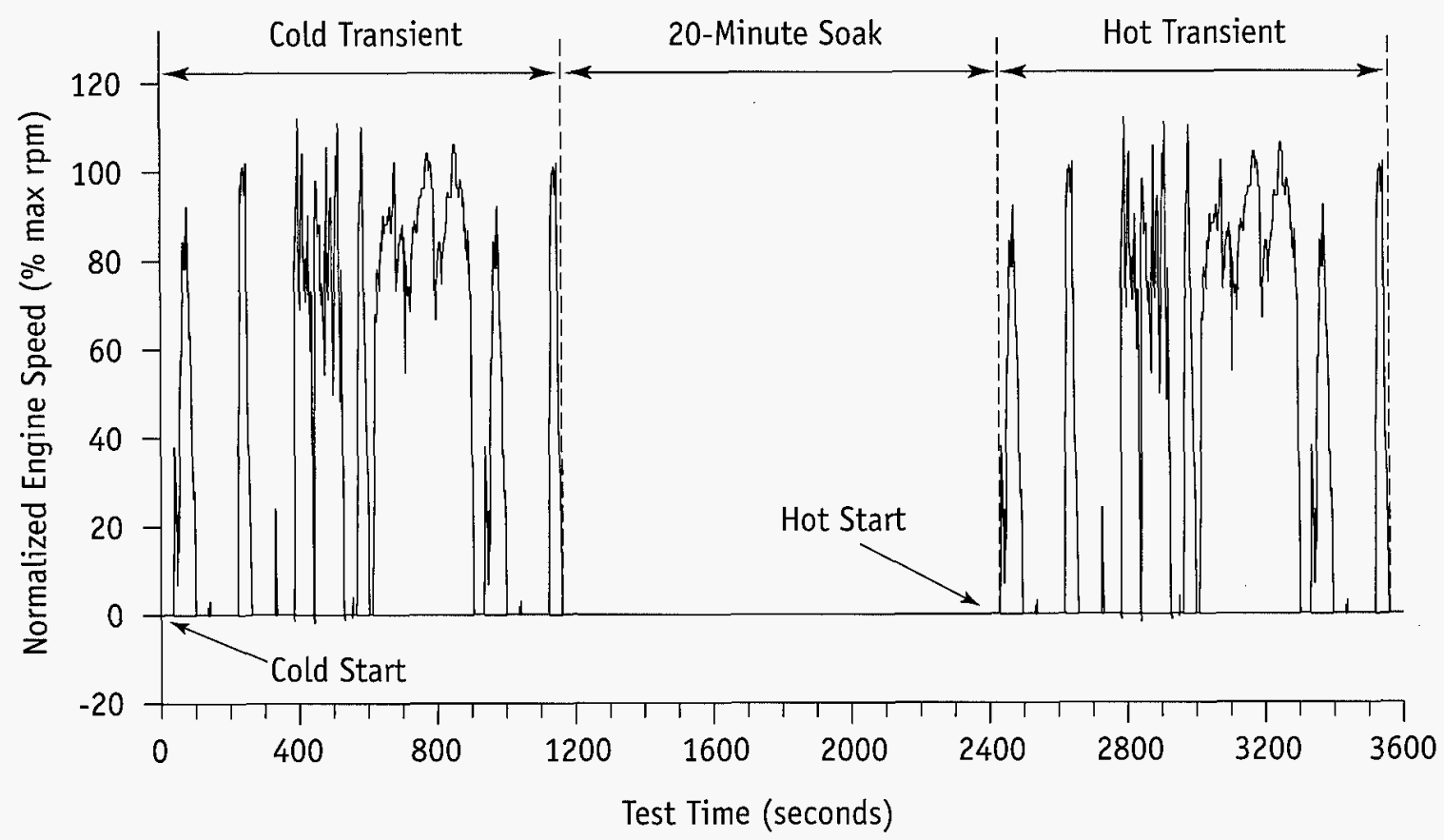

\section{Testing Facilities}

The EPA does not certify or approve emissions laboratories or test facilities, but it does maintain a list of organizations with which it has worked on emissionsrelated projects. Without making any endorsements or recommendations, the EPA makes this list of test facilities available on its site on the World Wide Web (see Appendix C). Because a number of new tests, such as the enhanced evaporative and the cold $\mathrm{CO}$ protocols, require extensive equipment and facilities, be sure to secure the services of a testing facility that maintains the appropriate equipment if such tests are required.

\section{Test Fuels}

The EPA provides specifications for the conventional fuels, as well as for CNG and LPG, to be used in emissions testing (see 40 CFR Part 86.113-94). Appendix E presents details on the specifications of the CNG to be used in exhaust and evaporative emissions testing. Because this is a special blend, allow adequate time in your testing schedule for the laboratory to obtain an ample supply. Commercialgrade fuel is suitable for in-service mileage accumulation. Commercial-grade LPG is acceptable for exhaust and evaporative testing, and for in-service mileage accumulation. The formulation of the CNG and LPG to be used in a testing protocol must be submitted as part of the certification application.

Table 8

Index for Locating Heavy-Duty Engine Test Procedures in Title 40, Part 86 of the Code of Federal Regulations (CFR)

\begin{tabular}{|l|c|}
\hline Test Procedure & Subpart \\
\hline Gaseous Exhaust & $\mathrm{N}$ \\
\hline Smoke Exhaust & $\mathrm{I}$ \\
\hline Evaporative & $\mathrm{M}$ \\
\hline Particulates & $\mathrm{N}$ \\
\hline Idle & $\mathrm{P}$ \\
\hline Altitude & $\mathrm{Q}$ \\
\hline
\end{tabular}




\section{Example of Applying Deterioration Factors}

Assume the manufacturer has decided to use EPA-assigned DFs for a dedicated light-duty LPG vehicle (Enclosure 5 of the EPA Manufacturer's Guidance Letter CD-95-14 provides the assigned DFs used in this example). The manufacturer completes the baseline testing at 2,000 miles and is given results for the various regulated exhaust emissions components. These results are then multiplied by the intermediate and full useful life DFs for each component. The calculated values are then compared to the intermediate and full useful life standards. If all the components are simultaneously below the values in the standard, the vehicle is in compliance. If any value exceeds its expected limit, the vehicle is not in compliance. See Appendix A for an explanation of all abbreviations.

\begin{tabular}{|c|c|c|c|c|c|c|}
\hline \multirow{2}{*}{ Mileage } & \multirow[b]{2}{*}{ Item } & \multicolumn{5}{|c|}{ Exhaust Emissions, in grams/mile } \\
\hline & & THC & NMHC & CO & $\mathrm{NO}_{\mathrm{x}}$ & PM \\
\hline 2,000 miles & Test Results & 0.15 & 0.12 & 1.8 & 0.19 & 0.01 \\
\hline \multirow[t]{3}{*}{50,000 miles } & Assigned DFs & 1.7 & 1.6 & 1.6 & 2.0 & 1.3 \\
\hline & Calculated Results & 0.26 & 0.19 & 2.9 & 0.38 & 0.01 \\
\hline & Tier 1 Standard & 0.41 & 0.25 & 3.4 & 0.4 & 0.08 \\
\hline \multirow[t]{3}{*}{100,000 miles } & Assigned DFs & $N / A^{a}$ & 1.9 & 1.9 & 2.3 & 1.3 \\
\hline & Calculated Results & $N / A^{a}$ & 0.23 & 3.4 & 0.44 & 0.01 \\
\hline & Tier 1 Standard & $N / A^{a}$ & 0.31 & 4.2 & 0.6 & 0.10 \\
\hline
\end{tabular}

${ }^{\mathrm{a}} \mathrm{N} / \mathrm{A}=$ "not applicable"

\section{Deterioration Factors}

Because the performance of emissions control systems is expected to decline (i.e., vehicle emissions will increase) with mileage or hours of service, compliance with the EPA emissions standards is based on applying DFs to the base emissions test results. DFs are used to predict this expected increase in vehicle emissions at the useful life mileage points. Refer to EPA Manufacturer's Guidance Letter CD95-14 and Advisory Circular A/C No. 51C for direction on whether the DF is multiplied or added to the baseline emission test results.
DFs are typically determined by the manufacturers through tightly controlled test procedures during which mileage or hours of service are accumulated and emissions tests are performed. For lightduty vehicles, the emissions standards are specified in terms of emissions limits to be met at the full or intermediate useful life. For instance, 1996 model year light-duty vehicles have one set of emissions standards to be met at the intermediate useful life (defined as five years or 50,000 miles) and another at the full useful life (ten years or 100,000 miles). The vehicle must comply with both sets of emissions standards. 
Compliance with heavy-duty engine standards is determined in much the same way. The base emissions measured on a new engine must be adjusted using the appropriate DFs before comparing the results to the emissions standards.

If the manufacturer qualifies for small volume manufacturer status (see the sidebar on page 11), some benefits can be realized from determining and assigning DFs for gaseous fueled vehicles and engines. The details are explained in 40 CFR 86.096.14 and Manufacturer's Guidance Letter CD-95-14. The available options are:

- Complete durability testing for the intermediate and full useful life of the vehicle

- An abbreviated durability test covering 25,000 miles, with more frequent emissions testing

- Using the EPA's assigned DFs or the DFs already established by the manufacturer from previous testing.

The EPA retains the right to rescind the use of its assigned DFs if subsequent testing indicates that emissions levels are higher than anticipated. Regardless of how the DFs are determined, they are subsequently applied to the baseline emissions test results of each vehicle to determine compliance with both its intermediate and full useful life emissions standards. The sidebar on page 20 gives an example of how DFs are applied to baseline emissions test results to determine compliance with the standards.

\section{Mileage Accumulation Cycle}

After converting the test vehicle to CNG or LPG, and before any emissions testing, each light-duty vehicle and truck must accumulate a minimum of 2,000 miles on its odometer. For heavy-duty engines, a minimum of 62 hours of operation must be accumulated. These vehicles or engines are known as emission data vehicles (EDVs) or engines.

For manufacturers of light-duty vehicles and trucks who choose to generate their own DFs by conducting durability testing, two methods may be applied to accumulate the required mileage.

The first method is specified in 40 CFR Part 86, Appendix IV ("Durability Driving Schedule"). Under this protocol, a vehicle is driven on a 3.7-mile course at various speeds (up to 70 miles per hour) for a specified period of time. The vehicles tested are referred to as durability data vehicles (DDVs). The second method, which requires prior approval from the EPA, is outlined in EPA Advisory Circular No. 37-A. Under this protocol, mileage can be accumulated on test tracks, dynamometers, or public roads as long as the mileage accumulation meets the criteria contained within No. 37-A. The maximum speed is 55 miles per hour over a 3.7-mile cycle.

\section{Maintenance Schedule during Testing and Data Collection}

EPA regulations specify the minimum maintenance interval for emissions control components. This schedule also applies to any maintenance performed during the mileage accumulation phase of durability testing. This information is contained in the EPA's information package and in 40 CFR 86.094-25. Maintenance may not be performed more frequently than specified in the regulations or the manufacturer's maintenance schedule. 


\section{Table 9}

\section{Required Number of Emissions Tests (FTP 75) for Dedicated Alternative Fuel Vehicles}

\begin{tabular}{|l|c|c|}
\hline $\begin{array}{l}\text { Option for Determining } \\
\text { Deterioration Factors (DFs) }\end{array}$ & $\begin{array}{c}\text { On the } \\
\text { Durability Data Vehicle }\end{array}$ & $\begin{array}{c}\text { On the } \\
\text { Emission Data Vehicle }\end{array}$ \\
\hline Full mileage accumulation & Minimum of 2 ${ }^{\text {a }}$ & 1 \\
\hline Abbreviated mileage accumulation & 5 required, 6 optional & 1 \\
\hline Manufacturer's own DF (previous history) & 0 & 1 \\
\hline EPA-assigned DF & 0 & 1 \\
\hline
\end{tabular}

a A minimum of two are required, but additional tests equally spaced in mileage are encouraged in order to confirm the DF. Six or seven tests would provide a more meaningful and reliable representation of this value.

\section{Required Number of Tests for Light-Duty Vehicles and Trucks}

The required number of emissions tests varies depending on which option is chosen to develop DFs. It is necessary to use only one DDV per engine family to establish the DFs and one EDV per engine family to measure emissions levels. The DFs are applied to the results of the EDV and are used to calculate the intermediate and full useful life values. Results of all tests must be supplied to the EPA. Table 9 outlines the required number of tests for various situations for dedicated CNG and LPG vehicles. For dual-fuel vehicles, the number of tests shown in Table 9 must be doubled. Because emissions test results are known to be variable depending on the vehicle being tested, it is wise to conduct more tests than the minimum number required to confirm the results.

\section{Carry-Across and Carry-Over}

"Carry-across" is the term used for applying emissions results generated for one engine family to another family from the same model year. Similarly, "carryover" is the term used for applying emissions results from an engine family in one year to an engine family in the succeeding model year. EPA Advisory Circular No. $17 \mathrm{~F}$ sheds more light on these concepts. The circular explains the EPA's position on the suitability of carrying results from test vehicles and durability data vehicles, as well as fuel economy, to other models in the same or later years. DFs are carried over more frequently than the baseline emissions test results.

\section{Corporate Average Fuel Economy (CAFE) Testing and the Gas Guzzler Tax}

Only new light-duty vehicles and trucks are subject to CAFE, fuel economy labeling, and the "gas guzzler" tax. Aftermarket conversions need not comply with these regulations.

\section{On-Board Diagnostics (OBD)}

The EPA has established regulations governing OBD systems for light-duty vehicles and trucks. These regulations require that certain components in the emissions control system be monitored for proper performance over the vehicle's lifetime. Typically, the vehicle's electronic control unit (ECU) is programmed to monitor the function of specific emissions control systems through signals it receives from various engine control sensors and actuators, such as the exhaust gas oxygen sensor. When unacceptable deterioration or malfunctions occur, a diagnostic trouble code is stored in the ECU, and a message light is illuminated on the vehicle's dashboard (for example, "Service Engine Soon" or "Check Engine"). These systems were 
originally designed by the vehicle manufacturers to detect and diagnose problems when electronic control systems replaced mechanical systems. The EPA now requires light-duty vehicles and trucks to be equipped with such systems in order to help reduce emissions caused by malfunctioning emissions controls.

The latest $\mathrm{OBD}$ requirements, known as federal OBD regulations, are virtually the same as California's OBD II regulations. All light-duty vehicles and trucks produced during and after the 1996 model year must meet these regulations. Federal OBD regulations require that virtually all the vehicle's emissions control system components be monitored, including catalyst efficiency, engine misfires, closed loop fuel system performance, oxygen sensor performance, and exhaust gas recirculation. Currently, CNG and LPG vehicles can receive justifiable waivers from the federal OBD requirements up to and including the 1998 model year. Even with this waiver, the OBD system must remain intact while the vehicle is operating on gasoline. Under an EPA notice of proposed rule-making published in May 1997, the EPA is proposing to extend the justifiable waivers. Here is an excerpt from the notice:

"EPA is proposing to extend the current flexibility provisions for alternative fuel vehicles through the 2004 model year. Such vehicles will be expected to comply fully with the OBD requirements during gasoline operation (if applicable), and during alternative fuel operation except where it is technologically infeasible to do so. Any manufacturer wishing to utilize this flexibility provision must demonstrate technological infeasibility concerns to EPA well in advance of certification application."

\section{Labels, Decals, and Maintenance Schedule}

After it has been converted, each vehicle or engine must display a supplemental emissions control label. This label must be placed adjacent to the original emissions control information label. The specific requirements governing the appearance and placement of the label are contained in 40 CFR Part 85.505. The new label must indicate that the vehicle has been converted to operate on an alternative fuel; it must specify the equipment manufacturer's and the installer's names, addresses, and telephone numbers; and it must present all conversion-related details, such as the model year, date of conversion, mileage at conversion, and changes made to the vehicle (for example, tuneup specifications).

Additional labeling requirements for CFF vehicles are found in 40 CFR Part 88 . Part 88 requires that the label in Part 86 also stipulate whether the vehicle or engine in question is LEV- or ULEV-compliant and meets all the requirements of Part 88.

Heavy-duty vehicles, as defined in Part 88 , are also required to display a label (see 40 CFR 88.305-94) if they are not covered by the requirements specified in Part 86.

Providing that certain criteria are met, vehicles that are ILEV-compliant may be able to take advantage of transportation control measure exemptions such as using high-occupancy vehicle (HOV) lanes. An example of such criteria is the requirement to mount special decals on the exterior of the vehicle.

Samples of these labels and decals must be submitted to the EPA before a Certificate of Conformity can be issued.

In addition to providing vehicle labels and decals, manufacturers are to provide vehicle owners with the maintenance schedule for emissions-related items (see 40 CFR Part 86.094-25(b)(1)). 


\section{Record Keeping}

Manufacturers are required to keep detailed certification information for a period of eight years from the date on which the Certificate of Conformity is issued. Manufacturers must also keep detailed records of the number of such vehicles that are converted (i.e., the number of conversion kits that are sold), but the eight-year period starts at the end of the model year. The EPA's requirements for record retention are outlined in 40 CFR Parts 86.094-7 and 86.096-7. All such information must be made available to the EPA on request.

Manufacturers are further responsible for maintaining conversion records on vehicles converted under the CFF Program (see 40 CFR Part 88.306-94 (f)). These records, which must include the following information, must be kept for a period of five years from the date of conversion.

- Engine or vehicle make, model, model year, and vehicle identification number (VIN)

- Certification number of the conversion configuration

- Brand name and numbers of parts used in the conversion

- Date of the conversion

- Facility where the conversion equipment was installed

- Results of post-conversion emissions testing.

\section{Warranty}

The EPA's regulations require that manufacturers provide both an emissions design and defect warranty and an emissions performance warranty for light-duty vehicles and trucks. Effective with the 1995 model year, the warranty period is two years or 24,000 miles, whichever comes first. For EPA-specified major emissions control components such as the catalytic converter, the electronic emissions control unit, and an on-board emissions diagnostic device, the warranty period is eight years or 80,000 miles, whichever comes first.

For heavy-duty Otto-Cycle engines and light heavy-duty diesel engines, manufacturers must provide a design and defect warranty of five years or 50,000 miles, whichever comes first; for medium- and heavy heavy-duty diesel engines, five years or 100,000 miles, whichever comes first. If the manufacturer provides a longer period on the basic mechanical warranty to the engine family, this period must also extend to the emissions warranty.

The warranty must cover the labor to diagnose and repair or replace the part as well as the cost of any replacement parts. The certification application for light-duty vehicles and trucks must contain the provisions of the warranty policy to be offered.

It is also important to note that the OEM continues to be responsible for those parts of the vehicle that retain their original function after conversion. In addition, the warranty period of an aftermarket conversion does not need to extend past that of the original vehicle or engine. For example, if a heavy-duty Otto-Cycle engine has 5,000 miles on its odometer at the time of conversion, its design and defect warranty period will end once its odometer reaches 50,000 miles (not 55,000 miles). 


\section{Audit and In-Use Surveillance}

To ensure that conversion equipment is designed, built, and installed so as to allow vehicles to meet emissions standards throughout their useful lives, the EPA has established a number of compliance programs that it enforces as part of its emissions regulations. For example, during the certification process, the EPA may evaluate the emissions control design of all conversion equipment. It also conducts selective enforcement audits of product assembly lines and equipment installers, and it evaluates vehicles during in-use operations. Vehicles and engines can be recalled if the EPA determines that they are not meeting the useful life standards to which they have been certified.

\section{Responsibilities of Distributors and Installers}

The manufacturer of record on the Certificate of Conformity is responsible for ensuring that all vehicles being converted comply with the terms of the certificate. The manufacturer's interests will be best served by providing the installer with a detailed parts list, complete installation instructions, all examples of proposed labels and decals, vehicle maintenance schedules, post-conversion inspection and testing requirements/ methods, information on record-keeping plans, and training for proper equipment installation.

Establishing a quality control program for the entire vehicle conversion process is also advisable. The installer must ensure that the vehicle being converted is of the same engine family as that for which the Certificate of Conformity has been granted. The installer must follow installation instructions exactly with no component substitutions.
Failure to install the conversion system on the correct engine family, installing the wrong parts, or improperly installing the correct parts may subject the manufacturer and/or the installer to a civil penalty of up to $\$ 25,000$ per vehicle or engine.

Certification under the CFF Program requires that the manufacturer provide installation instructions to the installer(s) (see 40 CFR Part 88.306-94). The manufacturer must also provide the name of the installer(s) to the EPA as part of the certification application. Only those installers listed on the application may perform conversions.

Vehicles and engines that are part of the CFF Program and are converted under the auspices of small volume manufacturer status must pass a post-conversion $\mathrm{CO}$ emissions test (see 40 CFR Part 88.306-94). There are two options for conducting the test: (1) for light-duty vehicles and trucks, follow the inspection and maintenance requirements and procedures applicable to the geographic area in which the vehicle will be operated; and (2) conduct a specific two-speed idle test, which must be conducted using certification fuel. Both methods require that dual-fuel vehicles be tested on each fuel.

Under certain conditions, fleet operators who are converting to an ILEV-compliant vehicle may be able to take advantage of transportation control measure exemptions such as using HOV lanes. First, fleets must verify that they are eligible for exemption from transportation control measures. If the fleet qualifies and wants to take advantage of the HOV lanes, the installer must also place three ILEV decals on the exterior of the vehicle to clearly signify ILEV status. Engines used in heavyduty vehicles weighing more than 26,000 pounds may not qualify for this exemption. 


\section{Liabilities}

Liabilities are incurred when all provisions of the CAA are not met. Section 205 (a) (see below) stipulates that penalties will be imposed on companies and individuals that do not comply with its provisions.

(a) Violations - any person who violates sections 203 (a) (1), 203 (a) (4), or 203 (a) (5) or any manufacturer or dealer who violates section 203 (a) (3) (A) shall be subject to a civil penalty of not more than $\$ 25,000$. Any person other than a manufacturer or dealer who violates section 203 (a) (3) (B) shall be subject to a civil penalty of not more than $\$ 2,500$. Any such violation with respect to paragraph (1), (3) (A), or (4) of section 203 (a) shall constitute a separate offense with respect to each motor vehicle or motor vehicle engine. Any such violation with respect to section 203 (a) (3) (B) shall constitute a separate offense with respect to each part or component. Any person who violates section 203 (a) (2) shall be subject to a civil penalty of not more than $\$ 25,000$ per day of violation. installation, the brand name(s) and part numbers of all equipment installed, and the calibration settings is also advisable.

Distributors should follow a similar process. If they did not perform the emissions testing, they should request and retain representation that the conversion system meets the addendum's requirements for the given engine family. They should also keep information on each conversion kit sold, the name of the purchaser, all part numbers, the date of sale, and the number of systems sold.

\section{Clean-Fuel Vehicles and Mobile Emissions Reduction Credits}

Under the provisions of the CAA, mobile emissions reduction credits may be granted for fuels and vehicles that meet the CFF Program requirements (see 40 CFR Part 88). To receive mobile emission reduction credits, the fleet must first exceed the minimum requirements of the CFF Program. This program applies to light-duty vehicles and trucks, heavy light-duty trucks, and heavy-duty engines that are certified to the LEV, ILEV, and ULEV standards. The original implementation date was model year 1998, but it has been recently postponed to model year 1999, although cities may opt in earlier.

Those cities that are in non-attainment with federal air quality standards, as outlined in the CAA, are elgible for the federal emissions reduction credits program. Fleets operating within these cities are required to purchase $C F V s$ as stipulated in 40 CFR Part 88 . Such vehicles must be certified to CFV emissions standards using the procedures outlined in 40 CFR Parts 86 and 88 .

In addition to qualifying for credits, CFVs are also exempt from a number of transportation control measures (see 40 CFR Part 88.307-94) in non-attainment areas. For example, vehicles that are ILEVcompliant may qualify to use HOV lanes. 


\section{California}

\section{Certification by the California Air Resources Board}

\section{General Information}

In California, CARB is responsible for the emissions certification on all motor vehicles. The California Health and Safety Code authorizes CARB to establish emissions certification procedures and to certify fuel systems that have met its requirements. Further, the California Vehicle Code prohibits the installation, sale, offering for sale, or advertisement of any motor vehicle pollution control device or system that alters or modifies the original design or emissions performance without CARB's approval.
California's certification process for aftermarket conversions is similar to the EPA's, but there are some significant differences. In some ways, it is more stringent than the EPA's; in other ways, it is not. Some of the major differences are:

- CARB certification applies to the model year in which the vehicle was originally produced, instead of the year or model year in which the vehicle is converted

- CARB does not impose a time limit on the terms of the certification

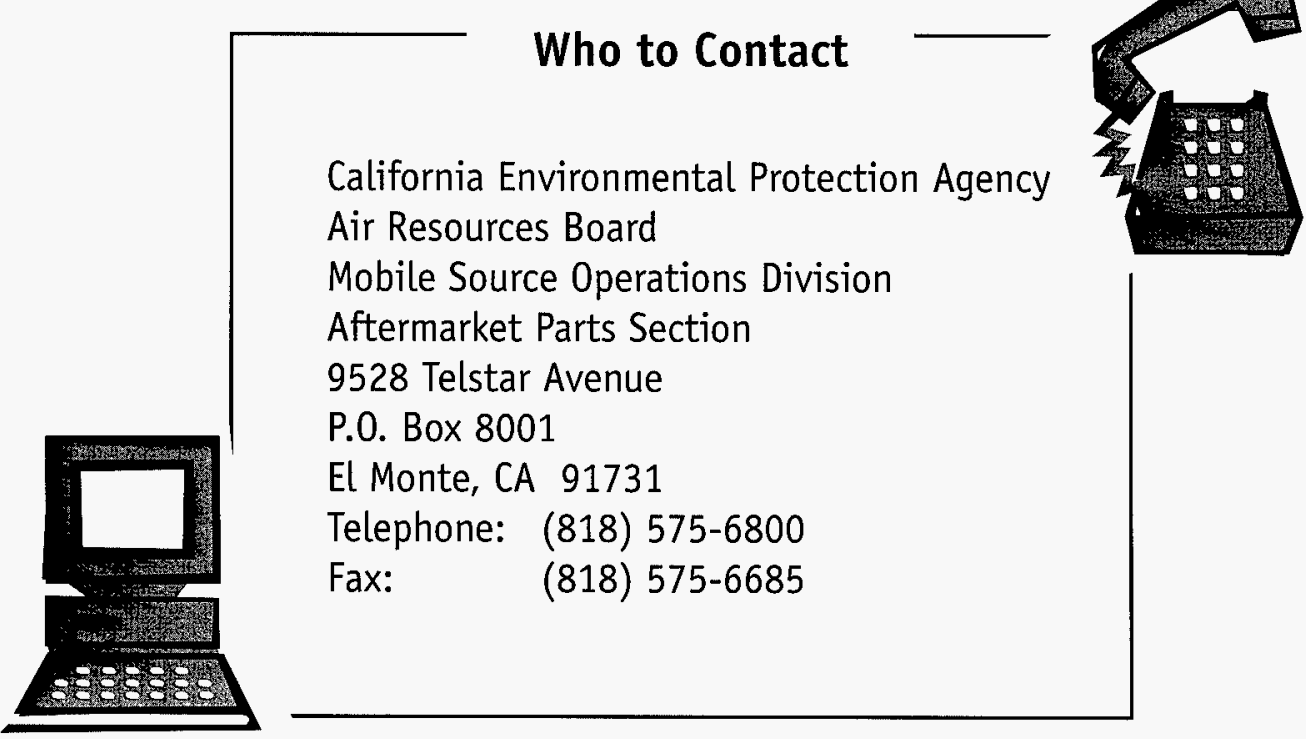


Table 10

\section{California Certification Procedures for Aftermarket Conversions}

Model Year of Vehicle or Engine

All Model Years

\section{Title of Certification Procedure}

California Certification and Installation Procedure for Alternative Fuel Retrofit Systems for Motor Vehicles Certified for 1994 and Subsequent Model Years and for All Model Year Motor Vehicle Retrofit Systems Certified for Emission Reduction Credit
- Medium- and heavy-duty vehicles can be certified in California using emissions test results obtained on a chassis dynamometer (instead of an engine dynamometer)

- CARB's requirements for durability testing are considerably different than the EPA's.

\section{Regulations}

The procedures for certifying CNG or LPG aftermarket vehicle conversions in California are contained in California Code of Regulations, Title 13, Section 2030. Various procedures have been in effect since 1975. See Table 10 for the title of the current certification procedure.

Prior to the release on September 4, 1997, of the EPA addendum to Memorandum $1 \mathrm{~A}$ (see page 7 ), California used the procedure entitled "California Exhaust Emission Standards and Test Procedures for Systems Designed to Convert Motor Vehicles Certified for 1993 and Earlier Model Years to Use Liquefied Petroleum Gas or Natural Gas Fuels" for 1993 and older vehicles. However, the EPA no longer accepts that procedure as a reasonable basis to believe that emissions performance has not been adversely affected.

\section{What Does Certification Apply To?}

The certification procedure identified in Table 10 applies to vehicles that have already been registered with the California Department of Motor Vehicles. Other procedures must be followed for new vehicles that have not yet been registered.
The procedure applies to dedicated, dual-fuel, and bi-fuel aftermarket conversions for light-duty vehicles and trucks, medium-duty vehicles, and heavy-duty engines/vehicles. CARB's definition of dual-fuel is the same as the EPA's (see page 2 or the glossary). CARB defines "bifuel" as any vehicle or engine with two separate fuel systems. Bi-fuel vehicles or engines can run on either the conventional fuel or on the conventional fuel and the alternative fuel simultaneously. An example of this type of vehicle/engine is a heavy-duty engine converted to run on diesel and CNG (or LPG) with a pilotignition system. In pilot-ignition systems, a small amount of diesel fuel starts and maintains combustion and CNG is added once power is required.

An alternative test method is available for certifying medium- and heavy-duty engines in vehicles without removing the engine from the vehicle (see the section on emissions testing on page 31 ). If the alternative method is used, the vehicle does not qualify for mobile source emission reduction credits (MSERCs; see page 35 for a discussion).

Each certification applies to a specific engine family, and the manufacturer may only convert vehicles from the engine family specified (see the sidebar on page 9 for an explanation of engine families). CARB uses the engine family names defined by the EPA, but does not change the engine family name after the vehicle has been converted. 
At the end of a successful certification process, CARB will issue an Executive Order (EO) that authorizes the applicant to proceed with vehicle conversions. The EO permits the manufacturer and installers to convert vehicles of the engine family specified in the EO. The EO does not include a date restriction beyond which vehicles can no longer be converted-it remains in effect for as long as the applicant wishes to convert vehicles of the particular model year in question.

\section{Introduction to the Certification Process}

The flow chart in Figure 4 illustrates the steps necessary to obtain emissions certification in California, using full durability testing. All steps must be completed before an EO can be issued. Alternative methods can be used for durability testing to determine DFs (see Appendices F through I for illustrations). DFs are explained on page 20 of this guide.

California's certification process includes the development and acceptance of both a certification plan and an application. CARB generally requires one to two weeks to review and approve the certification plan. Approving the certification application and issuing the EO takes about two months. If the manufacturer fails to supply all the required information, more time may be needed.

\section{Certification Plan, Application, and Fees}

As the first step in the certification process, the manufacturer must develop a certification plan for all the engine families that it intends to certify during the year. The plan must include the emissions standards applicable to each engine family, as well as information about the development of durability data, the format to be followed during durability testing, and the name of the laboratory that will conduct the emissions testing. The manufacturer should provide all relevant details on the conversion equipment, including the operating characteristics, a parts list, and installation instructions or manual. The plan should be as comprehensive as possible. Before any testing can begin, the plan must be submitted to CARB for review and approval.

Once CARB approves the certification plan, testing may begin. The testing must be accomplished according to the procedures that CARB approved in the certification plan. When testing is complete, the manufacturer may submit an application for certification, submitting a separate application for each engine family. Although CARB does not have a set format for the certification application, it does have a list of items that must be included. For more information, contact CARB at the address given on page 27 .

California does not charge a fee for certifying aftermarket vehicle conversions.

\section{Emissions Standards}

The emissions standards that apply to the certification of aftermarket conversions in California are those that were in effect for the model year of the vehicle being certified. For example, if a manufacturer wishes to certify a 1996 model year vehicle from a particular engine family, the applicable emissions standards are those that were in effect for the 1996 model year. There are some exceptions for medium- and heavy-duty vehicles. Refer to Section 5 of "California Certification and Installation Procedures for Alternative Fuel Retrofit Systems for Motor Vehicles Certified for 1994 and Subsequent Model Years and for All Model Year Motor Vehicle Retrofit Systems Certified for Emission Reduction Credit." 


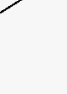

Certification plan (EF line-up)

No

unscheduled maintenance

EF from line-up?

Delete

CARB

approval of

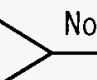

Conduct 4,000 mile testing and accumulate miles

Complete durability demonstration

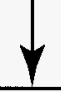

Validate $\mathrm{OBD}$ compliance

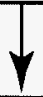

Figure 4:

Submit engineering report and perform unscheduled maintenance

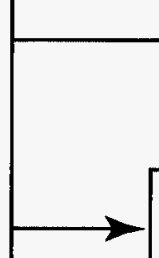

it application (emissions data

warranty, label, instructions, etc. ..)

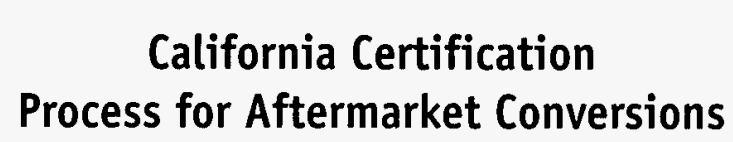

Manufacturer

Action

CARB

Action

(BAR

Action

\section{Abbreviations}

CARB - California Air Resources Board

BAR - Bureau of Automotive Repair

EF - Engine Family

E0 - Executive Order

OBD - On-Board Diagnostics

\section{Issue Executive Order}

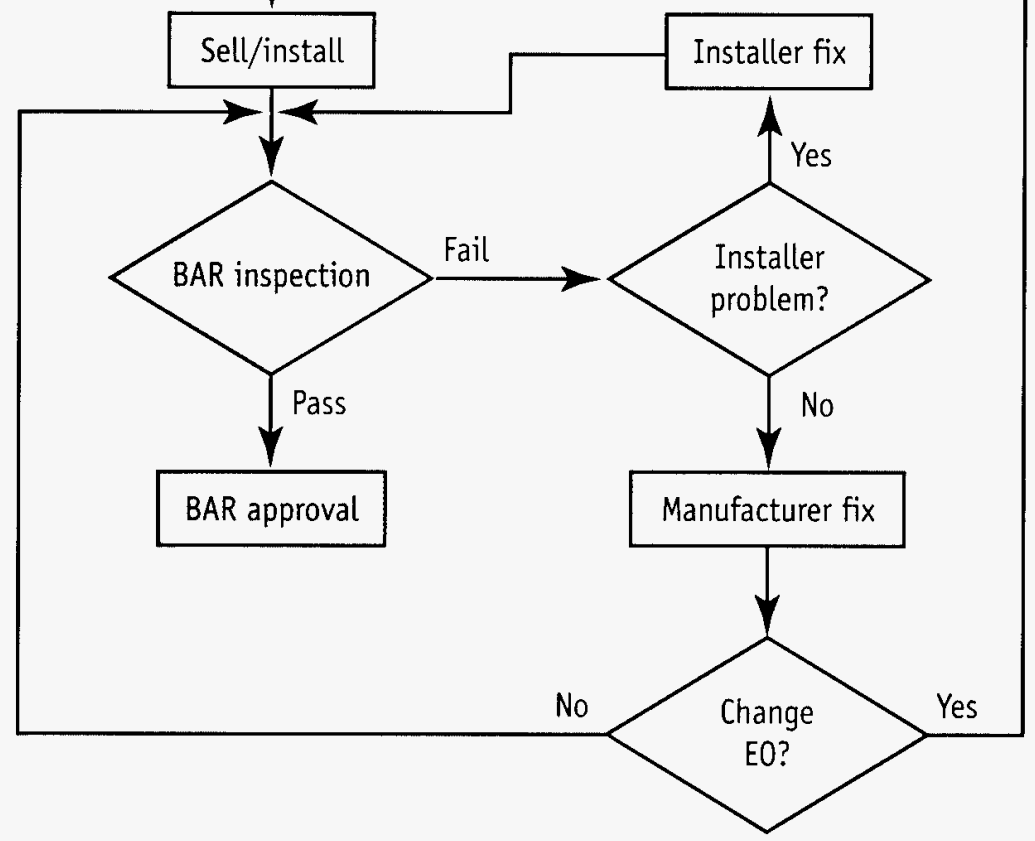


Table 11

\section{Index to California Exhaust, Evaporative, and Refueling Emissions Standards}

\begin{tabular}{|c|c|c|}
\hline Emissions Type & Vehicle Type & Name \\
\hline Exhaust & $\begin{array}{l}\text { Passenger Car, } \\
\text { Light-Duty Truck, } \\
\text { Medium-Duty Vehicle }\end{array}$ & $\begin{array}{l}\text { California Exhaust Emission Standards and } \\
\text { Test Procedures for } 1988 \text { and Subsequent Model } \\
\text { Passenger Cars, Light-Duty Trucks, and } \\
\text { Medium-Duty Vehicles }\end{array}$ \\
\hline Exhaust & $\begin{array}{l}\text { Heavy-Duty Engine, } \\
\text { Heavy-Duty Vehicle (Otto-Cycle) }\end{array}$ & $\begin{array}{l}\text { California Exhaust Emission Standards and } \\
\text { Test Procedures for } 1987 \text { and Subsequent Model } \\
\text { Heavy-Duty Otto-Cycle Engines and Vehicles }\end{array}$ \\
\hline Exhaust & $\begin{array}{l}\text { Heavy-Duty Engine, } \\
\text { Heavy-Duty Vehicle (Diesel-Cycle) }\end{array}$ & $\begin{array}{l}\text { California Exhaust Emission Standards and } \\
\text { Test Procedures for } 1985 \text { and Subsequent Model } \\
\text { Heavy-Duty Diesel-Engines and Vehicles }\end{array}$ \\
\hline Evaporative & $\begin{array}{l}\text { Passenger Car, Light-Duty Truck, } \\
\text { Medium-Duty Vehicle, } \\
\text { Heavy-Duty Vehicle }\end{array}$ & $\begin{array}{l}\text { California Evaporative Emission Standards and } \\
\text { Test Procedures for } 1978 \text { and Subsequent Model } \\
\text { Motor Vehicles }\end{array}$ \\
\hline Refueling & $\begin{array}{l}\text { Passenger Car, Light-Duty Truck, } \\
\text { Medium-Duty Vehicle with GVWR } \\
\text { less than or equal to } 8,500 \mathrm{lb}\end{array}$ & $\begin{array}{l}\text { California Refueling Emission Standards and } \\
\text { Test Procedures for } 1998 \text { and Subsequent Model } \\
\text { Motor Vehicles }\end{array}$ \\
\hline
\end{tabular}

Table 11 identifies the different California standards that apply to exhaust, evaporative, and refueling emissions. A conversion kit can only be certified to the same or more stringent standard as the one to which the vehicle/engine was originally certified. For instance, if the vehicle was originally certified to LEV emissions standards, the conversion can be certified to LEV or the more stringent ULEV standards, but not to the less stringent TLEV standards. Measured emissions must remain within the applicable standards for the useful life of the vehicle (see Appendix A for a definition of useful life). In the case of dual-fuel vehicles, both fuels must meet the standards. For "credit-generating vehicles" (vehicles that earn MSERCs; see the discussion on page 35 ), the certification standards applicable to both fuels under dual-fuel operation must not be more than one tier (see the sidebar on page 17) apart. Examples of standards that are one tier apart are TLEV for gasoline and LEV for propane, or LEV on gasoline and ULEV on CNG. See Appendix D for a summary of exhaust emissions standards.

\section{Emissions Testing}

For aftermarket conversions, vehicles are divided into the following three categories to determine the emissions testing method:

Category I - light-duty passenger cars, trucks, and medium-duty vehicles originally certified on a chassis dynamometer

Category II - vehicles weighing 14,000 pounds GVWR or less that were not originally certified on a chassis dynamometer

Category III - vehicles weighing more than 14,000 pounds GVWR.

The documents referenced in Tables 10 and 11 contain the processes for conducting the emissions testing. Passenger cars and light-duty trucks are tested using the
${ }^{a}$ Gross Vehicle Weight Rating 
${ }^{a}$ Mobile Source

Emission Reduction Credits

${ }^{b}$ Will not generate

Mobile Source

Emission Reduction

Credits

Table 12

\section{Test Procedures Required in California for Vehicle Categories}

\begin{tabular}{|c|c|c|}
\hline Vehicle Category & $\begin{array}{c}\text { Test Procedure Required } \\
\text { to Generate MSERCs }\end{array}$ & $\begin{array}{c}\text { Other Acceptable } \\
\text { Test Procedures }^{\mathbf{b}}\end{array}$ \\
\hline I & FTP 75 & none \\
\hline II & Heavy-Duty Transient & FTP Chassis Dynamometer Cycle \\
\hline III & Heavy-Duty Transient & Chassis Dynamometer Cycle \\
\hline
\end{tabular}

FTP 75 driving schedule (see Figure 2 on page 18). This same procedure can be used for vehicles in Category II and a suitable chassis dynamometer test for Category III, but they would not qualify for MSERCs. To qualify for MSERCs, Category II and III vehicles must be tested using heavy-duty transient procedures on an engine dynamometer. Table 12 summarizes the testing procedures that can be used for each vehicle category.

Like the EPA, CARB does not approve or recommend testing laboratories or facilities, although it does maintain a list of laboratories with which it has worked. If your company plans to use a facility that is not on CARB's list, provide detailed information about that laboratory and its qualifications as part of the certification plan. A number of new tests, such as enhanced evaporative testing and the cold CO procedure, require specialized equipment and facilities.

Following the installation of conversion systems, vehicles must be driven 4,000 \pm 100 miles to stabilize emission rates before exhaust and evaporative emissions testing can be conducted.

CARB requires that certification-grade fuel be used for emissions testing of CNG and LPG conversions. Commercial-grade fuel is acceptable for use during mileage accumulation for durability testing. Certification and commercial grades of fuel are compared in Appendix E.
Dedicated CNG vehicles are exempt from evaporative emissions testing. Dualfuel CNG vehicles, on the other hand, must comply with the applicable evaporative emissions standard when operating on gasoline. LPG vehicles must undergo evaporative emissions testing. The applicable standards and procedures are provided in "California Evaporative Emission Standards and Test Procedures for 1978 and Subsequent Model Motor Vehicles." If the vehicle is dual-fuel, both fuels must be tested. In lieu of actual testing, manufacturers may provide an engineering analysis of the impact of their systems on evaporative emissions. This analysis must demonstrate that the aftermarket fuel system or any other modification to the vehicle does not result in moving, removing, or recalibrating the OEM's gasoline evaporative control system.

If the vehicle and its engine family were originally certified to the new California enhanced evaporative emissions standards, the converted vehicle must also comply with these standards. These new standards are more involved than the previous evaporative standards and require both a three-day and a twoday diurnal test plus a running loss test.

One test vehicle is required for each engine family to be certified. If the CARBapproved certification plan permits the use of derived DFs, only one test is required per vehicle per fuel after accumulating 4,000 miles following conversion. This emissions test establishes a baseline on which to apply the DFs. The test vehicle is known as the EDV. 
If the CARB-approved certification plan requires the manufacturer to establish DFs, durability testing will be required. Durability data must be obtained on only one vehicle from each engine family to be certified. This vehicle is referred to as the DDV. Provisions that allow "carry-across" (see page 22) of previously established DFs are explained in the next section. The minimum number of tests to be conducted on the DDV depends on whether or not it must comply with intermediate useful life standards (see Appendix A for a definition of useful life). If the vehicle must comply with intermediate useful life standards, it must be tested three times per fuel-once at its baseline mileage level $(4,000$ miles after conversion), once after it accumulates its intermediate useful life mileage, and once after it accumulates its full useful life mileage. If the vehicle is not required to comply with intermediate useful life standards, only two tests are requiredone at the baseline mileage and one at the full useful life mileage.

Many manufacturers conduct more frequent tests on their DDVs to discover whether they have any early emissions problems, and to ensure more reliable trends with which to establish DFs. Under some of the certification procedures, the test vehicle and the DDV can be one and the same (see the discussion below about durability testing).

\section{Options for Durability Testing, and Carry-Across and Carry-Over} Provisions

Several alternative procedures for demonstrating the full useful life durability of emissions for each engine family are available. For example, under certain circumstances, it may be possible to apply a gasoline DF to the alternative fuel emissions results (gasoline DFs for various OEM vehicles are available from CARB). The process is outlined in CARB's Manufacturers Advisory Correspondence \#95-05. The flow chart in Appendix F illustrates the complete certification process when it entails a request for, and use of, gasoline DFs.

Remember that with this substitute procedure, a full in-use durability test on the alternative fuel is still required. First, the manufacturer must test and record data for emissions, catalytic converter temperatures, and air/fuel ratio calibrations on gasoline and the alternative fuel at 4,000 miles. Next, the same tests must be repeated for the alternative fuel at the intermediate and full useful life mileages. After the manufacturer has completed the testing, CARB will evaluate the alternative fuel calibration control capability and the thermal degradation of the catalyst, and make the appropriate comparisons. If the same conversion equipment is to be used on a wide array of vehicles, the durability test should be conducted using a "worst-case" vehicle. Usually, this vehicle will have the most advanced fuel metering technology, and will be certified to the most stringent emissions standard.

CARB's Manufacturers Advisory Correspondence \#95-05 outlines another method to demonstrate useful life durability. This particular method uses carryacross provisions. It also requires a full in-use demonstration of durability. Appendix G contains a flow chart illustrating the steps necessary under this procedure.

CARB has also implemented a program that allows manufacturers to apply derived DFs to the emissions test results from passenger cars, light-duty trucks, and medium-duty vehicles. These DFs must be confirmed through durability testing, but the testing can be accomplished over a two-year period. Under this scenario, an EO would be issued based on the use of derived DFs, with subsequent review after full durability testing is complete. With this approach, manufacturers may convert vehicles before the full durability testing is completed. Manufacturers 
assume liability for a recall if the durability data do not confirm the derived DFs. The process is outlined in CARB's Manufacturers Advisory Correspondence \#9510 , and the necessary steps are illustrated in Appendix $\mathrm{H}$ of this guide.

A similar program is available for heavy-duty engines using derived DFs. The program is outlined in CARB's Manufacturers Advisory Correspondence \#9507, and Appendix I illustrates the necessary steps.

\section{On-Board Diagnostics (OBD) Requirements}

An introduction to OBD is provided on page 22. California adopted its OBD II regulations in 1989, and implementation began in 1994. According to these regulations, aftermarket conversion of vehicles must not result in the disabling of the OBD systems-these systems must remain fully functional. Applications for waivers of this requirement for CNG and LPG vehicles may be approved if the manufacturer can provide a significant engineering analysis to justify foregoing the specific monitoring requirements. Currently, applications for waivers will be available for conversion of vehicles through the end of model year 2004. CNG and LPG vehicles must still comply with the less stringent $\mathrm{OBD}$ I regulations.

\section{General Emissions Warranty Coverage}

California's procedure for aftermarket conversions requires both the manufacturer and the installer to provide a warranty on emissions-related components. The warranty must cover all parts and labor, including those associated with problem diagnosis. Two levels of warranty coverage must be offered: (1) three years or 50,000 miles, whichever comes first, for all components; and (2) seven years or
70,000 miles, whichever comes first, for high-priced components. The value of high-priced components includes the price of the component and the labor for diagnosis and repair. CARB establishes a value of the high-priced components annually and disseminates this information through a Manufacturers Advisory Correspondence. For the 1998 model year, the value for high-priced components is $\$ 400$. The warranty periods begin on the date of conversion, and the vehicle mileage at that time is considered to be zero.

\section{Owner's Manual, Maintenance Schedule, and Vehicle Labels}

The manufacturer or installer must provide the customer with an owner's manual that includes details about the conversion system, refueling procedures, maintenance, warranty, and servicing locations.

CARB requires that a label providing certain information to the consumer be affixed under the hood of each converted vehicle. This label must be situated beside or close to the OEM emissions control label, and it must include information about the manufacturer and installer of the conversion equipment, emissions certification information, details of the installation procedure, alterations made to the original vehicle, and a vacuum hose routing diagram.

\section{Record Keeping}

Installers are required to retain certain information, listed below, in their files about each converted vehicle:

- Vehicle identification number (VIN)

- California license plate number

- Vehicle owner, address, and phone number

- Installation date

- EO number. 
Installers must also supply the same information to the manufacturer, who in turn is required by regulation to retain it. All information must be kept for six years after the date of conversion.

\section{Audit, In-Use Surveillance, and Liabilities}

In addition to other kinds of testing, CARB may require manufacturers to conduct in-use enforcement emissions testing. The enforcement testing may be the result of a number of different circumstances, including poor emissions performance reported by $\mathrm{CARB}^{\prime}$ s field organization. If required, such testing must be conducted on a minimum of ten vehicles per certified kit/engine family. If the results are unsatisfactory, CARB may request that the manufacturer initiate a recall. Section 8 ("InUse Enforcement Test Requirements") of the certification procedure contains additional details.

\section{Responsibilities of the Installer}

The installer must provide a warranty statement, preapproved by CARB, to the owner of each converted vehicle. The purpose of the warranty is to guarantee that the conversion system has been installed according to the manufacturer's installation instructions or manual and its EO. The minimum coverage period is for three years or 50,000 miles, whichever comes first, and it applies to both parts and labor.

Installers are required to fill out a portion of the under-hood emissions control label prior to its application. They are also required to retain certain conversionrelated information (see the discussion of record keeping on page 34 of this guide).
After each conversion is completed, the installer must transport the vehicle to a Bureau of Automotive Repair (BAR) Referee Smog Check Station for inspection and testing. It may be helpful to bring a copy of the EO to BAR for reference. CARB has an alternative inspection procedure to permit one out of ten vehicles to be inspected at the BAR station. The installer must obtain prior approval from CARB to use this alternative. If the vehicle passes the BAR inspection, it is issued a decal (different from the under-hood label), which is generally installed on the door jamb.

\section{Penalties and Liabilities}

Manufacturers that do not comply with either the California Health and Safety Code or the California Vehicle Code are subject to fines and vehicle recalls. Although manufacturers that have received EOs are exempt from the tampering provisions of the California Vehicle Code, they are still subject to recalls if vehicles fail subsequent emissions tests.

\section{Mobile Source Emission Reduction Credits}

A number of California's air quality districts have instituted programs for MSERCs. These credits apply to any vehicle or engine that is converted to meet a more stringent emissions standard (for example TLEV to LEV) than the one to which the vehicle was originally certified. 
California 


\section{r

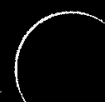 \\ Q \\ Frequently Asked Questions}

Here are answers to some commonly asked questions about emissions certification of aftermarket conversions.

\section{Why are the costs of emissions certification so high?}

EPA

Three components contribute to certification costs-fees, emission testing, and the labor associated with organizing and processing the certification. The EPA does charge fees to provide the certification service. Recognizing that the aftermarket vehicle conversion industry is still in its infancy, the EPA is currently looking at methods to reduce or eliminate fees for certifying to certain emissions standards. The EPA also provides an alternative method for determining fees. In regard to emissions testing, the EPA has attempted to reduce costs for small volume manufacturers by providing alternative methods to derive DFs (for example, using EPAassigned DFs or using assigned DFs from an abbreviated durability test). You can minimize the time required for organizing and processing of the certification by having a well-conceived plan and following the EPA's directions for the information required on the application (see page 12).

\section{California}

In California, two components contribute to the certification costs-emissions testing and the labor associated with organizing and processing the certification. California does not charge any fees for the certification service. Recognizing that the durability portion of emissions testing poses a hardship on manufacturers, CARB has developed alternative procedures for deriving DFs. CARB also stresses the need to have a well-conceived plan and to follow its directions for the certification application.

\section{Is the tank considered a part of the kit or aftermarket system for certification purposes?}

\section{$E P A$}

By definition, the tank is an emissions control component. You should list it as a system component, and describe it in the application. Holders of Certificates of Conformity must submit requests to the EPA for approval to change the size, model, or number of tanks installed. For metal tanks, this is normally considered a formality. However, if it is possible for fuel to permeate through the tank walls or fittings, the EPA is likely to conduct a formal evaluation before granting any approval for changes.

\section{California}

You are not required to list the tank as a system component. However, you must list all hoses, because they are possible sources of leaks that could affect evaporative emissions. 


\section{Questions}

\section{How long can vehicles be converted using the the EPA and California aftermarket certifications?}

$E P A$

The EPA Certificate of Conformity has a finite life. Conversions can start on the effective date of the certificate but must end no later than December 31 of the model year for which it is granted. The maximum period possible for conversions is one year and 364 days on that certificate (if the effective date was January 2 of the year prior to the model year). To convert that same engine/vehicle past the December 31 date, you would have to apply for a new certificate based on the standards and regulations that apply for the next model year (see page 9).

\section{California}

You may start conversions on the approval date of the EO. The EO does not list an end date and you can convert vehicles for however long engine families/vehicles are available to convert using that same EO.

\section{Does the engine family name change as a result of aftermarket certification?}

\section{$E P A$}

Yes, the engine family name changes to reflect the model year for which the certification is being granted (if different from that of the original engine family) and the name of the company that has received the certification. Also, three characters are reserved for your company's use (see page 9).

\section{California}

No, the engine family name stays the same.

\section{Do CNG and LPG aftermarket conversions need to meet the same $0 \mathrm{BD}$ regulations as gasoline vehicles?}

\section{EPA}

Yes, but you may request waivers from the federal OBD regulations. Providing you show technical justification, the EPA may grant waivers, applicable to the alternative fuel portion only. The balance of the OBD system must operate in compliance with the regulations. This waiver is available up to and including the 1998 model year. The EPA has proposed to extend the waivers up to and including the 2004 model year (see page 23).

\section{California}

Yes, but you may request a waiver from complying with the OBD II regulations; this waiver is available up to and including the 2004 model year. The aftermarket conversion system must still comply with California OBD I regulations (see page 34 ).

\section{Do manufacturers have to provide an emissions warranty as part of the certification requirements for aftermarket conversions?}

EPA

Yes, you are required to provide an emissions warranty. For light-duty vehicles and trucks, the warranty is in two parts-an emissions performance warranty and an emissions design and defect warranty. Both are two years or 24,000 miles, whichever comes first, and eight years or 80,000 miles, whichever comes first, for the catalytic converter, the OBD device, and the electronic control unit. Heavy-duty engine manufacturers are 
required to supply an emissions design and defect warranty of five years or 50,000 miles, whichever comes first, for heavy-duty Otto-Cycle engines and light heavy-duty diesel engines, and five years or 100,000 miles, whichever comes first, for all other heavy-duty engines. The warranty covers the labor to diagnose and repair or replace the part, as well as any parts that need replacing. The emissions warranty period does not extend beyond the emissions warranty that remained on the original vehicle prior to conversion (see page 24).

\section{California}

Yes, an emissions warranty is required. The same warranty applies to passenger cars, light-duty, mediumduty, and heavy-duty vehicles. The warranty period is three years or 50,000 miles, whichever comes first, and seven years or 70,000 miles, whichever comes first, for high-priced components. The warranty covers the labor to diagnose and repair or replace the part as well as any parts that need replacing. The installer is also required to supply a warranty that the installation was done correctly. The period of the warranty is three years or 50,000 miles, whichever comes first. The warranty is to cover the full repair of any damage resulting from an incorrect installation. The warranty period for both the manufacturer and installer starts on the date of conversion; the vehicle mileage at that time is considered to be zero (see page 34).

\section{If I obtain an EPA emissions certification for a 50-state (or California-only) vehicle, do I still need to obtain certification in California?}

California requires that you apply for certification from CARB for vehicles that are to be used in California. For a California-only vehicle, seek certification from CARB first, and then from the EPA. For a 50-state vehicle, obtain EPA certification first, and then from CARB.

\section{If I obtain a California aftermarket certification (an E0), will I be exempt from enforcement actions under the Clean Air Act anti-tampering provisions?}

In a September 4, 1997 EPA policy document, addendum to Memorandum 1A "Tampering Enforcement Policy for Alternative Fuel Aftermarket Conversions," the EPA clarifies the tampering enforcement policy and revises the terms for establishing a reasonable basis that performing an aftermarket conversion will not adversely affect emissions. If you follow one of the three options that are listed in the addendum, the EPA will not regard the conversion as a violation of the anti-tampering provisions. One of those options is to certify according to "California Certification and Installation Procedures for Alternative Fuel Retrofit Systems for Motor Vehicles Certified for 1994 and Subsequent Model Years and for All Model Year Motor Vehicle Retrofit Systems Certified for Emission Reduction Credit." This applies to a California-only engine family for use in California only or a 50-state engine family for nationwide use. The EPA no longer accepts that the pre-1994 California procedures provide an adequate demonstration that the aftermarket conversion will comply with the applicable emission standards for the vehicle's useful life (see page 7).

\section{When converting vehicles using Option 3 from the addendum to Memo $1 \mathrm{~A}$, do the FTP 75 results on the alternative fuel have to be better than those on gasoline?}

No. The result that is to be compared to the emission standard must include the FTP test and the appropriately applied DF. This overall result must then be compared to the standard for the model year of the vehicle or engine being converted. All results must be within the standards for each of the regulated emissions throughout the vehicle or engine's useful life. 


\section{$A$

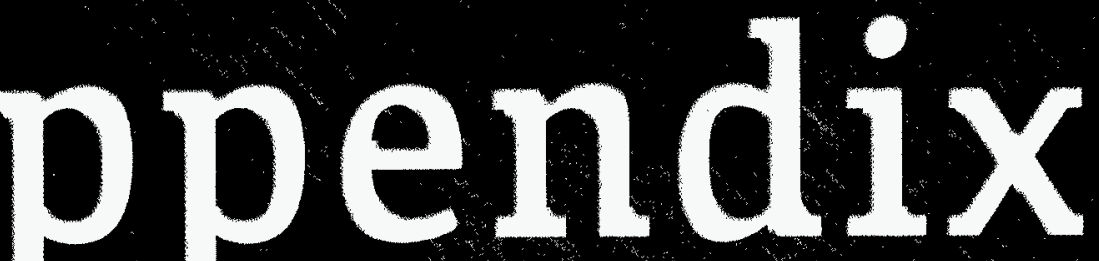

\section{Appendix A: Glossary of Terms}

\section{Abbreviations}

AFV ....... alternative fuel vehicle

ALVW ..... adjusted loaded vehicle weight

APCD ..... Air Pollution Control Division (Colorado)

BAR . . . . . . Bureau of Automotive Repair

CAA. ..... Clean Air Act

CAFE ..... corporate average fuel economy

CARB. ... . . California Air Resources Board

CD ........ Certification Division

CFF ....... Clean-Fuel Fleet

CFFP . . . . . Clean-Fuel Fleet Program

CFR ....... Code of Federal Regulations

CFV ........ clean-fuel vehicle

CNG....... compressed natural gas

$\mathrm{CO} \ldots . . .$. carbon monoxide

$\mathrm{CO}_{2} \ldots \ldots$ carbon dioxide

CPP ...... California Pilot Program

DDV ....... durability data vehicle

DF or DFs . . deterioration factor or factors

DOE..... . U.S. Department of Energy

DOT ...... . U.S. Department of Transportation

EDV ....... emissions data vehicle

EO ........ Executive Order (California)

EPA ..... . . U.S. Environmental Protection Agency

EPACT. . . . Energy Policy Act of 1992

FIP . . . . . . . Federal Implementation Plan

FR. ........ Federal Register

FTP. ........ Federal Test Procedure

GVWR.... gross vehicle weight rating

$\mathrm{HC} \ldots . .$. hydrocarbons

HCHO . . . . formaldehyde

HDDE .... . heavy-duty diesel engine (diesel-cycle)
HDE. . . . . . heavy-duty engine

HDGE . . . . heavy-duty gas engine (Otto-Cycle)

HDV ...... heavy-duty vehicle

HHDDE ... heavy heavy-duty diesel engine (diesel-cycle)

HLDT . . . . heavy light-duty truck

HOV ..... . high-occupancy vehicle

ILEV. . . . . . inherently low-emission vehicle

IM. . . . . . . inspection and maintenance

LDT ....... . light-duty truck

LDT1 . . . . . light-duty truck 1

LDT2 . . . . . light-duty truck 2

LDT3 .... . light-duty truck 3

LDT4 . . . . . light-duty truck 4

LDV ...... . light-duty vehicle

LEV . . . . . . low-emission vehicle

LHDDE . . . . light heavy-duty diesel engine (diesel-cycle)

LLDT . . . . . light light-duty truck

LNG. . . . . . liquefied natural gas

LPG ...... . liquefied petroleum gas

LVW..... . loaded vehicle weight

MAC . . . . . Manufacturers Advisory Correspondence (California)

MDV ...... medium-duty vehicle

MDV1 ..... medium-duty vehicle 1

MDV2 ..... medium-duty vehicle 2

MDV3 ..... medium-duty vehicle 3

MDV4 .... medium-duty vehicle 4

MDV5 ..... medium-duty vehicle 5

MERC . . . . . Mobile Emissions Reduction Credit (federal term) 
MHDDE ... medium heavy-duty diesel engine (diesel-cycle)

MSERC . . . . Mobile Source Emissions Reduction Credit (California term)

MY ....... model year

NAAQS. . . National Ambient Air Quality Standards

NMHC .... non-methane hydrocarbons

NMOG .... non-methane organic gases

$\mathrm{NO}_{\mathrm{x}} \ldots \ldots$. . oxides of nitrogen

NREL.... . . National Renewable Energy Laboratory

OBD ....... on-board diagnostics

OBD II . . . . on-board diagnostics II
OEM ..... original equipment manufacturer

PC ....... passenger car

PM ........ particulate matter

QVM ...... Qualified Vehicle Modifier

RAF ...... reactivity adjustment factor

SIP . . . . . . . State Implementation Plan

SULEV . . . . . super-ultra-low-emission vehicle

THC ...... total hydrocarbons

TLEV . . . . . transitional low-emission vehicle

TW ........ test weight

ULEV . . . . . ultra low-emission vehicle

VIN ...... vehicle identification number

ZEV ...... zero-emission vehicle

\section{Definitions}

Adjusted loaded vehicle weight (ALVW): the numerical average of the curb weight and the GVWR.

Aftermarket conversion: a vehicle originally designed to operate on gasoline or diesel that has been modified or altered to run on an alternative fuel. (See also 40 CFR Part 85.502(c).)

Alternative fuel: in the context of this guide, alternative fuel refers to CNG, LNG, and LPG.

Baseline emissions: emissions measured from relatively new vehicles or engines. Baseline emissions are compared with emissions at higher mileage levels to determine DFs.

Bi-fuel vehicle (industry definition): a vehicle with two separate fuel systems designed to run on either an alternative fuel, or gasoline or diesel, using only one fuel at a time. CARB defines bi-fuel differently, which can create confusion.

Bi-fuel vehicle (CARB definition): a vehicle with two fuel systems (the conventional fuel and an alternative fuel) capable of running on either the conventional fuel (gasoline or diesel) or both the conventional and alternative fuel simultaneously.

Clean-fuel vehicle (CFV): any vehicle certified by the EPA as meeting CFV federal emissions standards. The three categories of federal CFV standards from least to most stringent are LEV, ULEV, and ZEV. The ILEV standard is voluntary and does not need to be adopted by states as part of the Clean-Fuel Fleet Program (CFFP). CFVs are eligible for two federal programs, the California Pilot Program and the CFFP. CFV exhaust emissions standards for light-duty vehicles and trucks are numerically similar to those of California's Low-Emissions Vehicle Program.

Clean-Fuel Fleet Program (CFFP): a federal program that requires fleet purchase of CFVs beginning in model year 1999.

Compressed natural gas (CNG): natural gas that has been compressed under high pressure. When used as a motor vehicle fuel, it is stored in specially designed cylinders at pressures up to 3,600 pounds per square inch (see also natural gas).

Conventional fuel: in the context of this guide, conventional fuel refers to gasoline or diesel.

Converted or conversion: (see aftermarket conversion) 
Corporate Average Fuel Economy (CAFE): a program created to determine vehicle manufacturers' compliance with the fuel economy standards set by the federal government. The Energy Policy and Conservation Act, which passed in 1975, set the first federal fuel economy standards for light-duty vehicles and trucks. The CAFE values are a weighted harmonic average of the EPA city and highway fuel economy test results.

Conversion kit: equipment used to modify a vehicle originally designed to operate on gasoline or diesel that has been modified or altered to run on an alternative fuel.

Curb weight: the manufacturer's estimated weight of the vehicle in operational status with all standard equipment and weight of fuel at normal tank capacity, and the weight of optional equipment.

Dedicated alternative fuel vehicle: a vehicle that has been designed or modified to run on an alternative fuel only.

Deterioration factor (DF): a numerical factor that is determined through various durability test procedures and used to predict the increase in vehicle emissions caused by age or mileage accumulation. These factors are applied to baseline emissions test results to determine compliance with useful life emissions standards. Some are multiplied and others are added to the baseline emission results.

Diesel engine: any engine powered by diesel fuel or a gaseous fuel for which the diesel engine speed/torque characteristics and vehicle applications are retained. (Commonly referred to as a compression-ignition engine.)

Distributor: a company or individual that purchases aftermarket conversion equipment or kits for the purpose of reselling to other companies or individuals, such as an installer, without installing the conversion kit.

Dual-fuel vehicle (CAA/EPA/CARB definition): a vehicle with two separate fuel systems designed to run on either an alternative fuel or conventional gasoline, using only one fuel at a time. We use this definition for dual-fuel in this guide. (See also 40 CFR Part 88.102-94.)

Dual-fuel vehicle (industry/EPACT definition): a vehicle designed to operate on a combination of an alternative fuel and a conventional fuel, including: (1) vehicles using a mixture of gasoline or diesel and an alternative fuel in one fuel tank, commonly called flexible-fuel vehicles; and (2) vehicles capable of operating either on an alternative fuel, a conventional fuel, or both, simultaneously using two fuel systems.

Durability: a vehicle's or engine's ability to maintain a given emissions level over its useful life. Durability tests are performed by manufacturers to predict the emissions deterioration rate with increased mileage (see also DFs and useful life).

Durability data vehicle (DDV): a vehicle used to test for deterioration of emissions over a period of use. The test results are used to determine DFs.

Emissions data vehicle (EDV): a vehicle used to test for baseline emissions. DFs are applied to the baseline emissions results to determine compliance with useful life emissions standards.

Engine family: the EPA and CARB define engine family as a group of engines with the same emissions characteristics throughout their useful life. The engines must be identical in a number of respects such as cylinder bore center-to-center dimensions, cylinder block configuration, location of the intake and exhaust valves, method of air inspiration, combustion cycle, and catalytic converter characteristics.

Evaporative emissions: hydrocarbon vapors that escape from a fuel storage tank, a vehicle fuel tank, or a vehicle fuel system.

Full useful life: (see useful life)

Gross vehicle weight rating (GVWR): maximum loaded weight for which the vehicle is designed, as specified by the vehicle manufacturer. 
Heavy-duty engine: a diesel or an Otto-Cycle engine that powers a heavy-duty vehicle. The EPA designation for a heavy-duty vehicle is any vehicle above 8,500 pounds GVWR; the CARB designation is for any vehicle above 6,000 pounds GVWR. Exhaust emission testing is carried out on a engine dynamometer.

Heavy-duty vehicle: (see heavy-duty engine)

Inherently low-emission vehicle (ILEV): a vehicle meeting EPA's CFV ILEV standards (federal only-see Appendix D). Evaporative emissions must be 5 grams or less per test without using any and all auxiliary emission control devices. In most cases, ILEVs will be dedicated AFVs. Dual-fuel vehicles will be considered ILEVs only if both fuels meet the standard. ILEVs may be exempt from certain transportation control measures, including HOV lane restrictions. This standard is voluntary and need not be adopted by states.

Installer: any company or individual that installs an aftermarket conversion system on a vehicle or engine. (See also 40 CFR Part 85.502(d).)

Intermediate useful life: (see useful life)

Light-duty truck (LDT): there are a number of different vehicle weight categories within the light-duty truck vehicle designation. The EPA designation for light-duty truck is any truck with a GVWR of 8,500 pounds or less and a curb weight of 6,000 pounds or less; the CARB designation applies to any truck with a GVWR of less than 6,000 pounds.

Light-duty vehicle (LDV): an EPA term that means a passenger car or passenger-car derivative capable of seating 12 or fewer passengers (see also passenger car).

Liquefied natural gas (LNG): natural gas that has been condensed to a liquid-typically, by cryogenically cooling the gas (see also natural gas).

Liquefied petroleum gas (LPG): also known as propane, a mixture of hydrocarbons found in natural gas and also produced from crude oil. In addition to its use as a vehicle fuel, it is used principally as a feedstock for the chemical industry, a home heating fuel, and a motor vehicle fuel. When used as a motor vehicle fuel, the primary component of LPG is propane.

Loaded vehicle weight (LVW): a vehicle's curb weight plus 300 pounds.

Low-emission vehicle (LEV): a vehicle that meets either the EPA's CFV LEV standards or California's LowEmission Vehicle Program standards (see Appendix D). LEVs produce fewer emissions than TLEVs.

Medium-duty vehicle (MDV): CARB term that means any pre-1995 model year heavy-duty vehicle having a GVWR of 8,500 pounds or less; any 1992 and subsequent model year heavy-duty LEV, ULEV, SULEV, or ZEV having a GVWR of 14,000 pounds or less; or any 1995 and subsequent model year heavy-duty vehicle having a GVWR of 14,000 pounds or less. Exhaust emissions testing of MDVs is performed on a chassis dynamometer.

Model year: an OEM's annual production period. Further, a specific model year must include January 1 of that calendar year and not include January 1 of any other calendar year. The maximum duration of the model year is one calendar year plus 364 days. (See also 40 CFR Part 85.2302 and 85.2303.)

Natural gas: a mixture of gaseous hydrocarbons, primarily methane, which occurs naturally in the earth and is used principally as a fuel.

Non-methane organic gas (NMOG): the sum of non-oxygenated and oxygenated hydrocarbons contained in a gas sample as measured in accordance with California's test procedures. With vehicles using fuels other than gasoline, the level of NMOG emissions is adjusted based on the reactivity of the emissions relative to vehicles using gasoline.

Nonattainment area: a region, determined by population density in accordance with the U.S. Census Bureau, which exceeds minimum acceptable National Ambient Air Quality Standards (NAAQS) for one or more "criteria pollutants." Such areas are required to seek modifications to their State Implementation Plans, 
setting forth a reasonable timetable for meeting NAAQS using EPA-approved means. Under the CAA, if a nonattainment area fails to meet NAAQS, the EPA may impose a Federal Implementation Plan with stricter requirements, or impose fines, construction bans, or cutoffs in federal grant revenues, until the area achieves the applicable NAAQS.

Office of Mobile Sources: a division of the EPA that proposes, promulgates, and enforces regulations to control emissions from motor fuels, vehicles, motor vehicle engines, and non-road engines.

On-board diagnostics system (OBD system): a system made up of sensors, actuators, the OBD computer (which is usually the same as the electronic control unit that controls other engine functions) and its software, and interconnecting cables and wires. Its purpose is to ensure proper emission control system operation for the useful life of the vehicle by monitoring emissions-related components and systems for deterioration and malfunction.

On-board refueling vapor recovery (ORVR): a system required on vehicles beginning in 1998 to recover hydrocarbon vapors that escape during refueling.

Otto-Cycle engine: any engine in which the primary means of controlling power output is by limiting the amount of air and fuel that can enter the combustion chambers of the engine (commonly referred to as a spark-ignited engine).

Passenger car (PC): CARB term meaning any motor vehicle designed primarily for transportation of persons and having a design capacity of 12 or fewer persons (see also light-duty vehicle).

Reactivity adjustment factor (RAF): numerical multipliers used in the certification of vehicles to the California emissions standards to reflect reduced ozone-forming potential of emissions from various fuels, especially alternative fuels.

Retrofit: (see aftermarket conversion)

Super-ultra-low-emission vehicle (SULEV): an MDV in California that produces fewer emissions than a ULEV vehicle (see Appendix D). Because there is no federal equivalent, such a vehicle qualifies as a ULEV vehicle under the CFFP.

Tier 0: federal emissions standards for LDVs and trucks prior to the tier 1 phase (see Appendix D).

Tier 1: more stringent federal emissions standards for LDVs and LDTs phased in beginning in MY 1994 and required for all 1996 model year light-duty vehicles and trucks (see Appendix D).

Transitional low-emission vehicle (TLEV): a vehicle that meets either the EPA's TLEV standards or California's Low-Emissions Vehicle Program TLEV standards (see Appendix D). TLEVs produce fewer emissions than federal tier 1 vehicles. TLEVs are eligible for the federal California Pilot Program but are not eligible for the federal CFFP.

Ultra low-emission vehicle (ULEV): a vehicle that meets either the EPA's CFV ULEV standards or California's Low-Emission Vehicle Program ULEV standards (see Appendix D). ULEVs produce fewer emissions than LEVs. Fleets that purchase CFV ULEVs may earn credits under the CFFV Program. Manufacturers that sell CFV ULEVs may earn credits under the federal California Pilot Program.

Useful life: a period of vehicle or engine use expressed in years or miles defining the emissions standards to which a vehicle or engine is being certified. Vehicles or engines are certified to meet emissions standards that are projected out to their intermediate or full useful life (such as five years or 50,000 miles, whichever comes first; ten years or 100,000 miles, whichever comes first, etc.). Baseline emissions tests are performed and DFs are applied to determine if the vehicle will meet the standards defined for a given useful life.

Zero-emission vehicle (ZEV): a vehicle that meets either the EPA's CFV ZEV standards or CARB's California Low-Emission Vehicle ZEV standards. ZEV standards, usually met with electric vehicles, do not permit any exhaust emissions of the regulated pollutants or evaporative emissions during vehicle use. 


\section{Appendix B: Schematics of Commercial Aftermarket Conversion Systems}

This appendix contains schematics of two commercially available aftermarket conversion kits.

Example of a CNG Conversion System

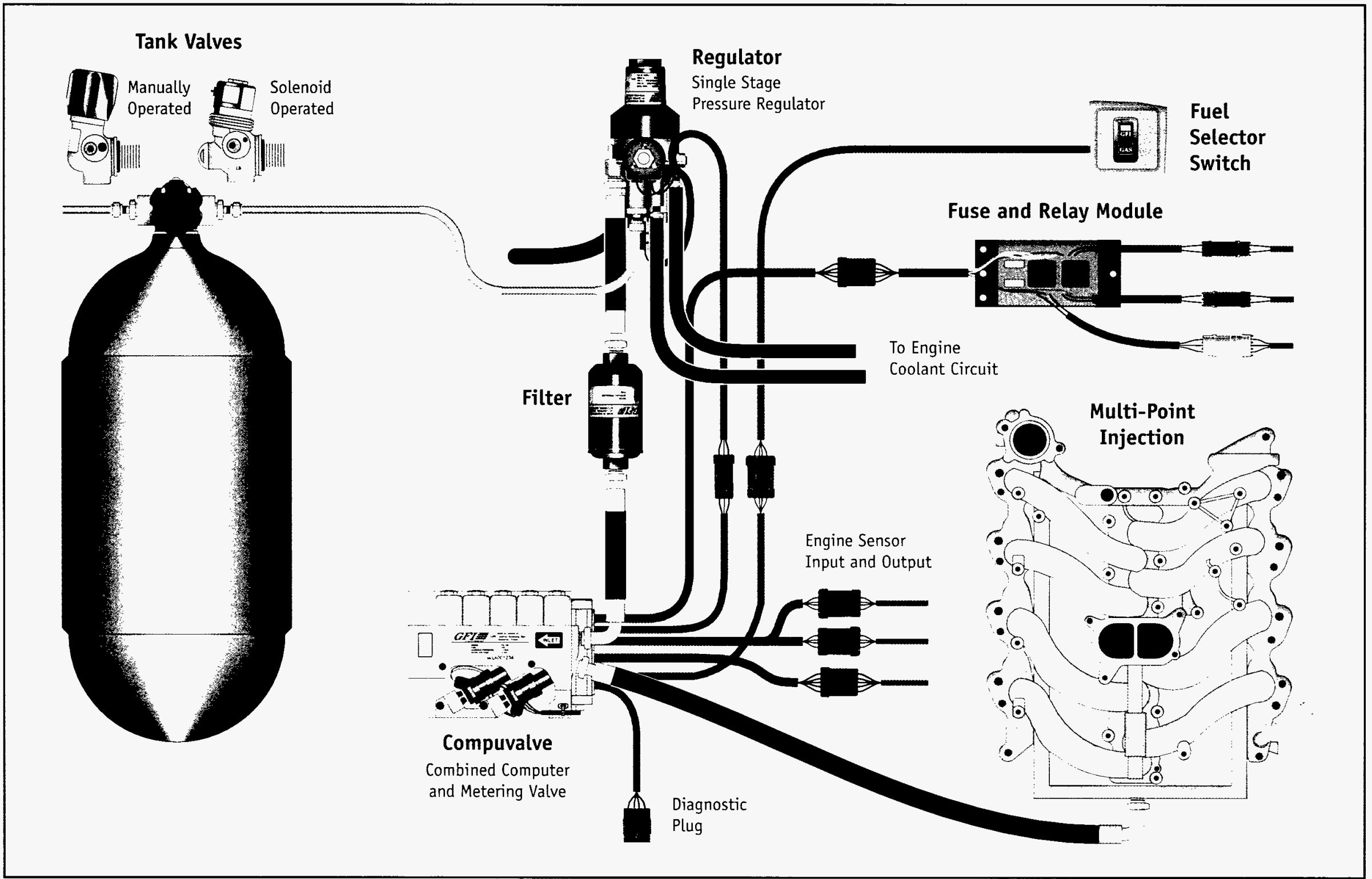

Schematic Courtesy of GFI Control Systems, Inc. 


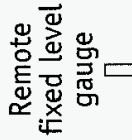

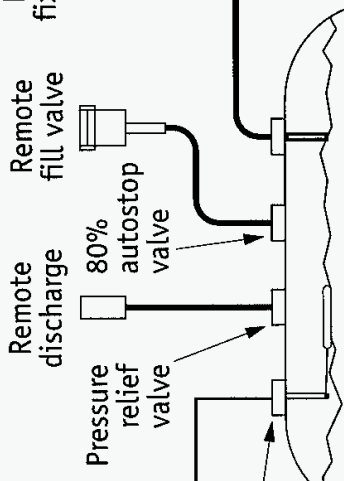

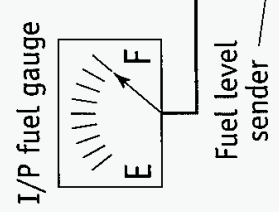
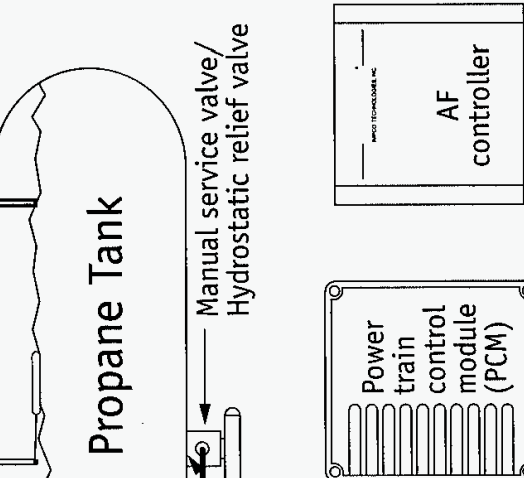

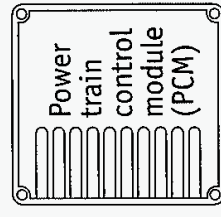

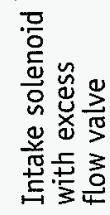
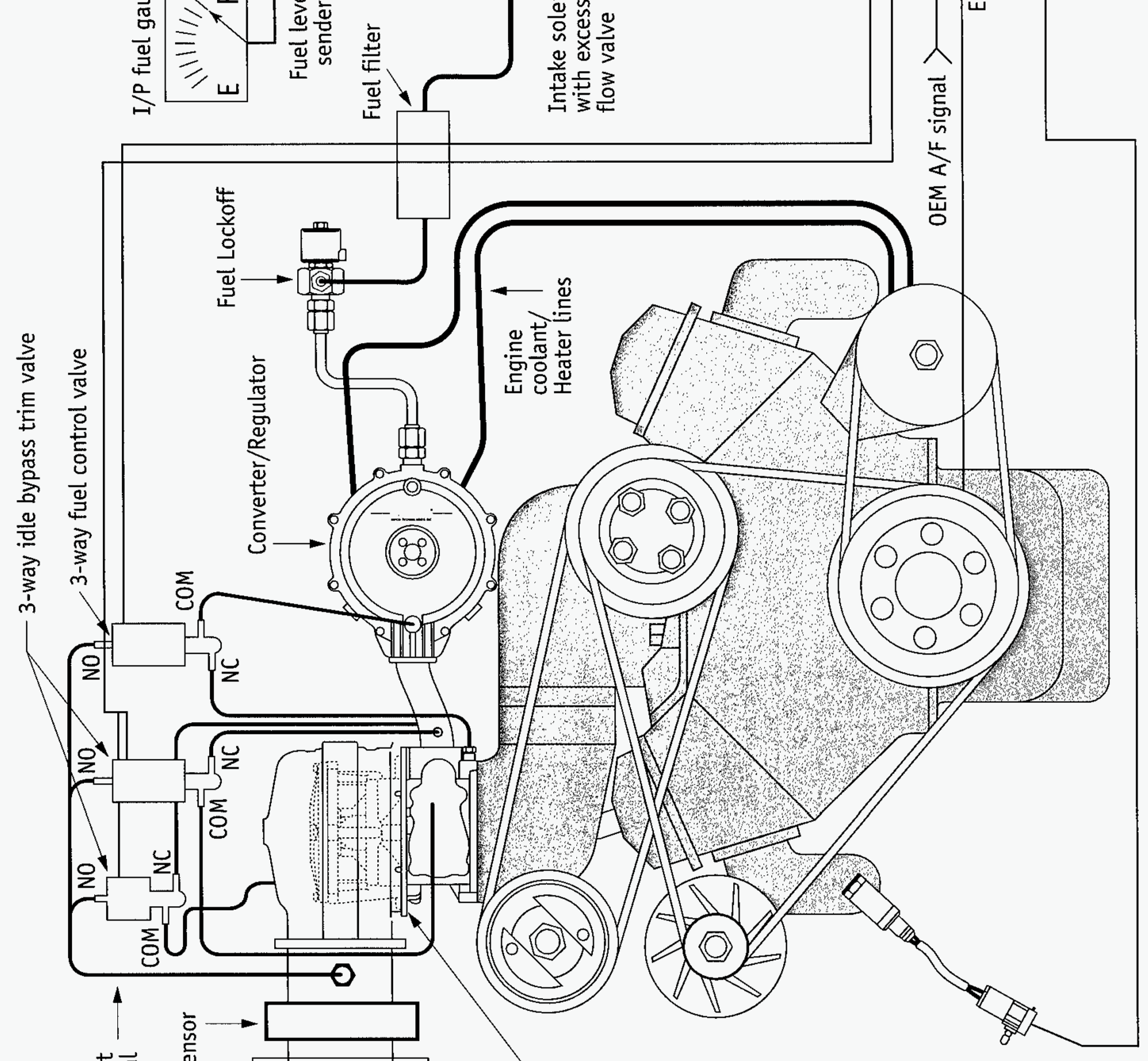

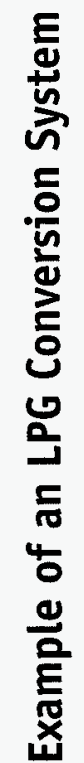


Appendix C

\section{Appendix C: Informative Web Sites}

\section{Certification and Regulations}

U.S. Government Printing Office

Code of Federal Regulations and Federal Register........ http:/ /www.access.gpo.gov/nara/index.html

U.S. Environmental Protection Agency

Office of Mobile Sources .....................tp://www.epa.gov/omswww

Clean Air Act Regulations......................tp://www.epa.gov/oar/caa/contents.html

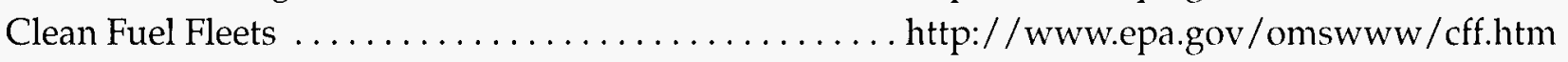

Small Volume Manufacturers Application -

for Certificate of Conformity. ................. http://www.epa.gov/omswww/gopher/Cert /

Standardized Engine and

Dearmfr/gasappx5.pdf (or/gasappx5.txt)

Evaporative Family Names ................ http://www.epa.gov/omswww/gopher/Cert / CFEIS/cmug-f.pdf

California Air Resources Board. ............... http://www.arb.ca.gov

Colorado Department of Public Health and Environment $\ldots \ldots \ldots \ldots \ldots \ldots \ldots \ldots \ldots \ldots \ldots h t t p: / /$ www.state.co.us/gov_dir/cdphe_dir

\section{General Alternative Fuels Information}

U.S. Department of Energy

Office of Transportation Technologies ...........http://www.ott.doe.gov

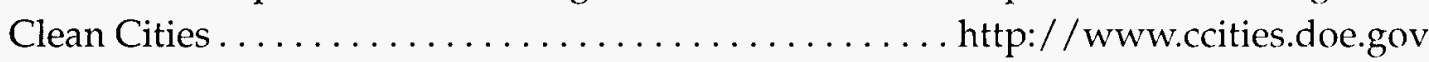

Alternative Fuels Data Center . . . . . . . . . . . http://www.afdc.doe.gov 
Appendix D: Emissions Standards

Summary of Federal and California Exhaust Emissions Standards for CNG, LPG, Gasoline, and Diesel ${ }^{1}$
This table summarizes exhaust emissions standards. Although it does not cover all the exhaust standards, it does provide information on those that we have mentioned frequently. See Tables 3, 4, and 11 in the body of the guide for sources of information for other details on exhaust, evaporative, and other emissions standards. See Appendix A for an explanation of all abbreviations.

\begin{tabular}{|c|c|c|c|c|c|c|c|c|c|c|c|c|c|c|c|c|c|c|c|c|}
\hline \multirow{2}{*}{\multicolumn{3}{|c|}{ Vehicle }} & \multirow{3}{*}{$\begin{array}{l}\text { Emissions } \\
\text { Category }^{\mathrm{a}}\end{array}$} & \multicolumn{17}{|c|}{ Exhaust Emissions Standards, in grams per mile } \\
\hline & & & & \multicolumn{6}{|c|}{50,000 Miles } & \multicolumn{5}{|c|}{100,000 Miles } & \multicolumn{6}{|c|}{120,000 Miles } \\
\hline $\begin{array}{l}\text { GVWR in } \\
\text { Pounds }\end{array}$ & $\begin{array}{c}\text { Weight in } \\
\text { Pounds }\end{array}$ & Type & & THC $^{\mathbf{b}}$ & $\begin{array}{c}\text { (NMHC) }^{c} \\
\text { NMOG }^{d}\end{array}$ & CO & $\mathrm{NO}_{\mathrm{x}}$ & HCHO & $\mathbf{P M}^{\mathbf{e}}$ & $\begin{array}{c}\text { (NMHC }^{\mathrm{C}} \\
\text { NMOG }^{\mathrm{d}}\end{array}$ & $\mathrm{CO}$ & $\mathrm{NO}_{\mathrm{x}}$ & HCHO & $\mathbf{P M}^{\mathrm{e}}$ & THC $^{b}$ & $\begin{array}{c}\left(\text { NMHC }^{\mathrm{C}}\right. \\
\text { NMOG }^{\mathrm{d}}\end{array}$ & $\mathrm{CO}$ & $\mathrm{NO} \mathrm{x}_{\mathrm{x}}$ & $\mathrm{HCHO}$ & $\mathrm{PM}^{\mathbf{e}}$ \\
\hline & & \multirow{5}{*}{$\begin{array}{l}\text { Light-Duty } \\
\text { Vehicle }\end{array}$} & Fed tier 0 & 0.41 & $(0.34)^{f}$ & 3.4 & 1.0 & & 0.20 & & & & & & & & & & & \\
\hline & & & Fed tier 1 & 0.41 & $(0.25)$ & 3.4 & 0.4 & & 0.08 & $(0.31)$ & 4.2 & 0.6 & & 0.10 & & & & & & \\
\hline & & & Fed LEV & & 0.075 & 3.4 & 0.2 & 0.015 & & 0.090 & 4.2 & 0.3 & 0.018 & 0.08 & & & & & & \\
\hline & & & Fed ILEV & & 0.075 & 3.4 & 0.2 & 0.015 & & 0.090 & 4.2 & 0.3 & 0.018 & 0.08 & & & & & & \\
\hline & & & Fed ULEV & & 0.040 & 1.7 & 0.2 & 0.008 & & 0.055 & 2.1 & 0.3 & 0.011 & 0.04 & & & & & & \\
\hline & & \multirow{5}{*}{ Passenger Car } & Ca tier 0 & & $(0.39)$ & 7.0 & 0.4 & & 0.08 & & & & & & & & & & & \\
\hline & & & CA tier 1 & & $(0.25)$ & 3.4 & 0.4 & & 0.08 & $(0.31)$ & 4.2 & 0.6 & & & & & & & & \\
\hline & & & CA TLEV & & 0.125 & 3.4 & 0.4 & 0.015 & & 0.156 & 4.2 & 0.6 & 0.018 & 0.08 & & & & & & \\
\hline & & & CA LEV & & 0.075 & 3.4 & 0.2 & 0.015 & & 0.090 & 4.2 & 0.3 & 0.018 & 0.08 & & & & & & \\
\hline & & & CA ULEV & & 0.040 & 1.7 & 0.2 & 0.008 & & 0.055 & 2.1 & 0.3 & 0.011 & 0.04 & & & & & & \\
\hline \multirow{20}{*}{$0-6,000$} & \multirow{10}{*}{$\begin{array}{c}0-3,750 \\
\text { LVW }\end{array}$} & \multirow{10}{*}{$\begin{array}{l}\text { Light-Duty } \\
\text { Truck } 1\end{array}$} & Fed tier 0 & & & & & & & & & & & & 0.80 & $(0.67)^{f}$ & 10 & 1.2 & & 0.26 \\
\hline & & & Fed tier 1 & & $(0.25)$ & 3.4 & 0.4 & & 0.08 & $(0.31)$ & 4.2 & 0.6 & & 0.10 & 0.80 & & & & & \\
\hline & & & Fed LEV & & 0.075 & 3.4 & 0.2 & 0.015 & & 0.090 & 4.2 & 0.3 & 0.018 & 0.08 & & & & & & \\
\hline & & & Fed ILEV & & 0.075 & 3.4 & 0.2 & 0.015 & & 0.090 & 4.2 & 0.3 & 0.018 & 0.08 & & & & & & \\
\hline & & & Fed ULEV & & 0.040 & 1.7 & 0.2 & 0.008 & & 0.055 & 2.1 & 0.3 & 0.011 & 0.04 & & & 2.1 & & 0.055 & \\
\hline & & & CA tier 0 & & $(0.39)$ & 9.0 & 0.4 & & 0.08 & & & & & & & & & & & \\
\hline & & & CA tier 1 & & $(0.25)$ & 3.4 & 0.4 & & 0.08 & $(0.31)$ & 4.2 & 0.6 & & & & & & & & \\
\hline & & & CA TLEV & & 0.125 & 3.4 & 0.4 & 0.015 & & 0.156 & 4.2 & 0.6 & 0.018 & 0.08 & & & & & & \\
\hline & & & CA LEV & & 0.075 & 3.4 & 0.2 & 0.015 & & 0.090 & 4.2 & 0.3 & 0.018 & 0.08 & & & & & & \\
\hline & & & CA ULEV & & 0.04 & 1.7 & 0.2 & 0.008 & & 0.055 & 2.1 & 0.3 & 0.011 & 0.04 & & & & & & \\
\hline & & & Fed tier 0 & & & & & & & & & & & & 0.80 & $(0.67)^{f}$ & 10 & 1.7 & & 0.13 \\
\hline & & & Fed tier 1 & & $(0.32)$ & 4.4 & 0.7 & & 0.08 & $(0.40)$ & 5.5 & 0.97 & & 0.10 & 0.80 & & & & & \\
\hline & $3751-$ & & Fed LEV & & 0.100 & 4.4 & 0.4 & 0.018 & & 0.130 & 5.5 & 0.5 & 0.023 & 0.08 & & & & & & \\
\hline & 5750 & Light-Duty & Fed ILEV & & 0.100 & 4.4 & 0.4 & 0.018 & & 0.130 & 5.5 & 0.5 & 0.023 & 0.08 & & & & & & \\
\hline & LVW & Truck 2 & Fed ULEV & & 0.050 & 2.2 & 0.4 & 0.009 & & 0.070 & 2.8 & 0.5 & 0.013 & 0.04 & & & & & & \\
\hline & & & CA tier 0 & & $(0.50)$ & 9.0 & 1.0 & & 0.08 & & & & & & & & & & & \\
\hline & & & CA tier 1 & & $(0.32)$ & 4.4 & 0.7 & & 0.08 & $(0.40)$ & 5.5 & 0.97 & & & & & & & & \\
\hline & & & CA TLEV & & 0.160 & 4.4 & 0.7 & 0.018 & & 0.200 & 5.5 & 0.9 & 0.023 & 0.10 & & & & & & \\
\hline & & & CA LEV & & 0.100 & 4.4 & 0.4 & 0.018 & & 0.130 & 5.5 & 0.5 & 0.023 & 0.10 & & & & & & \\
\hline & & & CA ULEV & & 0.050 & 2.2 & 0.4 & 0.009 & & 0.070 & 2.8 & 0.5 & 0.013 & 0.05 & & & & & & \\
\hline
\end{tabular}




\begin{tabular}{|c|c|c|c|c|c|c|c|c|c|c|c|c|c|c|c|c|c|c|c|c|}
\hline \multirow{2}{*}{\multicolumn{3}{|c|}{ Vehicle }} & \multirow{3}{*}{$\begin{array}{l}\text { Emissions } \\
\text { Category }\end{array}$} & \multicolumn{17}{|c|}{ Exhaust Emissions Standards, in grams per mile } \\
\hline & & & & \multicolumn{6}{|c|}{50,000 Miles } & \multicolumn{5}{|c|}{100,000 Miles } & \multicolumn{6}{|c|}{120,000 Miles } \\
\hline $\begin{array}{l}\text { GVWR in } \\
\text { Pounds }\end{array}$ & $\begin{array}{l}\text { Weight in } \\
\text { Pounds }\end{array}$ & Type & & $\mathrm{THC}^{\mathrm{b}}$ & $\begin{array}{l}\text { (NMHC) }^{\mathrm{N}} \\
\text { NMOG }^{\mathrm{d}}\end{array}$ & $\mathrm{CO}$ & $\mathrm{NO}_{\mathrm{x}}$ & HCHO & $\mathrm{PM}^{\mathrm{e}}$ & \begin{tabular}{|l|} 
(NMHC) \\
NMOG $^{\mathrm{C}}$
\end{tabular} & $\mathrm{CO}$ & $\mathrm{NO}_{\mathrm{x}}$ & HCHO & $\mathrm{PM}^{\mathrm{e}}$ & $\mathrm{THC}^{\mathrm{b}}$ & \begin{tabular}{|c|} 
(NMHC) $^{\mathrm{C}}$ \\
NMOG $^{\mathrm{d}}$
\end{tabular} & CO & $\mathrm{NO} \mathrm{O}_{\mathrm{x}}$ & HСHO & $\mathrm{PM}^{\mathrm{e}}$ \\
\hline \multirow{28}{*}{$\begin{array}{l}6,001- \\
8,500\end{array}$} & \multirow{2}{*}{$\begin{array}{c}0-3,750 \\
L V W\end{array}$} & Heavy Light-Duty Truck & Fed tier 0 & & & & & & & & & & & & 0.80 & $(0.67)^{f}$ & 10 & 1.2 & & 0.26 \\
\hline & & Medium-Duty Vehicle & CA tier 0 & & $(0.39)$ & 9.0 & 0.4 & & 0.08 & & & & & & & & & & & \\
\hline & \multirow{2}{*}{\begin{tabular}{|c|}
$3,751-$ \\
$5,750 \mathrm{LVW}$ \\
\end{tabular}} & Heavy Light-Duty Truck & Fed tier 0 & & & & & & & & & & & & 0.80 & $(0.67)^{f}$ & 10 & 1.7 & & 0.13 \\
\hline & & Medium-Duty Vehicle & CA tier 0 & & $(0.50)$ & 9.0 & 1.0 & & 0.08 & & & & & & & & & & & \\
\hline & \multirow{2}{*}{\begin{tabular}{|c|}
$5,751-$ \\
$8,500 \mathrm{LVW}$ \\
\end{tabular}} & Heavy Light-Duty Truck & Fed tier 0 & & & & & & & & & & & & 0.80 & $(0.67)^{f}$ & 10 & 1.7 & & 0.13 \\
\hline & & Medium-Duty Vehicle & CA tier 0 & & $(0.60)$ & 9.0 & 1.5 & & 0.08 & & & & & & & & & & & \\
\hline & \multirow{6}{*}{$\begin{array}{l}0-3,750 \\
\text { ALVW }\end{array}$} & \multirow{3}{*}{$\begin{array}{l}\text { Heavy Light-Duty } \\
\text { Truck }\end{array}$} & Fed LEV & & 0.125 & 3.4 & 0.4 & 0.015 & & & & & & & & 0.180 & 5.0 & 0.6 & 0.022 & 0.08 \\
\hline & & & Fed ILEV & & 0.125 & 3.4 & 0.2 & 0.015 & & & & & & & & 0.180 & 5.0 & 0.3 & 0.022 & 0.08 \\
\hline & & & Fed ULEV & & 0.075 & 1.7 & 0.2 & 0.008 & & & & & & & & 0.107 & 2.5 & 0.3 & 0.012 & 0.04 \\
\hline & & \multirow{3}{*}{$\begin{array}{l}\text { Medium-Duty } \\
\text { Vehicle } 1\end{array}$} & CA tier 1 & & $(0.25)$ & 3.4 & 0.4 & & & & & & & & & $(0.36)$ & 5.0 & 0.55 & & 0.08 \\
\hline & & & CA LEV & & 0.125 & 3.4 & 0.4 & 0.015 & & & & & & & & 0.180 & 5.0 & 0.6 & 0.022 & 0.08 \\
\hline & & & CA ULEV & & 0.075 & 1.7 & 0.2 & \begin{tabular}{|l|}
0.008 \\
\end{tabular} & & & & & & & & 0.107 & 2.5 & 0.3 & 0.012 & 0.04 \\
\hline & \multirow{8}{*}{$\begin{array}{c}3,751- \\
5,750 \\
\text { ALVW }\end{array}$} & \multirow{4}{*}{$\begin{array}{l}\text { Light-Duty } \\
\text { Truck } 3\end{array}$} & Fed tier 1 & & $(0.32)$ & 4.4 & 0.7 & & & & & & & & 0.80 & $(0.46)$ & 6.4 & 0.98 & & 0.10 \\
\hline & & & Fed LEV & & 0.160 & 4.4 & 0.7 & 0.018 & & & & & & & & 0.230 & 6.4 & 1.0 & \begin{tabular}{|l|}
0.027 \\
\end{tabular} & 0.10 \\
\hline & & & Fed ILEV & & 0.160 & 4.4 & 0.4 & 0.018 & & & & & & & & 0.230 & 6.4 & 0.5 & 0.027 & 0.10 \\
\hline & & & Fed ULEV & & 0.100 & 2.2 & 0.4 & 0.009 & & & & & & & & 0.143 & 3.2 & 0.5 & 0.013 & 0.05 \\
\hline & & \multirow{4}{*}{$\begin{array}{l}\text { Medium-Duty } \\
\text { Vehicle } 2\end{array}$} & CA tier 1 & & \begin{tabular}{|l|}
$(0.32)$ \\
\end{tabular} & 4.4 & 0.7 & & & & & & & & & $(0.46)$ & 6.4 & 0.98 & & 0.10 \\
\hline & & & CA LEV & & 0.160 & 4.4 & $0.4^{9}$ & 0.018 & & & & & & & & 0.230 & 6.4 & $0.6^{h}$ & 0.027 & 0.10 \\
\hline & & & CA ULEV & & 0.100 & 4.4 & 0.4 & 0.009 & & & & & & & & 0.143 & 6.4 & 0.6 & 0.013 & 0.05 \\
\hline & & & CA SULEV & & 0.050 & 2.2 & 0.2 & \begin{tabular}{|l|}
0.004 \\
\end{tabular} & & & & & & & & 0.072 & 3.2 & 0.3 & 0.006 & 0.05 \\
\hline & \multirow{8}{*}{$\begin{array}{l}5,751- \\
8,500 \\
\text { ALVW }\end{array}$} & \multirow{4}{*}{$\begin{array}{l}\text { Light-Duty } \\
\text { Truck } 4\end{array}$} & Fed tier 1 & & $(0.39)$ & 5.0 & 1.1 & & & & & & & & 0.80 & $(0.56)$ & 7.3 & 1.53 & & 0.12 \\
\hline & & & Fed LEV & & 0.195 & 5.0 & 1.1 & \begin{tabular}{|l|}
0.022 \\
\end{tabular} & & & & & & & & 0.280 & 7.3 & 1.5 & 0.032 & 0.12 \\
\hline & & & Fed ILEV & & 0.195 & 5.0 & 0.6 & 0.022 & & & & & & & & 0.280 & 7.3 & 0.8 & 0.032 & 0.12 \\
\hline & & & Fed ULEV & & 0.117 & 2.5 & 0.6 & 0.011 & & & & & & & & 0.167 & 3.7 & 0.8 & 0.016 & 0.06 \\
\hline & & \multirow{4}{*}{$\begin{array}{l}\text { Medium-Duty } \\
\text { Vehicle } 3\end{array}$} & CA tier 1 & & $(0.39)$ & 5.0 & 1.1 & & & & & & & & & $(0.56)$ & 7.3 & 1.53 & & 0.12 \\
\hline & & & CA LEV & & 0.195 & 5.0 & $0.6^{i}$ & 0.022 & & & & & & & & 0.280 & 7.3 & 0.9 & 0.032 & 0.12 \\
\hline & & & CA ULEV & & 0.117 & 5.0 & 0.6 & \begin{tabular}{|l|}
0.011 \\
\end{tabular} & & & & & & & & 0.167 & 7.3 & 0.9 & 0.016 & 0.06 \\
\hline & & & CA SULEV & & 0.059 & 2.5 & 0.3 & 0.006 & & & & & & & & 0.084 & 3.7 & 0.45 & 0.008 & 0.06 \\
\hline & $8.501-$ & & CA tier 1 & & $(0.46)$ & 5.5 & 1.3 & & & & & & & & & $(0.66)$ & 8.1 & 1.81 & & 0.12 \\
\hline & 10,000 & Medium-Duty & CA LEV & & 0.230 & 5.5 & $0.7^{k}$ & 0.028 & & & & & & & & 0.330 & 8.1 & $1.0^{1}$ & 0.040 & 0.12 \\
\hline & ALVW & Vehicle 4 & CA ULEV & & 0.138 & 5.5 & 0.7 & 0.014 & & & & & & & & 0.197 & 8.1 & 1.0 & 0.021 & 0.06 \\
\hline $8,501-$ & & & CA SULEV & & 0.069 & 2.8 & 0.35 & 0.007 & & & & & & & & 0.100 & 4.1 & 0.5 & 0.010 & 0.06 \\
\hline 14,000 & & & CA tier 1 & & $(0.60)$ & 7.0 & 2.0 & & & & & & & & & $(0.86)$ & 10.3 & 2.77 & & 0.12 \\
\hline & $\begin{array}{l}10,001- \\
14,000\end{array}$ & Medium-Duty & CA LEV & & 0.300 & 7.0 & $1.0^{\mathrm{m}}$ & 0.036 & & & & & & & & 0.430 & 10.3 & $1.5^{n}$ & 0.052 & 0.12 \\
\hline & ALVW & Vehicle 5 & CA ULEV & & 0.180 & 7.0 & 1.0 & \begin{tabular}{|l|}
0.018 \\
\end{tabular} & & & & & & & & 0.257 & 10.3 & 1.5 & 0.026 & 0.06 \\
\hline & & & CA SULEV & & 0.090 & 3.5 & 0.5 & \begin{tabular}{|l|}
0.090 \\
\end{tabular} & & & & & & & & 0.130 & 5.2 & 0.7 & \begin{tabular}{|l|}
0.013 \\
\end{tabular} & 0.06 \\
\hline
\end{tabular}




\begin{tabular}{|c|c|c|c|c|c|c|c|c|c|c|c|c|c|c|c|c|c|c|c|c|}
\hline \multirow{2}{*}{\multicolumn{3}{|c|}{ Vehicle }} & \multirow{3}{*}{$\begin{array}{l}\text { Emissions } \\
\text { Category }^{\mathrm{a}}\end{array}$} & \multicolumn{17}{|c|}{ Exhaust Emissions Standards, in grams per mile } \\
\hline & & & & \multicolumn{6}{|c|}{50,000 Miles } & \multicolumn{5}{|c|}{100,000 Miles } & \multicolumn{6}{|c|}{120,000 Miles } \\
\hline $\begin{array}{l}\text { GVWR in } \\
\text { Pounds }\end{array}$ & $\begin{array}{c}\text { Weight in } \\
\text { Pounds }\end{array}$ & Type & & THC $^{\mathbf{b}}$ & $\begin{array}{c}\left(\mathrm{NMHC}^{\mathrm{c}}\right. \\
\text { NMOG }^{\mathrm{d}} \\
\end{array}$ & $\mathrm{CO}$ & $\mathrm{NO}_{\mathrm{x}}$ & HCHO & $\mathrm{PM}^{\mathrm{e}}$ & $\begin{array}{l}\text { (NMHC) }^{c} \\
\text { NMOG }^{d}\end{array}$ & $\mathrm{CO}$ & $\mathrm{NO} \mathrm{x}_{\mathrm{x}}$ & HCHO & $\mathbf{P M}^{\mathrm{e}}$ & THC $^{b}$ & $\begin{array}{c}\left(\mathrm{NMHC}^{\mathrm{c}}\right. \\
\text { NMOG }^{\mathrm{d}} \\
\end{array}$ & CO & $\mathrm{NO}_{\mathrm{X}}$ & $\mathrm{HCHO}$ & $\mathrm{PM}^{\mathrm{e}}$ \\
\hline \multirow{3}{*}{$\begin{array}{l}8,501- \\
14,000\end{array}$} & & \multirow{3}{*}{$\begin{array}{c}\text { Medium-Duty } \\
\text { Vehicle (OPT) }^{\circ} \\
8,501-14,000 \text { GVWR }\end{array}$} & CA tier 1 & & & & & & & & & & & & & $(3.9)^{p}$ & 14.4 & & & 0.10 \\
\hline & & & CA LEV & & & & & & & & & & & & & $(3.5)^{p}$ & 14.4 & & 0.050 & 0.10 \\
\hline & & & CA ULEV & & & & & & & & & & & & & $(2.5)^{p}$ & $14.4^{9}$ & & $0.050^{r}$ & 0.05 \\
\hline $\begin{array}{l}8,501- \\
14,000 \\
\end{array}$ & & $\begin{array}{c}\text { Heavy-Duty } \\
\text { Otto-Cycle Engine }{ }^{s, t}\end{array}$ & Fed & & & & & & & & & & & & 1.1 & $(0.9)^{f}$ & 14.4 & $4.0^{u}$ & & \\
\hline $\begin{array}{c}\text { Greater Than } \\
14,000\end{array}$ & & $\begin{array}{c}\text { Heavy-Duty } \\
\text { Otto-Cycle Engine } \\
\end{array}$ & Fed \& CA & & & & & & & & & & & & 1.9 & $(1.7)^{\mathrm{v}}$ & 37.1 & $4.0^{\mathrm{w}}$ & & \\
\hline \multirow{4}{*}{$\begin{array}{l}\text { Greater Than } \\
\qquad 8,501^{x}\end{array}$} & & $\begin{array}{c}\text { Heavy-Duty } \\
\text { Diesel Engine } \\
\end{array}$ & Fed \& CA & & & & & & & & & & & & 1.3 & $(1.2)^{v}$ & 15.5 & $4.0^{w}$ & & 0.10 \\
\hline & & \multirow{3}{*}{$\begin{array}{l}\text { Heavy-Duty Otto-Cycle } \\
\text { and Diesel Engine }{ }^{\text {st,y }}\end{array}$} & Fed LEV & & & & & & & & & & & & $1.3^{\mathrm{z}}$ & $(3.8)^{p}$ & $15.5^{\text {aa }}$ & $4.0^{4}$ & & 0.10 \\
\hline & & & Fed ILEV & & & & & & & & & & & & $1.3^{z}$ & $(2.5)^{\mathrm{P}}$ & 14.4 & $4.0^{4}$ & 0.05 & 0.10 \\
\hline & & & Fed ULEV & & & & & & & & & & & & $1.3^{z}$ & $(2.5)^{\mathrm{p}}$ & 7.2 & $4.0^{4}$ & 0.025 & 0.05 \\
\hline
\end{tabular}

${ }^{1}$ Diesel standards are provided for HDEs only.

a "Fed" means federal; "CA" means California

${ }^{b}$ CNG is exempt from THC standard.

${ }^{c}$ NMHC standards are within parentheses.

d Dual-fuel PCs, LDVs, LDTs, and MDVs that are a part of federal LEV and ULEV and California TLEV, LEV, ULEV, \& SULEV emission categories may have different NMOG standards than those listed in this table. Gasoline is required to meet the standards for the emissions category for the original MY and a new gasoline NMOG standard. Refer to the next table for the NMOG standards if different than above.

e Shaded PM standards in this column refer to diesel only standard.

f NMHC standard applies to CNG only.

g Prior to MY 1998, the standard is 0.7 .

h Prior to MY 1998, the standard is 1.0.

i Prior to MY 1998, the standard is 1.1.

j Prior to MY 1998, the standard is 1.5 .

k Prior to MY 1998, the standard is 1.3.

1 Prior to MY 1998, the standard is 1.8.

$\mathrm{m}$ Prior to MY 1998, the standard is 2.0 .

n Prior to MY 1998, the standard is 2.8 .

- Optional standard for incomplete medium-duty vehicles of 8,501-14,000 lb

GVWR. Emissions standards are in grams per brake horsepower-hour.

${ }^{\mathrm{P}}$ Combined NMHC and $\mathrm{NO}_{\mathrm{x}}$ standard. q 14.4 grams per brake horsepower-hour for Otto-Cycle and 7.2 for diesel-cycle.

${ }^{\mathrm{r}} 0.050$ applies to Otto-Cycle engines. For diesel-cycle engines, the standard is 0.025 .

s Standards are in grams per brake horsepower-hour.

t Useful life is eight years or 110,000 miles for heavy-duty Otto-Cycle engines.

u Prior to MY 1998, the standard is 5.0. CNG remains at 5.0 for MY 1998. In MY 1998, the year portion of useful life becomes ten years.

v Optional for California. For federal, applies to CNG only.

w Prior to MY 1998, the standard is 5.0. In MY 1998, CNG remains at 5.0 for federal certification and changes to 4.0 for California certification. In MY 1998 the year portion of useful life becomes ten years.

x California vehicle weight category is greater than 14,000 lb GVWR.

${ }^{y}$ Useful life is eight years or 110,000 miles for LHDDE, 185,000 miles for MHDDE, and 290,000 miles for HHDDE.

z 1.3 grams per brake horsepower-hour for diesel-cycle, 1.1 for Otto-Cycle engines in vehicles weighing $14,000 \mathrm{lb}$ or less GVWR, and 1.9 for Otto-Cycle engines in vehicles weighing more than $14,000 \mathrm{lb}$ GVWR.

aa 15.5 grams per brake horsepower-hour for diesel-cycle, 14.4 for Otto-Cycle engines in vehicles weighing 14,000 lb or less GVWR, and 37.1 for Otto-Cycle engines in vehicles weighing more than $14,000 \mathrm{lb}$. 


\section{Appendix D}

\section{Appendix D - Emission Standards (concluded):}

\section{Additional NMOG Standards ${ }^{\mathrm{a}}$ for Dual-Fuel Vehicles, in grams per mile}

In order to certify a dual-fuel vehicle to a TLEV, LEV, ULEV, or SULEV emissions standard, emissions on both CNG and LPG must comply with the standards specified in the previous table with the exception of those NMOG standards listed here. Gasoline emissions are not to exceed the standards applicable to the original model year of the vehicle, and the NMOG standards given here. See Appendix A for an explanation of all abbreviations.

\begin{tabular}{|c|c|c|c|c|c|}
\hline \multirow[b]{3}{*}{ Vehicle Type } & \multirow[b]{3}{*}{$\begin{array}{l}\text { Emissions } \\
\text { Category }^{b}\end{array}$} & \multicolumn{4}{|c|}{ NMOG Standards, in grams per mile } \\
\hline & & \multicolumn{2}{|c|}{50,000 Miles } & \multicolumn{2}{|c|}{100,000 Miles } \\
\hline & & $\begin{array}{l}\text { CNG } \\
\text { or LPG }\end{array}$ & Gasoline & $\begin{array}{l}\text { CNG } \\
\text { or LPG }\end{array}$ & Gasoline \\
\hline \multirow{4}{*}{$\begin{array}{l}\text { Light-Duty Vehicle, } \\
\text { Passenger Car, } \\
\text { Light-Duty Truck } 1 \\
(0-3750 \text { lb LVW) }\end{array}$} & Fed All & 0.125 & 0.25 & 0.156 & 0.31 \\
\hline & CA TLEV & & 0.25 & & 0.31 \\
\hline & CA LEV & & 0.125 & & 0.156 \\
\hline & CA ULEV & & 0.075 & & 0.090 \\
\hline \multirow{4}{*}{$\begin{array}{l}\text { Light-Duty Truck } 2 \\
(3751-5750 \text { lb LVW) }\end{array}$} & Fed All & 0.160 & 0.32 & 0.200 & 0.40 \\
\hline & CA TLEV & & 0.32 & & 0.40 \\
\hline & CA LEV & & 0.160 & & 0.200 \\
\hline & CA ULEV & & 0.100 & & 0.130 \\
\hline \multirow{3}{*}{$\begin{array}{l}\text { Heavy Light-Duty Truck, } \\
\text { Medium-Duty Vehicle } 1 \\
\text { (0-3750 lb ALVW) }\end{array}$} & Fed All & 0.125 & 0.25 & 0.180 & 0.36 \\
\hline & CA LEV & & 0.25 & & 0.36 \\
\hline & CA ULEV & & 0.125 & & 0.180 \\
\hline \multirow{4}{*}{$\begin{array}{l}\text { Light-Duty Truck 3, } \\
\text { Medium-Duty Vehicle } 2 \\
\text { (3751-5750 lb ALVW) }\end{array}$} & Fed All & 0.160 & 0.32 & 0.230 & 0.46 \\
\hline & CA LEV & & 0.32 & & 0.46 \\
\hline & CA ULEV & & 0.160 & & 0.230 \\
\hline & CA SULEV & & 0.100 & & 0.143 \\
\hline \multirow{4}{*}{$\begin{array}{l}\text { Light-Duty Truck 4, } \\
\text { Medium-Duty Vehicle } 3 \\
\text { (5751-8500 lb ALVW) }\end{array}$} & Fed All & 0.195 & 0.39 & 0.280 & 0.56 \\
\hline & CA LEV & & 0.39 & & 0.56 \\
\hline & CA ULEV & & 0.195 & & 0.280 \\
\hline & CA SULEV & & 0.117 & & 0.167 \\
\hline \multirow{3}{*}{$\begin{array}{l}\text { Medium-Duty Vehicle } 4 \\
(8501-10,000 \text { lb ALVW) }\end{array}$} & CA LEV & & 0.46 & & 0.66 \\
\hline & CA ULEV & & 0.230 & & 0.330 \\
\hline & CA SULEV & & 0.138 & & 0.197 \\
\hline \multirow{3}{*}{$\begin{array}{l}\text { Medium-Duty Vehicle } 5 \\
(10,001-14,000 \text { lb ALVW })\end{array}$} & CA LEV & & 0.60 & & 0.86 \\
\hline & CA ULEV & & 0.300 & & 0.430 \\
\hline & CA SULEV & & 0.180 & & 0.257 \\
\hline
\end{tabular}

a Applies to federal CFV and California TLEV, LEV, ULEV, and SULEV emissions categories.

b "Fed" means federal; "CA" means California 


\section{Appendix E - Fuel Specifications for Emissions Certification Purposes}

EPA - Natural Gas Certification (Test) Fuel for Exhaust and Evaporative Emission Testing

\begin{tabular}{|l|l|}
\hline Constituent & $\begin{array}{l}\text { Certification Test Fuel for Exhaust } \\
\text { and Evaporative Emission Testing }\end{array}$ \\
\hline Methane & Minimum of 89.0 \\
\hline Ethane & Maximum of 4.5 \\
\hline$C_{3}$ and higher & Maximum of 2.3 \\
\hline$C_{6}$ and higher & Maximum of 0.2 \\
\hline Oxygen & Maximum of 0.6 \\
\hline Inert Gases & Maximum of 4.0 \\
\hline Odorant & $\begin{array}{l}\text { The natural gas at ambient conditions must have a } \\
\text { distinctive odor potent enough for its presence to } \\
\text { be detected down to a concentration in air of not } \\
\text { over one-fifth of the lower limit of flammability. }\end{array}$ \\
\hline
\end{tabular}

a All units are in mole percent

\section{California - Natural Gas Certification (Test) Fuel and Commercial Fuel}

\begin{tabular}{|l|l|l|}
\hline Constituent & $\begin{array}{l}\text { Certification Test Fuel for Exhaust } \\
\text { and Evaporative Emission Testing }\end{array}$ & $\begin{array}{l}\text { Commercial Fuel for } \\
\text { Mileage Accumulation }\end{array}$ \\
\hline Methane & $90.0 \% \pm 1 \%$ & Minimum of $88.0 \%$ \\
\hline Ethane & $4.0 \% \pm 0.5 \%$ & Maximum of $6.0 \%$ \\
\hline $\mathrm{C}_{3}$ and higher & $2.0 \% \pm 0.3 \%$ & Maximum of $3.0 \%$ \\
\hline Oxygen & maximum of $0.5 \%$ & Maximum of $1.0 \%$ \\
\hline Inert Gases & $3.5 \% \pm 0.5 \%$ & $1.5 \%$ to $4.5 \%$ \\
\hline
\end{tabular}

\section{California - Liquefied Petroleum Gas Certification (Test) Fuel and Commercial Fuel}

\begin{tabular}{|l|l|l|}
\hline Constituent & $\begin{array}{l}\text { Certification Test Fuel for Exhaust } \\
\text { and Evaporative Emission Testing }\end{array}$ & $\begin{array}{l}\text { Commercial Fuel for } \\
\text { Mileage Accumulation }\end{array}$ \\
\hline Propane & $93.5 \% \pm 1.0 \%$ by volume & Minimum of $85.0 \%$ by volume \\
\hline Butane and heavier & $1.9 \% \pm 0.3 \%$ by volume & Maximum of $2.5 \%$ by volume \\
\hline Propene & $3.8 \% \pm 0.5 \%$ by volume & Maximum of $5.0 \%$ by volume \\
\hline
\end{tabular}




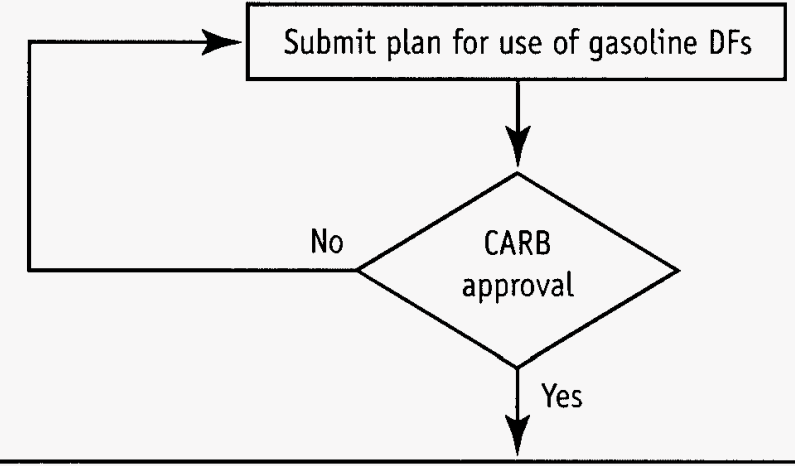

Acquire the following data at 4,000 miles on gasoline and on alternative fuel, and at the useful life mileage level on alternative fuel only:

1) emissions

2) catalyst temperatures

3) air/fuel calibration

\section{Appendix F:}

\section{California Certification Process for Aftermarket Conversions- Use of Gasoline Deterioration Factors}

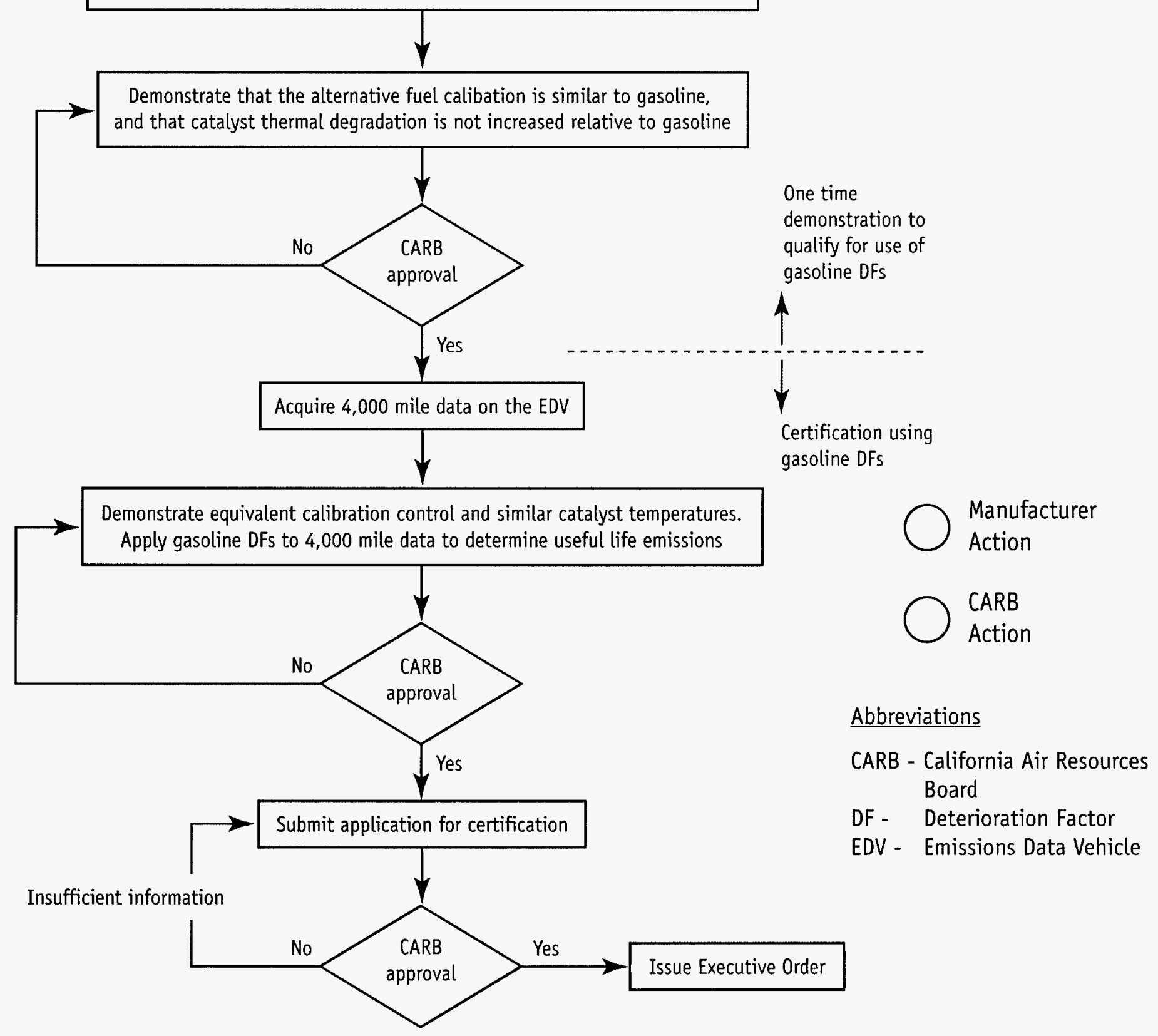


Appendix G:

California Certification Process for Aftermarket ConversionsUsing Carry-Over and Carry-Across of Deterioration Factors
Submit certification plan for EFs
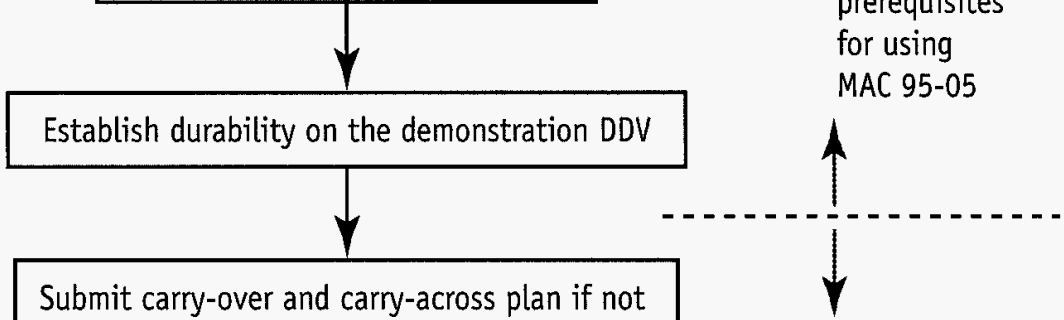
submitted previously with certification plan

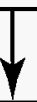

The provisions of MAC 95-05 are applicable

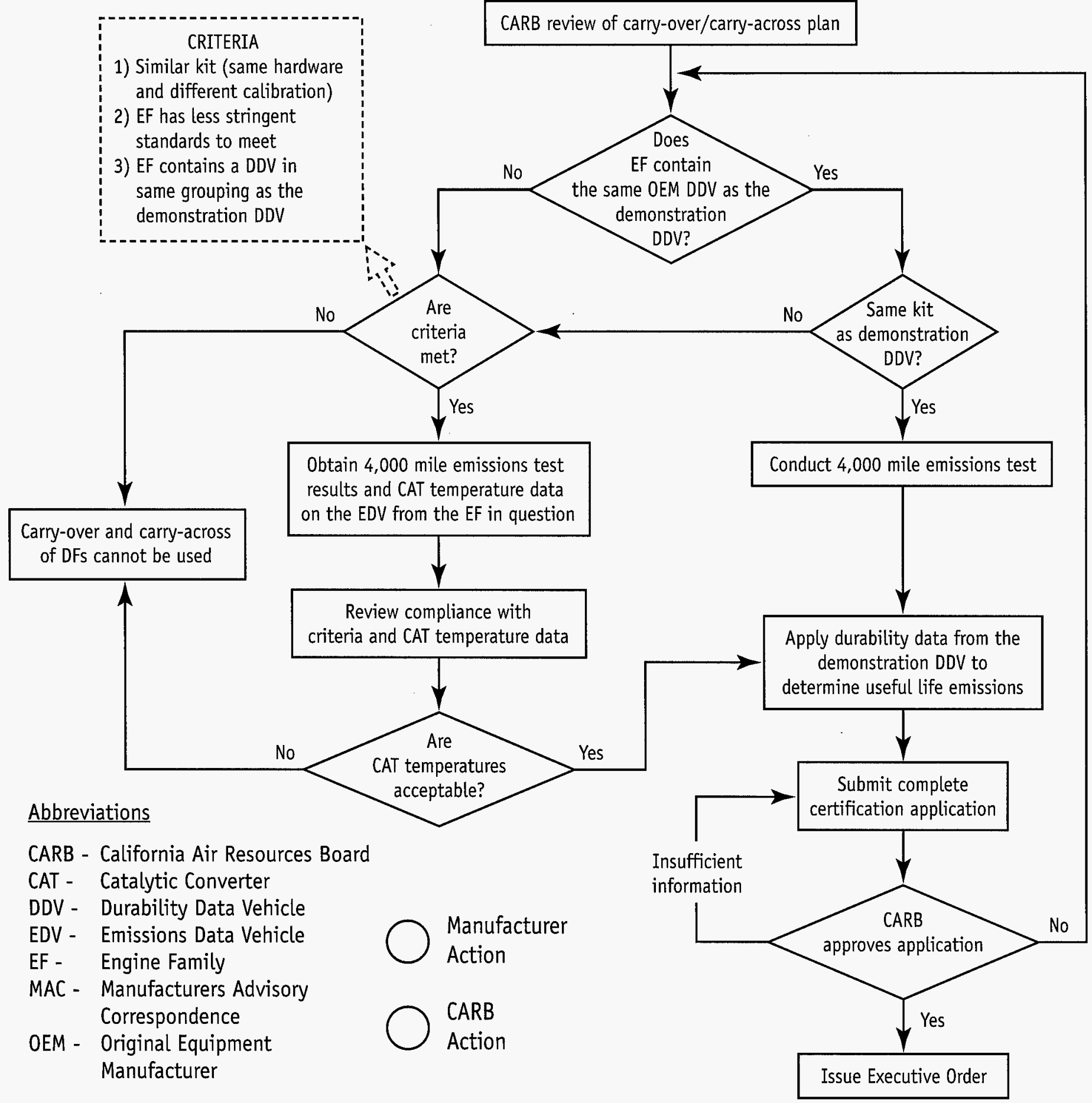




\section{Appendix H:}

California Certification Process

for Light- and Medium-Duty

Aftermarket Conversions-

\section{Using Derived Deterioration Factors}

Submit certification plan
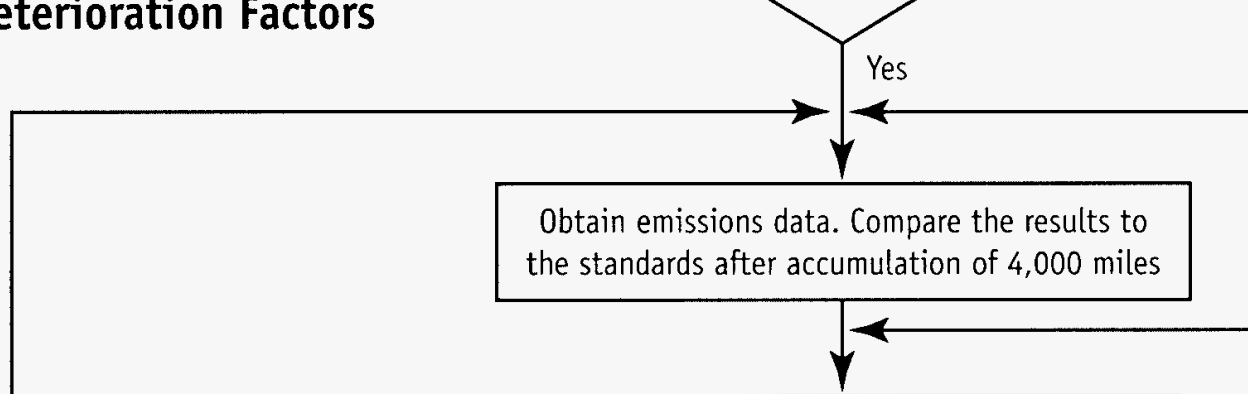

Submit data, warranty, installation

instructions, label, durability testing plan, etc.

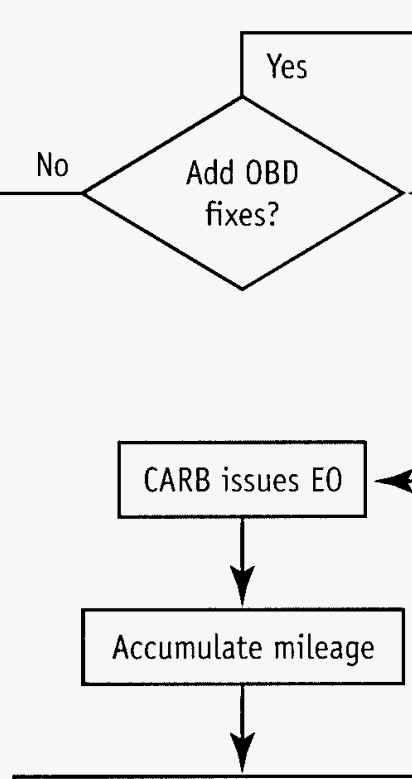

Submit year 1 validation report

Abbreviations

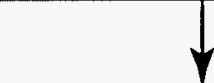

Conduct emissions tests at 100,000 and 120,000 miles
CARB - California Air Resources Board

DF - Deterioration Factor

EO - Executive Order

OBD - On-Board Diagnostics
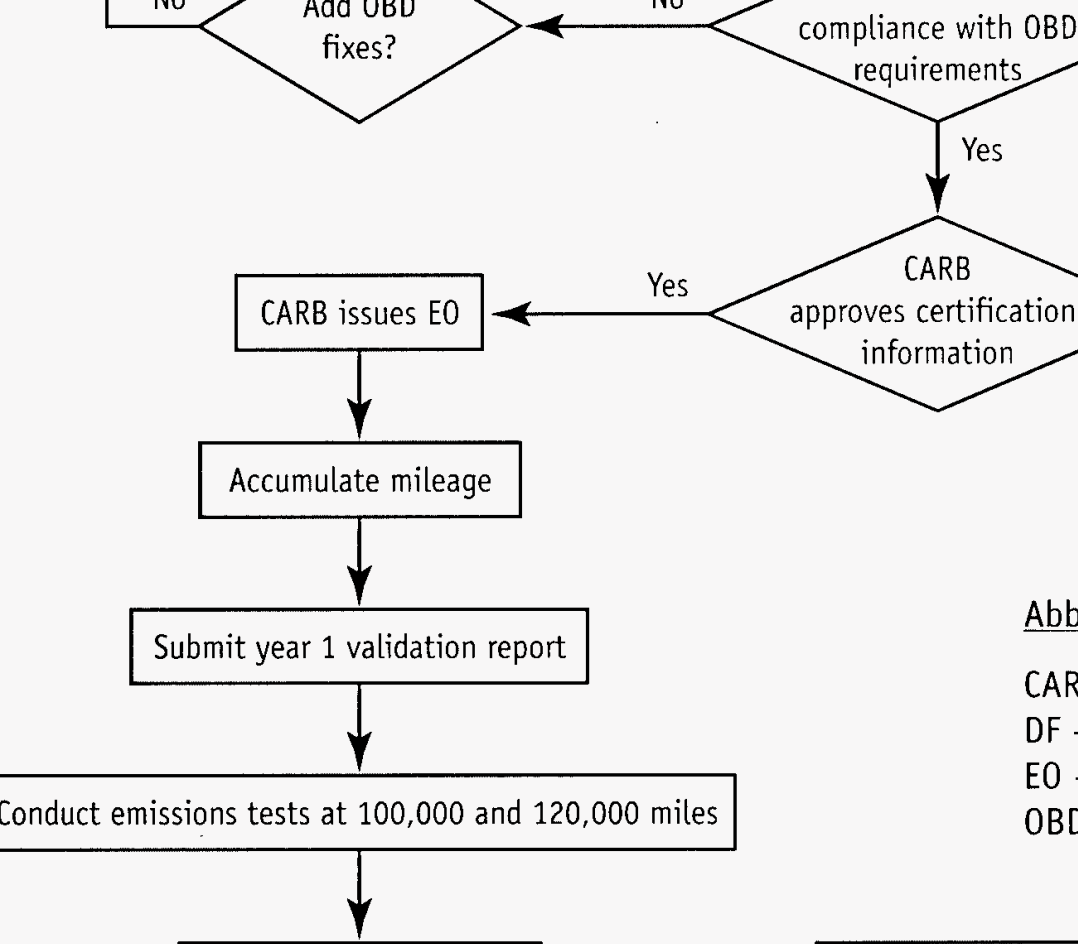

approves certification

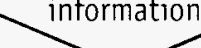

Submit validation data
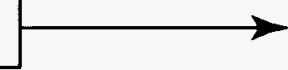

CARB reviews data
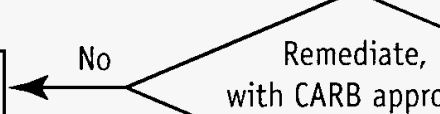
with CARB approval

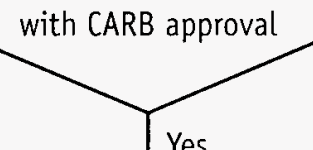

Yes
$(3$

Manufacturer Action

CARB

Action 


\section{Appendix I:}

\section{California Certification Process for} Heavy-Duty Aftermarket ConversionsUsing Derived Deterioration Factors

(

Manufacturer

Action

CARB

Action

\section{Abbreviations}

CARB - California Air Resources Board

DF - Deterioration Factor

EO - Executive Order

$M A C$ - Manufacturers Advisory Correspondence
Submit intent/plan to use MAC 95-07

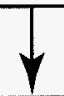

1) Make performance comparison

2) Demonstrate component durability

3) Conduct certification test after 100 hours and apply manufacturer-derived DFs to determine useful life emissions

4) Submit validation plan

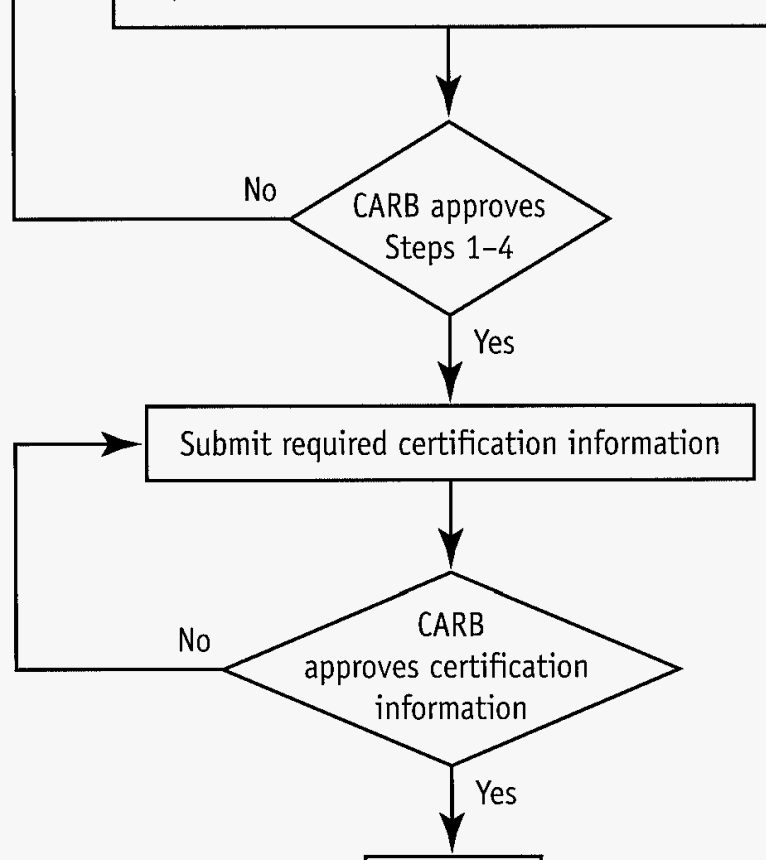

Issue EO

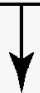

Accumulate hours on engine (submit progress report after one year)

Test at 1,000 hours and project emissions to useful life

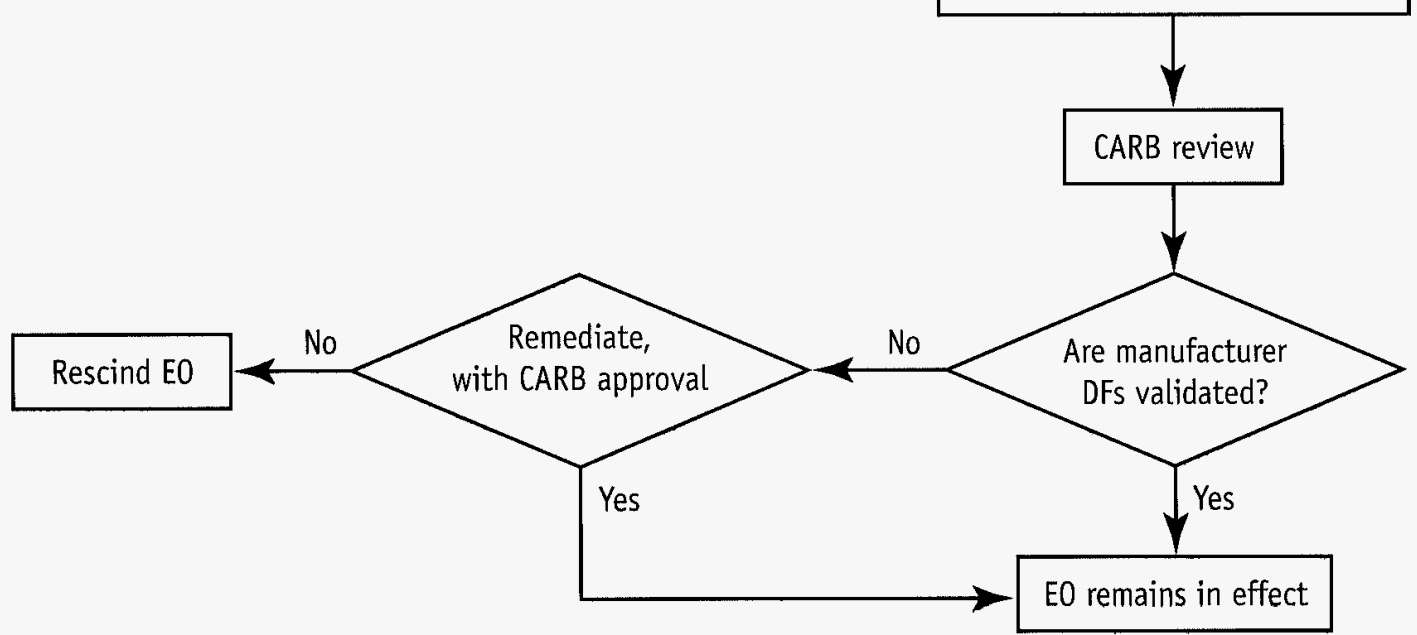




\section{Appendix J: Contacts}

\section{Government Certification Organizations}

EPA - Light-Duty Vehicles and Trucks

Environmental Protection Agency

Office of Mobile Sources

Vehicle Programs and Compliance Division

Vehicle Programs Group

2565 Plymouth Road

Ann Arbor, MI 48105

EPA Alternative Fuels Hotline

Telephone: (734) 668-4312

Fax: $\quad$ (734) 741-7869

**New Hotline numbers as of May 1998

Telephone: (734) 214-4312

Fax: $\quad$ (734) 214-4869

EPA - Heary-Duty Engines

Environmental Protection Agency

Office of Mobile Sources

Engine Compliance Programs Group

Mailing Address: $401 \mathrm{M}$ St. S.W. (6403J)

Washington, DC 20460

Visiting Location and Courier Shipments:

501 3rd St. N.W.

Washington, DC 20001

Telephone: (202) 564-9261

Fax: (202) 565-2057

\section{California}

California Environmental Protection Agency

Air Resources Board

Mobile Source Operations Division

Aftermarket Parts Section

9528 Telstar Avenue

P.O. Box 8001

El Monte, CA 91731

Telephone: (818) 575-6800

Fax: $\quad$ (818) $575-6685$

\section{Colorado}

Colorado Department of Public Health and Environment

APCD-MSP-B1

4300 Cherry Creek Drive South

Denver, CO 80222

Telephone: (303) 692-3125

Fax:

(303) $782-5693$
Information about EPA Memorandum 1A or the Addendum to Memorandum 1A

Environmental Protection Agency

Office of Enforcement and Compliance Assurance

Mobile Source Enforcement Branch

Washington, DC 20460

Telephone: (202) 564-2255

\section{Ordering Information for Code of Federal Regulations or Federal Register}

U.S. Government Printing Office

Superintendent of Documents

P.O. Box 371954

Pittsburgh, PA 15250-7954

Telephone: (202) 512-1800

Fax: (202) $512-2250$

\section{DOE National Alternative Fuels Hotline}

Department of Energy

Office of Transportation Technologies

National Alternative Fuels Hotline

9300 Lee Highway

Fairfax, VA 22031

Telephone: (800) 423-1363

Fax: (703) 934-3183

\section{Industry Organizations}

The Natural Gas Vehicle Coalition

1515 Wilson Boulevard

Suite 1030

Arlington, VA 22209

Telephone: (703) 527-3022

Fax: $\quad$ (703) $527-3025$

Propane Vehicle Council

1101 17th Street, N.W.

Suite 1004

Washington, DC 20036

Telephone: (202) 530-0479

Fax: (202) 466-7205 


\section{Appendix K: Important Documents}

The documents listed in this appendix are available from the organization listed in the source column of the table. Many of the EPA and Government Printing Office documents can be downloaded from either the EPA Office of Mobile Sources or the U.S. Government Printing Office (Code of Federal Regulations and Federal Register) Web sites, which are provided in Appendix C. Mailing and telephone information is provided in Appendix J. Refer to Appendix A for an explanation of abbreviations.

\begin{tabular}{|c|c|c|}
\hline Title or Description & Source & Publication Date \\
\hline $\begin{array}{l}\text { Addendum to Mobile Source Enforcement Memorandum 1A, } \\
\text { "Tampering Enforcement Policy for Alternative Fuel } \\
\text { Aftermarket Conversions" }\end{array}$ & EPA & Sept. 4, 1997 \\
\hline $\begin{array}{l}\text { Certification and Fuel Economy Information System Manufacturer } \\
\text { User Guide, Appendix F, "EPA Standardized Engine and } \\
\text { Evaporative Family Names" }\end{array}$ & EPA & Apr. 7, 1997 \\
\hline EPA Small Volume Manufacturers Application Letter and Package & EPA & Mar. 19, 1997 \\
\hline $\begin{array}{l}\text { Fact Sheet - "Certification and Fuel Economy Guidelines Small } \\
\text { Volume Light-Duty Vehicle and Light-Duty Truck Manufacturers" }\end{array}$ & & Mar. 17, 1988 \\
\hline "Mobile Source Emission Standards Summary" & & July 16,1992 \\
\hline $\begin{array}{l}\text { OMS Advisory Circular A/C No. 17F, "General Criteria for the } \\
\text { Carryover and Carry-Across of Certification Data and the } \\
\text { Carryover of Fuel Economy Data for Light-Duty Vehicles and } \\
\text { Light-Duty Trucks" }\end{array}$ & & Nov. 16,1982 \\
\hline $\begin{array}{l}\text { MSAPC Advisory Circular A/C No. 37-A, } \\
\text { "Alternative Mileage Accumulation Procedure" }\end{array}$ & & July 22,1975 \\
\hline $\begin{array}{l}\text { OMS Advisory Circular A/C No. } 51 \mathrm{C} \text {, } \\
\text { "Assigned Deterioration Factors for } 1988 \text { Model Year Light-Duty } \\
\text { Vehicles, Light-Duty Trucks, and Heavy Duty Engines" }\end{array}$ & & Dec. 4,1986 \\
\hline $\begin{array}{l}\text { Manufacturer's Guidance Letter CD-87-02 (LD/HD), } \\
\text { "Assigned Deterioration Factor Addendum" }\end{array}$ & & Feb. 26, 1987 \\
\hline $\begin{array}{l}\text { Manufacturer's Guidance Letter CD-88-02 (LD), } \\
\text { "Catalyst Thermal Degradation Criteria Contained in Advisory } \\
\text { Circular \#17F; Revision to Endnote \#4" }\end{array}$ & & Jan. 21,1988 \\
\hline $\begin{array}{l}\text { Federal Regulations } 40 \text { CFR } 80.24 \text {, } \\
\text { "Controls Applicable to Motor Vehicle Manufacturers" }\end{array}$ & & \\
\hline $\begin{array}{l}\text { Federal Register, February } 28,1990 \text { (Volume } 55, \text { Number } 40 \text { ), } \\
\text { "Small volume manufacturer," Final Rule }\end{array}$ & & Feb. 28,1990 \\
\hline $\begin{array}{l}\text { "Mederal Register, July 7, 1992, (Volume 57, Number 130), } \\
\text { "Might-Duty Vehicles; Light-Duty Trucks; Heavy-Duty Vehicles } \\
\text { and Engines; and Motorcycles Fees," Final Rule }\end{array}$ & & July, 1992 \\
\hline $\begin{array}{l}\text { Manufacturer's Guidance Letter CD-92-07 (LDV/LDT/HDV } \\
\text { /HDE/MC/ICI/SM), "Implementation of the Motor Vehicle and } \\
\text { Engine Compliance Program. Fees" }\end{array}$ & & July 7,1992 \\
\hline "Phase-In of New Regulations (Implementation Schedule)" & & 1995 \\
\hline $\begin{array}{l}\text { "Instructions for the Preparation and Submission of } 1996 \text { \& Later } \\
\text { MY Small Volume Application for Certificates of Conformity for } \\
\text { Light-Duty Vehicles, Light-Duty Trucks, and Heavy-Duty Engines" }\end{array}$ & EPA & Mar. 1996 \\
\hline
\end{tabular}


Appendix K

Important Documents - continued

\begin{tabular}{|c|c|c|}
\hline Title or Description & Source & Publication Date \\
\hline $\begin{array}{l}\text { Manufacturer's Guidance Letter CD-94-14 (LDV } \backslash \mathrm{LDT} \backslash \mathrm{HD} \backslash \mathrm{GF} \text { ), } \\
\text { "Assigned Deterioration Factors for Gaseous-Fueled Vehicles } \\
\text { and Engines" }\end{array}$ & EPA & Sept. 27, 1995 \\
\hline $\begin{array}{l}\text { Manufacturer's Guidance Letter Dear Concerned Party, } \\
\text { "Concerning Coverage of the Federal Motor Vehicle Emissions } \\
\text { Warranty Section 207(I) of the Clean Air Act" }\end{array}$ & EPA & July 18,1995 \\
\hline $\begin{array}{l}\text { Manufacturer's Guidance Letter EPCD-Large Engine-96-01, } \\
\text { "Streamlined Combined On-Highway and Nonroad Compression } \\
\text { Ignition Engine Application Format, Large Engine Guidance Document } \\
\text { and Announcement of Steamlined Application Workshop" and } \\
\text { attachment "U.S. EPA Large Engine \& Evaporative Certification } \\
\text { Guidance (Draft)" }\end{array}$ & EPA & Nov. 19,1996 \\
\hline $\begin{array}{l}\text { Manufacturer's Guidance Letter, CD-91-08 (LDV/HDE/HDV/ } \\
\text { MC/ICI/SM), "Revised Engine Family Name and New Evaporative } \\
\text { Family Name" }\end{array}$ & EPA & Dec. 12,1991 \\
\hline $\begin{array}{l}\text { Mobile Source Enforcement Memorandum No. 1A, } \\
\text { "Interim Tampering Enforcement Policy" }\end{array}$ & EPA & June 25,1974 \\
\hline $\begin{array}{l}\text { MSAPC Advisory Circular A/C No. 20-B, "Determination of Engine } \\
\text { Families and Classification of Emission Control Systems" }\end{array}$ & EPA & June 27,1974 \\
\hline $\begin{array}{l}\text { MSAPC Advisory Circular A/C No. 59, "Determination of Evaporative } \\
\text { Emission Families and Evaporative Emission Control Systems" }\end{array}$ & EPA & Aug. 31, 1976 \\
\hline $\begin{array}{l}\text { Title } 40 \text { Code of Federal Regulations Part 85, "Control of Air Pollution } \\
\text { From Motor Vehicles and Motor Vehicle Engines" }\end{array}$ & $\begin{array}{l}\text { U.S. Government } \\
\text { Printing Office }\end{array}$ & July 1, 1996 \\
\hline $\begin{array}{l}\text { Title } 40 \text { Code of Federal Regulations Part 86, "Control of Air Pollution } \\
\text { From New and In-Use Motor Vehicles and New and In-Use Motor } \\
\text { Vehicle Engines: Certification and Test Procedures" }\end{array}$ & $\begin{array}{l}\text { U.S. Government } \\
\text { Printing Office }\end{array}$ & July 1,1996 \\
\hline Title 40 Code of Federal Regulations Part 88, "Clean-Fuel Vehicles" & $\begin{array}{l}\text { U.S. Government } \\
\text { Printing Office }\end{array}$ & July 1,1996 \\
\hline $\begin{array}{l}\text { Title } 40 \text { Code of Federal Regulations Part 600, } \\
\text { "Fuel Economy of Motor Vehicles" }\end{array}$ & $\begin{array}{l}\text { U.S. Government } \\
\text { Printing Office }\end{array}$ & July 1,1996 \\
\hline $\begin{array}{l}\text { Federal Register, May 28, } 1997 \text { (Volume 62, Number 102), } \\
\text { "Control of Air Pollution From Motor Vehicles and New Motor } \\
\text { Vehicle Engines; Modification of Federal On-board Diagnostic } \\
\text { Regulations for Light-Duty Vehicles and Light-Duty Trucks; Extension } \\
\text { of Acceptance of California OBD 1l Requirements," Proposed Rule }\end{array}$ & $\begin{array}{l}\text { U.S. Government } \\
\text { Printing Office }\end{array}$ & May 28,1997 \\
\hline $\begin{array}{l}\text { Federal Register, September 21, } 1994 \text { (Volume 59, Number 182), } \\
\text { "Standards for Emissions From Natural Gas-Fueled, and Liquefied } \\
\text { Petroleum Gas-Fueled Motor Vehicles and Motor Vehicle Engines, and } \\
\text { Certification Procedures for Aftermarket Conversions," Final Rule }\end{array}$ & $\begin{array}{l}\text { U.S. Government } \\
\text { Printing Office }\end{array}$ & Sept. 21, 1994 \\
\hline $\begin{array}{l}\text { Federal Register, September 30, 1994, "Emission Standards for } \\
\text { Clean-Fuel Vehicles and Engines, Requirements for Clean-Fuel } \\
\text { Vehicle Conversions, and California Pilot Test Program," Final Rule }\end{array}$ & $\begin{array}{l}\text { U.S. Governmemt } \\
\text { Printing Office }\end{array}$ & Sept. 30, 1994 \\
\hline $\begin{array}{l}\text { "California Certification and Installation Procedures for Alternative } \\
\text { Fuel Retrofit Systems for Motor Vehicles Certified for } 1994 \text { and } \\
\text { Subsequent Model Years and for All Model Year Motor Vehicle } \\
\text { Retrofit Systems Certified for Emission Reduction Credit" }\end{array}$ & CARB & Nov. 21,1995 \\
\hline
\end{tabular}




\section{Important Documents - continued}

\begin{tabular}{|c|c|c|}
\hline Title or Description & Source & Publication Date \\
\hline $\begin{array}{l}\text { California Code of Regulations, Title 13, Section 2292.5, } \\
\text { "Specifications for Compressed Natural Gas" }\end{array}$ & CARB & Sept. 27, 1996 \\
\hline $\begin{array}{l}\text { California Code of Regulations, Title 13, Section 2292.6, } \\
\text { "Specifications for Liquefied Petroleum Gas" }\end{array}$ & CARB & Sept. 27, 1996 \\
\hline $\begin{array}{l}\text { "California Evaporative Emission Standards and Test Procedures } \\
\text { for } 1978 \text { and Subsequent Model Motor Vehicles" }\end{array}$ & CARB & Apr. 24, 1996 \\
\hline $\begin{array}{l}\text { "California Exhaust Emission Standards and Test Procedures for } 1988 \\
\text { and Subsequent Model Passenger Cars, Light-Duty Trucks, and } \\
\text { Medium-Duty Vehicles" }\end{array}$ & CARB & July 24, 1996 \\
\hline $\begin{array}{l}\text { "California Exhaust Emission Standards and Test Procedures for } 1985 \\
\text { and Subsequent Model Heavy-Duty Diesel-Engines and Vehicles" }\end{array}$ & CARB & Mar. 24, 1994 \\
\hline $\begin{array}{l}\text { "California Exhaust Emission Standards and Test Procedures for } 1987 \\
\text { and Subsequent Model Heavy-Duty Otto-Cycle Engines and Vehicles" }\end{array}$ & CARB & June 24, 1996 \\
\hline $\begin{array}{l}\text { "California Exhaust Emission Standards and Test Procedures for } \\
\text { Systems Designed to Convert Motor Vehicles Certified for } 1993 \\
\text { and Earlier Model Years to Use Liquefied Petroleum Gas or Natural } \\
\text { Gas Fuels" }\end{array}$ & CARB & Nov. 21, 1995 \\
\hline $\begin{array}{l}\text { "California Motor Vehicle Emission Control and Smog Index } \\
\text { Label Specifications" }\end{array}$ & CARB & Sept. 20, 1996 \\
\hline $\begin{array}{l}\text { "California Refueling Emission Standards and Test Procedures for } \\
1998 \text { and Subsequent Model Motor Vehicles" }\end{array}$ & CARB & Apr. 24, 1996 \\
\hline $\begin{array}{l}\text { Mail Out MSCD 97-01, "Amendments to Regulations Regarding } \\
\text { On-Board Diagnostic System Requirements for } 1994 \text { and Later } \\
\text { Passenger Cars, Light-Duty Trucks, and Medium-Duty Vehicles } \\
\text { and Engines (OBD II)" }\end{array}$ & CARB & Jan. 1997 \\
\hline $\begin{array}{l}\text { Manufacturers Advisory Correspondence \#97-02, } \\
\text { "Cost Limit for High-Priced Warranted Parts of 1998 Model-Year (MY) } \\
\text { Passenger Cars (PCs), Light-Duty Trucks (LDTs), and Medium-Duty } \\
\text { Vehicles (MDVs)" }\end{array}$ & CARB & Apr. 14,1997 \\
\hline $\begin{array}{l}\text { Manufacturers Advisory Correpondence \#96-10, } \\
\text { "1998 and Later Model-Year (MY) Vehicle Emission } \\
\text { Configuration (VEC) Bar Codes" }\end{array}$ & CARB & Sept. 9, 1996 \\
\hline $\begin{array}{l}\text { Manufacturers Advisory Correspondence \#95-05, } \\
\text { "Alternative Fuel Retrofit System Certification Procedures" }\end{array}$ & CARB & Apr. 7, 1995 \\
\hline $\begin{array}{l}\text { Manufacturers Advisory Correspondence \#95-07, } \\
\text { "Alternative Fuel Retrofit System Certification Procedures for } \\
\text { Heavy-Duty Engine Applications" }\end{array}$ & CARB & Sept. 5, 1995 \\
\hline $\begin{array}{l}\text { Manufacturers Advisory Correspondence \#95-10, } \\
\text { "Alternative Fuel Retrofit System Certification Procedures for } \\
\text { Light-Duty and Medium-Duty Vehicle Applications" }\end{array}$ & CARB & Dec. 6,1995 \\
\hline $\begin{array}{l}\text { Letter from Colorado Department of Health and Environment, } \\
\text { "Important Notice - Changes in AQCC Regulation No. } 14 \text { and } \\
\text { EPA's Tampering Policy" }\end{array}$ & Colorado APCD & Sept. 18, 1997 \\
\hline $\begin{array}{l}\text { Regulation No. 14, "The Control of Emissions from } \\
\text { Alternative Fueled Motor Vehicles" }\end{array}$ & Colorado APCD & Aug. 30, 1993 \\
\hline
\end{tabular}


Report Number (14) NREL/TP-

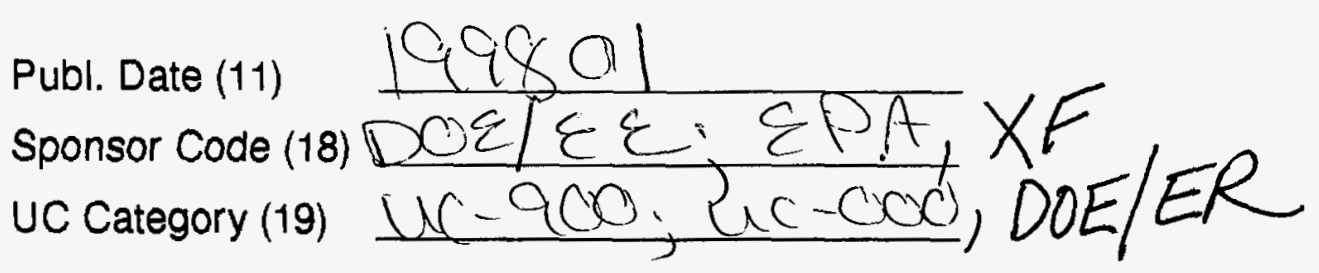

$$
19980619105
$$




\section{NOTICE}

This report was prepared as an account of work sponsored by an agency of the United States government. Neither the United States government nor any agency thereof, nor any of their employees, makes any warranty, express or implied, or assumes any legal liability or responsibility for the accuracy, completeness, or usefulness of any information, apparatus, product, or process disclosed, or represents that its use would not infringe privately owned rights. Reference herein to any specific commercial product, process, or service by trade name, trademark, manufacturer, or otherwise does not necessarily constitute or imply its endorsement, recommendation, or favoring by the United States government or any agency thereof. The views and opinions of authors expressed herein do not necessarily state or reflect those of the United States government or any agency thereof.

Available to DOE and DOE contractors from:

Office of Scientific and Technical Information (OSTI)

P.0. Box 62

Oak Ridge, TN 37831

Prices available by calling 423-576-8401

Available to the public from:

National Technical Information Service (NTIS)

U.S. Department of Commerce

5285 Port Royal Road

Springfield, VA 22161

$703-487-4650$ 
Produced by the

Center for Transportation Technologies and Systems at the National Renewable Energy Laboratory (NREL), a U.S. Department of Energy national laboratory

NREL

1617 Cole Blvd.

Golden, CO 80401-3393

NREL/TP-540-22757

January 1998

Printed with a renewable-source ink on paper containing at least $50 \%$ wastepaper, including $20 \%$ postconsumer waste

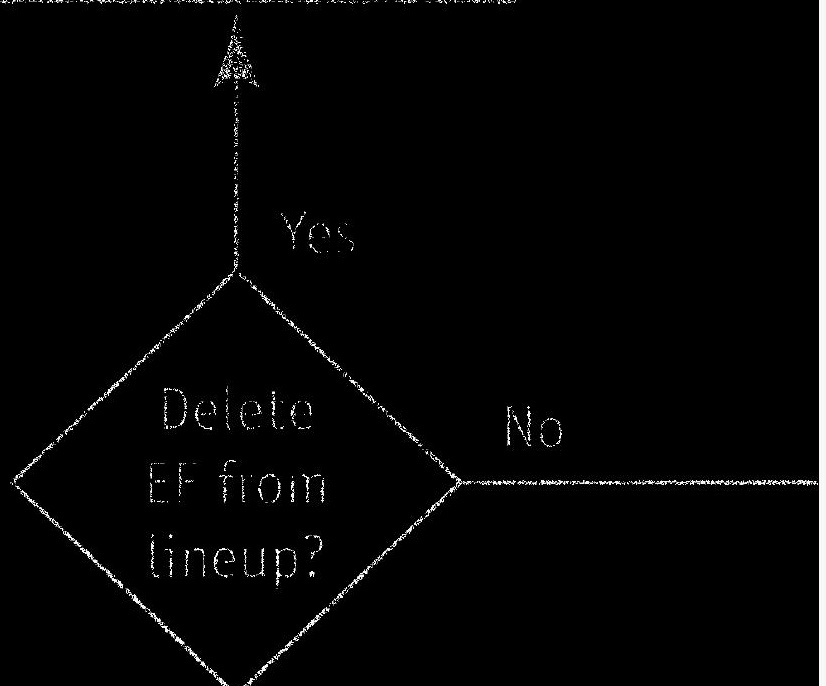

